\title{
2D MXene-Based Materials for Electrocatalysis
}

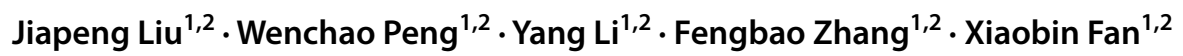

Received: 31 October 2019 / Revised: 20 November 2019 / Accepted: 17 December 2019 / Published online: 5 February 2020 (c) The Author(s) 2020

\begin{abstract}
MXenes, as an emerging 2D material, are expected to exert a great influence on future energy storage and conversion technologies. In this review, we systematically summarize recent advances in MXene-based materials in electrocatalysis, particularly in the hydrogen evolution, oxygen evolution, oxygen reduction, nitrogen reduction, and $\mathrm{CO}_{2}$ reduction reactions. Crucial factors influencing the properties of these materials, such as functional groups, conductivity, and interface, are discussed, and challenges to the future development of MXene-based electrocatalysts are presented.
\end{abstract}

Keywords 2D material $\cdot$ MXenes $\cdot$ Electrocatalyst $\cdot$ Hydrogen evolution reaction $\cdot$ Oxygen evolution reaction $\cdot$ Oxygen reduction reaction $\cdot$ Nitrogen reduction reaction $\cdot \mathrm{CO}_{2}$ reduction reaction

\section{Introduction}

Since graphene was first prepared by mechanical exfoliation in 2004 [1], various two-dimensional (2D) materials have attracted extensive attention on account of their unique physical and chemical properties [2]. These materials consist of atomically thin sheets with inherently large surface areas; they can be used extensively in various areas, such as electrocatalysis [3], photocatalysis [4], energy storage [5], membrane separation [6, 7], and biotherapy [8]. Besides graphene, a wide range of atomically thin $2 \mathrm{D}$ materials have also been successfully prepared, including transition metal dichalcogenides [9-11], phosphorenes [12-14], silicenes $[15,16]$, germanene antimonenes $[17,18]$, boron nitrides [19-21], and layered double hydroxides [22].

Transition metal carbides, carbonitrides, and nitrides (MXenes) are a new addition to the family of 2D materials [23]. The common form of MXene is $\mathrm{M}_{n+1} \mathrm{X}_{n} \mathrm{~T}_{x}(n=1,2$, 3 ), where $M$ represents an early transition metal, $\mathrm{X}$ represents carbon and/or nitrogen, and $\mathrm{T}_{x}$ denotes surface functional groups, such as $-\mathrm{O},-\mathrm{OH}$, or $-\mathrm{F}$ [24]. MXenes have

Xiaobin Fan

xiaobinfan@tju.edu.cn

1 School of Chemical Engineering and Technology, Tianjin University, Tianjin 300072, China

2 State Key Laboratory of Chemical Engineering, Collaborative Innovation Center of Chemical Science and Engineering, Tianjin 300072, China representative structures of $\mathrm{M}_{2} \mathrm{XT}_{x}, \mathrm{M}_{3} \mathrm{X}_{2} \mathrm{~T}_{x}$, and $\mathrm{M}_{4} \mathrm{X}_{3} \mathrm{~T}_{x}$ with $n$ layers of $\mathrm{X}$ elements covered by $n+1$ layers of $\mathrm{M}$ (Fig. 1) [25]. Since the first MXene, $\mathrm{Ti}_{3} \mathrm{C}_{2} \mathrm{~T}_{x}$, was synthesized in 2011, over 19 types of MXenes have been subsequently prepared, and more MXenes are predicted to exist. As-synthesized MXene-based materials are widely applied in various fields, such as in alkali metal batteries [26-29], photothermal conversion [30-32], photocatalysis [33-35], supercapacitors [36-38], and membrane separation [39-41], where they consistently show excellent performance. The outstanding electrical conductivity and hydrophilic surfaces of MXenes also ensure their stable performance as electrocatalysts in the hydrogen evolution reaction (HER) [42-44], oxygen evolution reaction (OER) [45, 46], oxygen reduction reaction (ORR) [47, 48], nitrogen reduction reaction (NRR) $[49,50]$, and $\mathrm{CO}_{2}$ reduction reaction $\left(\mathrm{CO}_{2} \mathrm{RR}\right)[51,52]$.

Although the preparation, properties, and applications of MXenes in energy storage and conversion have been summarized [23, 25, 53-55], explorations of MXene-based materials for electrocatalysis have not been developed as quickly. Moreover, reviews focusing on MXene-based materials for electrocatalysts are scarce [56]. Therefore, new reviews covering research from the early stages of MXene-based materials to their present use in electrocatalysis, including their preparation, properties and the latest advances, are essential. In this review, we aim to describe recent progress on MXene-based materials for electrocatalysis. 
Fig. 1 Three different formulas $\left(\mathrm{M}_{2} \mathrm{XT}_{x}, \mathrm{M}_{3} \mathrm{X}_{2} \mathrm{~T}_{x}\right.$, and $\left.\mathrm{M}_{4} \mathrm{X}_{3} \mathrm{~T}_{x}\right)$ and compositions (mono$\mathrm{M}$ MXenes and double-M MXenes) of MXenes. Reproduced with permission [25]. Copyright 2019, Wiley-VCH

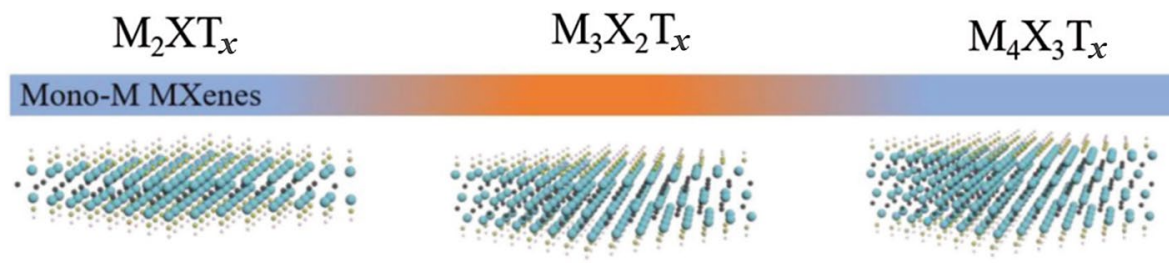

Double-M MXenes (Solid solution)

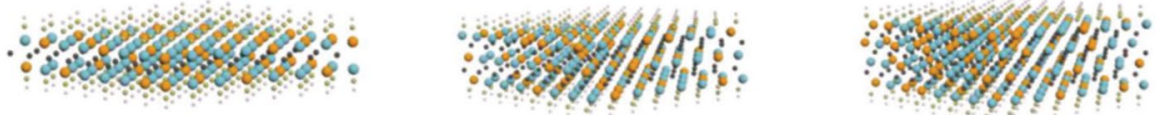

Double-M MXenes (Ordered)

$\circ \mathrm{M} 1 \bullet \mathrm{C} \odot \mathrm{O}$

M2 $\odot \mathrm{H}$

\section{Synthesis of MXenes}

MXenes are usually obtained by selective etching of specific atomic layers from their layered precursors, such as MAX phases. To date, over 70 types of MAX phases have been reported.

Since the first MXene was synthesized by etching with HF at room temperature (Fig. 2a) [57], other types of MXenes, such as $\mathrm{TiC}_{2} \mathrm{~T}_{x}$ [58], $\mathrm{Ti}_{3} \mathrm{CN}_{x} \mathrm{~T}_{x}$ [59], TiNbCT [60], $\mathrm{Mo}_{2} \mathrm{CT}_{x}$ [61], $\mathrm{Mo}_{2} \mathrm{TiC}_{2} \mathrm{~T}_{x}$ [62], $\mathrm{Mo}_{2} \mathrm{Ti}_{2} \mathrm{C}_{3} \mathrm{~T}_{x}$ [62], $\mathrm{V}_{2} \mathrm{CT}_{x}$ [61], $\mathrm{Ta}_{4} \mathrm{C}_{3} \mathrm{~T}_{x}$ [60], $\mathrm{Nb}_{2} \mathrm{CT}_{x}$ [26], $\mathrm{Nb}_{4} \mathrm{C}_{3} \mathrm{~T}_{x}$ [61], $\mathrm{Zr}_{3} \mathrm{C}_{2} \mathrm{~T}_{x}$ [63], $\mathrm{Hf}_{3} \mathrm{C}_{2} \mathrm{~T}_{x}$ [64], $\left(\mathrm{Nb}_{0.8} \mathrm{Ti}_{0.2}\right)_{4} \mathrm{C}_{3} \mathrm{~T}_{x}$ [65], and $\left(\mathrm{Nb}_{0.8} \mathrm{Zr}_{0.2}\right)_{4} \mathrm{C}_{3} \mathrm{~T}_{x}$ [65], have been successfully prepared by this method. However, the aqueous HF etching method requires the handling of high-concentration HF and a strenuous multi-step procedure. Ghidiu et al. [38] proposed a safer and easier synthetic route to MXene synthesis by in situ formation of $\mathrm{HF}$ via the reaction of $\mathrm{HCl}$ and $\mathrm{LiF}$. Subsequently, other fluorides, such as NaF [66], KF [66], $\mathrm{CsF}$ [38], $\mathrm{CaF}$ [38], $\mathrm{FeF}_{3}$ [67], and tetra- $n$-butylammonium fluoride [38], have been used to synthesize MXenes. $\mathrm{NH}_{4} \mathrm{~F}$ [68] and $\mathrm{NH}_{4} \mathrm{HF}_{2}$ [69] have also been employed to synthesize MXenes (e.g., $\mathrm{Ti}_{3} \mathrm{C}_{2} \mathrm{~T}_{x}$ ). Some MXenes, such as $\mathrm{Ti}_{4} \mathrm{~N}_{3}$, have been obtained through etching with molten fluoride salt mixtures at high temperature [70].

Although various MXenes have been achieved by etching with HF or in situ formation of HF (Fig. 2b) [71], these methods limit the large-scale preparation and application of the catalysts owing to the acute toxicity of HF. Therefore, the development of novel HF-free methods is necessary. Xuan et al. [72], for instance, presented a strategy involving the organic base-driven intercalation and delamination of $\mathrm{TiC}$ (Fig. 2c). In another work, $\mathrm{Li}$ and co-workers [73] reported that $\mathrm{KOH}$ in the presence of a small amount of water can serve as an etchant to prepare MXenes (Fig. 2d). Pang et al. [74] reported a HF-free facile and rapid MXene synthesis method via thermal-assisted electrochemical etching (Fig. 2e). Li et al. [75] proposed an element-replacement approach by reaction with Lewisacidic molten salts (Fig. 2f). Thus, future developing trends may focus on safe and efficient preparation methods for MXenes.

\section{Structural and Electronic Properties}

\section{Structural Properties}

The overall crystal geometry of MXene presents a hexagonal close-packed structure, which is analogous to its MAXphase precursor. Here, $\mathrm{M}$ atoms are arranged in a closepacked structure, and octahedral sites are occupied by $\mathrm{X}$ atoms. The adjacent layered units are connected via van der Waals forces, similar to other 2D materials [53].

MXenes are usually prepared in aqueous solutions, including acidic fluorides. Therefore, the surface of MXenes is occupied by a mixture of $-\mathrm{OH},-\mathrm{O}$, and $-\mathrm{F}$ terminations. For brevity, these molecules are denoted $\mathrm{M}_{n+1} \mathrm{X}_{n} \mathrm{~T}_{x}$, where $\mathrm{T}$ represents the surface termination. Non-terminated MXenes have never been obtained [23, 76]. Recent computational studies demonstrate that the surface termination exerts significant impacts on the properties of MXenes. For example, Hu et al. [77] systematically studied the chemical origin of termination-functionalized MXenes by Bader charge analysis and thermodynamic calculations; the materials revealed stability in the order of $\mathrm{Ti}_{3} \mathrm{C}_{2} \mathrm{O}_{2}>\mathrm{Ti}_{3} \mathrm{C}_{2} \mathrm{~F}_{2}>\mathrm{Ti}_{3} \mathrm{C}_{2}(\mathrm{OH})_{2}>\mathrm{Ti}_{3} \mathrm{C}_{2} \mathrm{H}_{2}>\mathrm{Ti}_{3} \mathrm{C}_{2}$, which was attributed to the splitting of the highly degenerated $3 d$ orbitals of surface Ti. In another study, Fu and co-workers 
A (a)

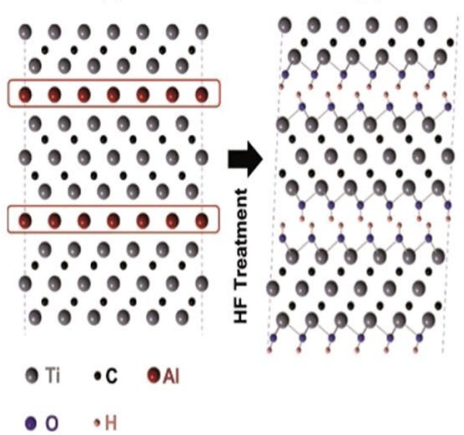

C

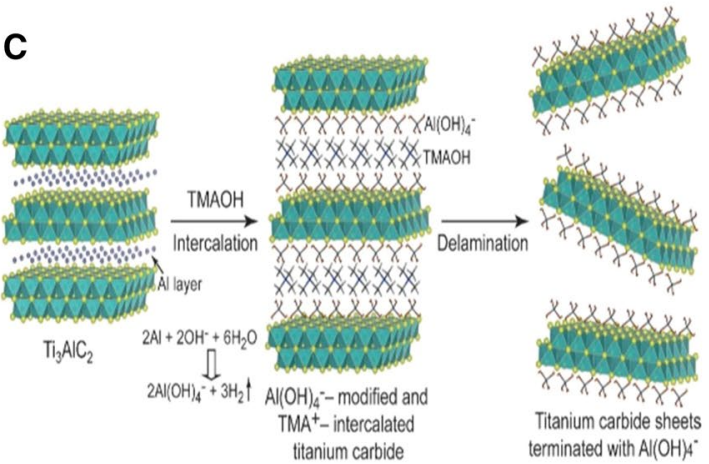

E

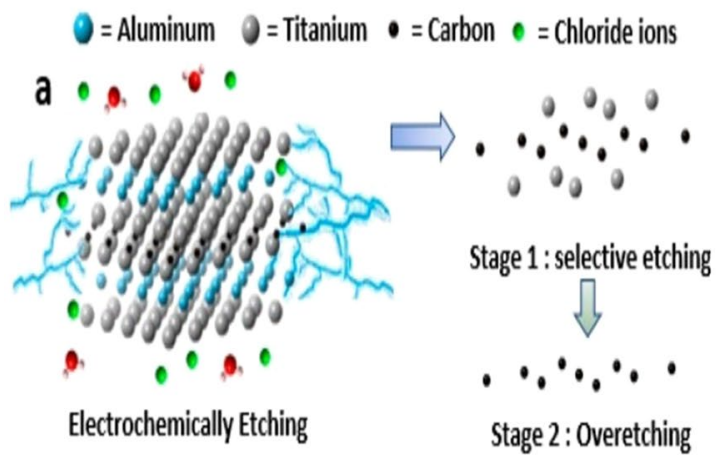

Fig. 2 Schematic of the exfoliation process of $\mathrm{Ti}_{3} \mathrm{AlC}_{2}$. A HF etching method. Reproduced with permission [57]. Copyright 2011, Wiley-VCH. B $\mathrm{LiF}+\mathrm{HCl}$ etching method. Reproduced with permission [71]. Copyright 2016, Wiley-VCH. C Organic base (TMAOH) method. Reproduced with permission [72]. Copyright 2016, WileyVCH. D KOH method. Reproduced with permission [73]. Copy-

[78] systematically explored the effects of several functional groups (i.e., $-\mathrm{Cl},-\mathrm{F},-\mathrm{H},-\mathrm{O}$, and $-\mathrm{OH}$ ) on the stabilization, mechanical properties, and electronic structures of a representative MXene $\left(\mathrm{Ti}_{3} \mathrm{C}_{2}\right)$; the authors found that oxygen-functionalized $\mathrm{Ti}_{3} \mathrm{C}_{2}$ shows better thermodynamic stabilization and strength than their other counterparts due to significant charge transfers from inner bonds to the outer surface of the material. While MXenes with specific terminations may be gained by a post-synthesis method, very few studies on this topic have been reported. For example, Meng
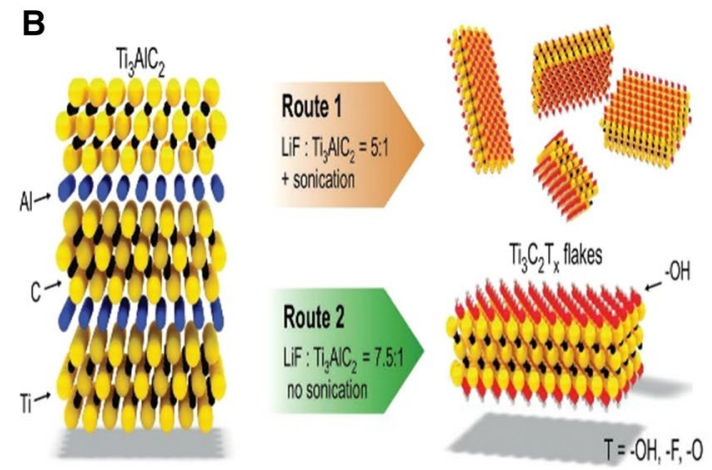

D
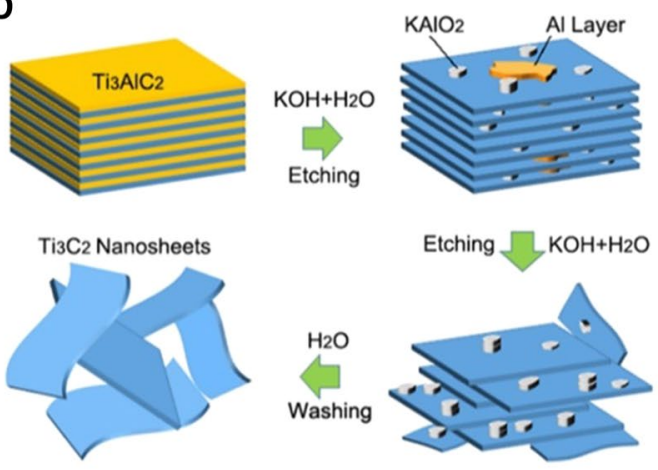

$\mathbf{F}$

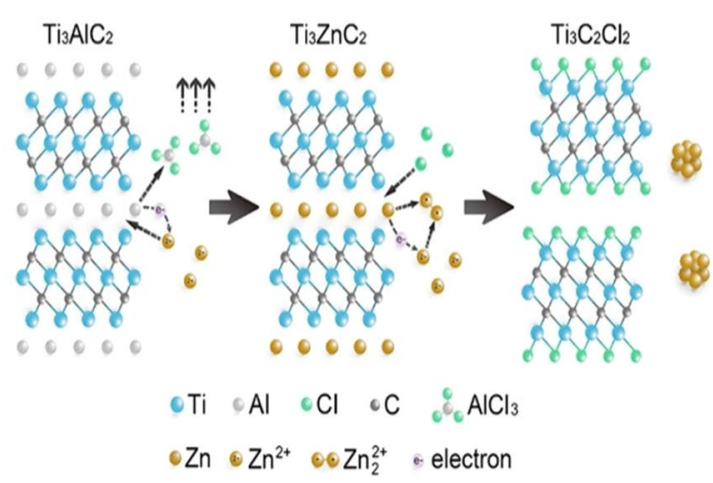

right 2017, American Chemical Society. E Proposed electrochemical etching mechanism of $\mathrm{Ti}_{2} \mathrm{AlC}$ in $\mathrm{HCl}$ electrolyte. Reproduced with permission [74]. Copyright 2019, American Chemical Society. F Schematic of the exfoliation process of $\mathrm{Ti}_{3} \mathrm{AlC}_{2}$ by molten $\mathrm{ZnCl}_{2}$. Reproduced with permission [75]. Copyright 2019, American Chemical Society

et al. [79] predicted that $\mathrm{S}$-functionalized $\mathrm{Ti}_{3} \mathrm{C}_{2}$ displays metallic behavior, a stable structure, a low diffusion barrier, and outstanding storage capacity for Na-ion batteries.

Besides theoretical explorations, surface termination of MXenes such as $\mathrm{Ti}_{3} \mathrm{C}_{2} \mathrm{~T}_{x}$ and $\mathrm{V}_{2} \mathrm{CT}_{x}$ has also been investigated by using experimental methods. For instance, Wang et al. [80] revealed the surface atomic scale of $\mathrm{Ti}_{3} \mathrm{C}_{2} \mathrm{~T}_{x}$ through aberration-corrected scanning transmission electron microscopy (STEM); the group found that surface functional groups (e.g., $-\mathrm{OH},-\mathrm{F}$, and $-\mathrm{O}$ ) are randomly distributed 
on the MXene surfaces and prefer to occupy the top sites of the central Ti atom. Karlsson's group [81] observed individual and double sheets of $\mathrm{Ti}_{3} \mathrm{C}_{2}$ by aberration-corrected STEM-EELS and revealed sheet coverage and intrinsic defects and $\mathrm{TiO}_{x}$ adatom complexes. In another study, Sang and co-workers [24] observed the different point defects in monolayer $\mathrm{Ti}_{3} \mathrm{C}_{2}$ nanosheets via STEM through the minimally intensive layer delamination method. Hope et al. [82] quantified the surface functional groups of $\mathrm{Ti}_{3} \mathrm{C}_{2} \mathrm{~T}_{x}$ by ${ }^{1} \mathrm{H}$ and ${ }^{19} \mathrm{~F}$ nuclear magnetic resonance (NMR) experiments and found that the proportions of different surface terminations highly rely on the preparation method of the material. Harris et al. [83] directly measured the surface termination groups of $\mathrm{V}_{2} \mathrm{CT}_{x}$ MXenes via solid-state NMR.

\section{Electronic Properties}

The applications of MXenes in electrochemistry energy storage and electrocatalysis largely rely on the inherent excellent electronic properties of the catalyst materials. Recent theoretical computational studies have been carried out to explore the effect of different $\mathrm{M}, \mathrm{X}$, and surface functional groups on the electronic properties of most MXenes. Since MXenes include various transition metals, the electronic properties of MXenes may be expected to range from metallic to semiconducting [55]. However, some MXenes have been predicted to be topological insulators because they contain heavy transition metals, such as Mo, W, and Cr [23, 25]. Additionally, surface termination could change the electronic properties of bare MXenes. For example, Fredrickson et al. [84] investigated the structural and electronic properties of layered bulk $\mathrm{Ti}_{2} \mathrm{C}$ and $\mathrm{Mo}_{2} \mathrm{C}$ with multiple functional groups in aqueous media by density functional theory (DFT) calculations. The out-of-plane lattice parameter of bulk MXenes is obviously affected by surface functional groups and intercalation of water. At zero applied potential, bulk MXenes $\left(\mathrm{Ti}_{2} \mathrm{C}\right.$ and $\left.\mathrm{Mo}_{2} \mathrm{C}\right)$ were functionalized by one monolayer of $\mathrm{O}$. However, bare MXenes were unstable, regardless of the applied potential. In addition, changes in the surface functional groups of $\mathrm{Ti}_{2} \mathrm{C}$ from $\mathrm{O}$-covered to $\mathrm{H}$-covered could promote metal-insulator transition under an applied potential. In another study, Tang et al. [28] reported that bare MXenes (e.g., $\mathrm{Ti}_{3} \mathrm{C}_{2}$ ) show metallic properties; however, functionalizing $\mathrm{Ti}_{3} \mathrm{C}_{2}$ with different groups (e.g., $-\mathrm{OH},-\mathrm{F}$, and $-\mathrm{I}$ ) yields semiconductor properties with narrow band gaps. This study also demonstrated that the M layer could obviously affect the electronic properties of the resulting material. Interestingly, whereas $\mathrm{Ti}_{3} \mathrm{C}_{2} \mathrm{~T}_{x}$ is metallic, MXenes containing Mo display semiconductor properties. Wang and Liao [85] reported that $\mathrm{Ni}_{2} \mathrm{~N}$ MXenes show intrinsic halfmetallicity using DFT calculations. The electronic properties of MXene have been related to their nanostructures. Enyashin and Ivanovskii [86], for instance, predicted that hydroxylated $\mathrm{Ti}_{3} \mathrm{C}_{2}$ nanotubes have metallic-like characteristics. Zhao et al. [87] predicted that $\mathrm{Ti}_{3} \mathrm{C}_{2}$ nanoribbons have distinct electronic properties different from those of MXenes nanosheets.

Several experiments have been performed to study the electronic properties of MXenes. However, only the electronic properties of some MXenes, such as $\mathrm{Ti}_{2} \mathrm{CT}_{x}, \mathrm{Ti}_{3} \mathrm{C}_{2} \mathrm{~T}_{x}$, and $\mathrm{Mo}_{2} \mathrm{CT}_{x}$, have been experimentally evaluated thus far [55]. For example, Halim et al. [88] evaluated the electronic conduction of $\mathrm{Ti}_{3} \mathrm{C}_{2} \mathrm{~T}_{x}$ and $\mathrm{Mo}_{2} \mathrm{CT}_{x}$ films. Lipatov and co-workers [71] measured the electronic properties of monolayer $\mathrm{Ti}_{3} \mathrm{C}_{2} \mathrm{~T}_{x}$ flakes. Lai et al. [89] revealed the excellent electronic properties of $2 \mathrm{D} \mathrm{Ti}_{2} \mathrm{CT}_{x}$. Computational and experimental results demonstrate that MXenes have excellent electronic properties and are promising candidate materials for electrochemistry, energy storage, and electrocatalysis.

\section{Applications in Electrocatalysis}

In the following section, we summarize current progress on the applications of MXene-based materials in electrocatalysis, including $\mathrm{HER}, \mathrm{OER}, \mathrm{ORR}, \mathrm{NRR}$, and $\mathrm{CO}_{2} \mathrm{RR}$, as presented in Table 1.

\section{Hydrogen Evolution Reaction}

Hydrogen is a promising energy carrier that may be harnessed to solve energy and environmental problems due to its high energy density and environmental friendliness. Electrochemical water splitting via HER offers the possibility of obtaining hydrogen through a clean and sustainable strategy. Pt-based catalysts display excellent performance for HER, but their high cost and scarcity seriously hinder their practical applications [121, 122]. Therefore, exploring earthabundant electrocatalysts that can potentially replace Pt is of paramount importance. As described earlier, MXenes exhibit outstanding electronic properties due to their inherent metallic character. Thus, the development of MXenebased HER electrocatalysts has attracted extensive attention.

Several theoretical calculations and experiments on MXene-based catalysts have been carried out to explore their applications in HER. Seh et al. [90] first performed a combined theoretical calculation and experimental study on pristine MXenes as electrocatalysts for HER. DFT calculations revealed that $\mathrm{Mo}_{2} \mathrm{CT}_{x}$ is a promising candidate HER catalyst, as shown in Fig. 3a, b. Experiments indicated that $\mathrm{Mo}_{2} \mathrm{CT}_{x}$ requires an overpotential of $189 \mathrm{mV}$ to reach a current density of $10 \mathrm{~mA} / \mathrm{cm}^{2}$ (Fig. 3c) and, thus, is superior to $\mathrm{Ti}_{2} \mathrm{CT}_{x}$. In addition, theoretical calculations indicate that the basal planes of $\mathrm{Mo}_{2} \mathrm{CT}_{x}$ could act as active sites for HER, 
Table 1 Summary of the current progress on MXene-based materials as electrocatalysts

\begin{tabular}{|c|c|c|c|c|}
\hline Catalyst & Application & Performance & Electrolyte & References \\
\hline $\mathrm{Mo}_{2} \mathrm{CT}_{x}$ & HER & $189 \mathrm{mV}$ at $10 \mathrm{~mA} / \mathrm{cm}^{2}$ & $0.5 \mathrm{~mol} / \mathrm{L} \mathrm{H}_{2} \mathrm{SO}_{4}$ & {$[90]$} \\
\hline $\mathrm{Ti}_{3} \mathrm{C}_{2} \mathrm{~T}_{x}$ & HER & $538 \mathrm{mV}$ at $10 \mathrm{~mA} / \mathrm{cm}^{2}$ & $0.5 \mathrm{~mol} / \mathrm{L} \mathrm{H}_{2} \mathrm{SO}_{4}$ & [91] \\
\hline F-terminated $\mathrm{Ti}_{2} \mathrm{CT}_{x}$ & HER & $170 \mathrm{mV}$ at $10 \mathrm{~mA} / \mathrm{cm}^{2}$ & $0.5 \mathrm{~mol} / \mathrm{L} \mathrm{H}_{2} \mathrm{SO}_{4}$ & {$[92]$} \\
\hline O-terminated $\mathrm{Ti}_{3} \mathrm{C}_{2} \mathrm{~T}_{x}$ & HER & $190 \mathrm{mV}$ at $10 \mathrm{~mA} / \mathrm{cm}^{2}$ & $0.5 \mathrm{~mol} / \mathrm{L} \mathrm{H}_{2} \mathrm{SO}_{4}$ & {$[44]$} \\
\hline $\mathrm{V}_{4} \mathrm{C}_{3} \mathrm{~T}_{x}$ & HER & $200 \mathrm{mV}$ at $10 \mathrm{~mA} / \mathrm{cm}^{2}$ & $0.5 \mathrm{~mol} / \mathrm{L} \mathrm{H}_{2} \mathrm{SO}_{4}$ & [93] \\
\hline $\mathrm{N}-\mathrm{Ti}_{2} \mathrm{CT}_{x}$ & HER & $215 \mathrm{mV}$ at $10 \mathrm{~mA} / \mathrm{cm}^{2}$ & $0.5 \mathrm{~mol} / \mathrm{L} \mathrm{H}_{2} \mathrm{SO}_{4}$ & [94] \\
\hline $\mathrm{Ti}_{3} \mathrm{C}_{2} \mathrm{~T}_{x}$ nanofibers & HER & $169 \mathrm{mV}$ at $10 \mathrm{~mA} / \mathrm{cm}^{2}$ & $0.5 \mathrm{~mol} / \mathrm{L} \mathrm{H}_{2} \mathrm{SO}_{4}$ & [95] \\
\hline $\mathrm{Ni}_{0.9} \mathrm{Co}_{0.1} @ \mathrm{Nb}-\mathrm{Ti}_{3} \mathrm{C}_{2} \mathrm{~T}_{x}$ & HER & $43.4 \mathrm{mV}$ at $10 \mathrm{~mA} / \mathrm{cm}^{2}$ & $1.0 \mathrm{~mol} / \mathrm{L} \mathrm{KOH}$ & [43] \\
\hline $\mathrm{Pt} / \mathrm{Ti}_{3} \mathrm{C}_{2} \mathrm{~T}_{x}-550$ & HER & $32.7 \mathrm{mV}$ at $10 \mathrm{~mA} / \mathrm{cm}^{2}$ & $0.1 \mathrm{~mol} / \mathrm{L} \mathrm{HClO}_{4}$ & [96] \\
\hline TBA-Ti ${ }_{3} \mathrm{C}_{2} \mathrm{~T}_{x}-\mathrm{Pt}-20$ & HER & $70 \mathrm{mV}$ at $10 \mathrm{~mA} / \mathrm{cm}^{2}$ & $0.5 \mathrm{~mol} / \mathrm{L} \mathrm{H}_{2} \mathrm{SO}_{4}$ & [97] \\
\hline $\mathrm{Co}^{3+}-\mathrm{Cr}_{2} \mathrm{CT}_{x}$ & HER & $404 \mathrm{mV}$ at $10 \mathrm{~mA} / \mathrm{cm}^{2}$ & $1.0 \mathrm{~mol} / \mathrm{L} \mathrm{KOH}$ & [74] \\
\hline $\mathrm{Co}^{3+}-\mathrm{V}_{2} \mathrm{CT}_{x}$ & HER & $460 \mathrm{mV}$ at $10 \mathrm{~mA} / \mathrm{cm}^{2}$ & $1.0 \mathrm{~mol} / \mathrm{L} \mathrm{KOH}$ & [74] \\
\hline $\mathrm{Co}^{3+}-\mathrm{Ti}_{2} \mathrm{CT}_{x}$ & HER & $458 \mathrm{mV}$ at $10 \mathrm{~mA} / \mathrm{cm}^{2}$ & $1.0 \mathrm{~mol} / \mathrm{L} \mathrm{KOH}$ & [74] \\
\hline $\mathrm{Co}-\mathrm{MoS}_{2} @ \mathrm{Mo}_{2} \mathrm{CT}_{x}$ & HER & $112 \mathrm{mV}$ at $10 \mathrm{~mA} / \mathrm{cm}^{2}$ & $1.0 \mathrm{~mol} / \mathrm{L} \mathrm{KOH}$ & [98] \\
\hline PtNPs $/ \mathrm{Ti}_{3} \mathrm{C}_{2} \mathrm{~T}_{x}$ & HER & $226 \mathrm{mV}$ at $10 \mathrm{~mA} / \mathrm{cm}^{2}$ & $0.1 \mathrm{~mol} / \mathrm{L} \mathrm{H}_{2} \mathrm{SO}_{4}$ & [99] \\
\hline $\mathrm{MoS}_{2} \perp \mathrm{Ti}_{3} \mathrm{C}_{2}$ & HER & $110 \mathrm{mV}$ at $10 \mathrm{~mA} / \mathrm{cm}^{2}$ & $0.5 \mathrm{~mol} / \mathrm{L} \mathrm{H}_{2} \mathrm{SO}_{4}$ & {$[100]$} \\
\hline $\mathrm{PtO}_{\mathrm{a}} \mathrm{PdO}_{\mathrm{b}} \mathrm{NPs} @ \mathrm{Ti}_{3} \mathrm{C}_{2} \mathrm{~T}_{x}$ & HER & $57 \mathrm{mV}$ at $10 \mathrm{~mA} / \mathrm{cm}^{2}$ & $0.5 \mathrm{~mol} / \mathrm{L} \mathrm{H}_{2} \mathrm{SO}_{4}$ & [101] \\
\hline $\mathrm{Ni}_{0.9} \mathrm{Fe}_{0.1} \mathrm{PS}_{3} @ \mathrm{Ti}_{3} \mathrm{C}_{2} \mathrm{~T}_{x}$ & HER & $196 \mathrm{mV}$ at $10 \mathrm{~mA} / \mathrm{cm}^{2}$ & $1.0 \mathrm{~mol} / \mathrm{L} \mathrm{KOH}$ & [102] \\
\hline $\mathrm{MoS}_{2} / \mathrm{Ti}_{3} \mathrm{C}_{2}$-MXene@C & HER & $135 \mathrm{mV}$ at $10 \mathrm{~mA} / \mathrm{cm}^{2}$ & $0.5 \mathrm{~mol} / \mathrm{L} \mathrm{H}_{2} \mathrm{SO}_{4}$ & [103] \\
\hline $\mathrm{MoS}_{2} / \mathrm{Ti}_{3} \mathrm{C}_{2} \mathrm{~T}_{x}$ nanoroll & HER & $168 \mathrm{mV}$ at $10 \mathrm{~mA} / \mathrm{cm}^{2}$ & $0.5 \mathrm{~mol} / \mathrm{L} \mathrm{H}_{2} \mathrm{SO}_{4}$ & {$[42]$} \\
\hline $\mathrm{Mo}_{2} \mathrm{TiC}_{2} \mathrm{~T}_{x}-\mathrm{Pt}_{\mathrm{SA}}$ & HER & $30 \mathrm{mV}$ at $10 \mathrm{~mA} / \mathrm{cm}^{2}$ & $0.5 \mathrm{~mol} / \mathrm{L} \mathrm{H}_{2} \mathrm{SO}_{4}$ & [104] \\
\hline CoP@3D $\mathrm{Ti}_{3} \mathrm{C}_{2} \mathrm{~T}_{x}$ & HER & $168 \mathrm{mV}$ at $10 \mathrm{~mA} / \mathrm{cm}^{2}$ & $1.0 \mathrm{~mol} / \mathrm{L} \mathrm{KOH}$ & [105] \\
\hline FeNi-LDH/ $/ \mathrm{Ti}_{3} \mathrm{C}_{2} \mathrm{~T}_{x}$ & OER & $298 \mathrm{mV}$ at $10 \mathrm{~mA} / \mathrm{cm}^{2}$ & $1.0 \mathrm{~mol} / \mathrm{L} \mathrm{KOH}$ & {$[45]$} \\
\hline CoNi-ZIF-67@ $\mathrm{Ti}_{3} \mathrm{C}_{2} \mathrm{~T}_{x}$ & OER & $323 \mathrm{mV}$ at $10 \mathrm{~mA} / \mathrm{cm}^{2}$ & $1.0 \mathrm{~mol} / \mathrm{L} \mathrm{KOH}$ & [106] \\
\hline $\mathrm{Ti}_{3} \mathrm{C}_{2} \mathrm{~T}_{x}-\mathrm{CoBDC}$ & OER & $410 \mathrm{mV}$ at $10 \mathrm{~mA} / \mathrm{cm}^{2}$ & $0.1 \mathrm{~mol} / \mathrm{L} \mathrm{KOH}$ & [107] \\
\hline $\mathrm{g}-\mathrm{C}_{3} \mathrm{~N}_{4} / \mathrm{Ti}_{3} \mathrm{C}_{2} \mathrm{~T}_{x}$ film & OER & $420 \mathrm{mV}$ at $10 \mathrm{~mA} / \mathrm{cm}^{2}$ & $0.1 \mathrm{~mol} / \mathrm{L} \mathrm{KOH}$ & [108] \\
\hline Co- $\mathrm{B}_{\mathrm{i}} / \mathrm{Ti}_{3} \mathrm{C}_{2} \mathrm{~T}_{x}$ & OER & $250 \mathrm{mV}$ at $10 \mathrm{~mA} / \mathrm{cm}^{2}$ & $1.0 \mathrm{~mol} / \mathrm{L} \mathrm{KOH}$ & [46] \\
\hline $\mathrm{S}-\mathrm{NiFe}_{2} \mathrm{O}_{4} @ \mathrm{Ti}_{3} \mathrm{C}_{2} @ \mathrm{NF}$ & OER & $270 \mathrm{mV}$ at $10 \mathrm{~mA} / \mathrm{cm}^{2}$ & $1.0 \mathrm{~mol} / \mathrm{L} \mathrm{KOH}$ & [109] \\
\hline $\mathrm{NiCoS} / \mathrm{Ti}_{3} \mathrm{C}_{2} \mathrm{~T}_{x}$ & OER & $365 \mathrm{mV}$ at $10 \mathrm{~mA} / \mathrm{cm}^{2}$ & $1.0 \mathrm{~mol} / \mathrm{L} \mathrm{KOH}$ & [110] \\
\hline $\mathrm{Co}^{3+}-\mathrm{Cr}_{2} \mathrm{CT}_{x}$ & OER & $420 \mathrm{mV}$ at $10 \mathrm{~mA} / \mathrm{cm}^{2}$ & $1.0 \mathrm{~mol} / \mathrm{L} \mathrm{KOH}$ & [74] \\
\hline $\mathrm{Co}^{3+}-\mathrm{V}_{2} \mathrm{CT}_{x}$ & OER & $420 \mathrm{mV}$ at $10 \mathrm{~mA} / \mathrm{cm}^{2}$ & $1.0 \mathrm{~mol} / \mathrm{L} \mathrm{KOH}$ & {$[74]$} \\
\hline $\mathrm{Co}^{3+}-\mathrm{Ti}_{2} \mathrm{CT}_{x}$ & OER & $420 \mathrm{mV}$ at $10 \mathrm{~mA} / \mathrm{cm}^{2}$ & $1.0 \mathrm{~mol} / \mathrm{L} \mathrm{KOH}$ & {$[74]$} \\
\hline $\mathrm{PtO}_{\mathrm{a}} \mathrm{PdO}_{\mathrm{b}} \mathrm{NPs}_{\mathrm{S}} @ \mathrm{Ti}_{3} \mathrm{C}_{2} \mathrm{~T}_{x}$ & OER & $310 \mathrm{mV}$ at $10 \mathrm{~mA} / \mathrm{cm}^{2}$ & $0.1 \mathrm{~mol} / \mathrm{L} \mathrm{KOH}$ & [101] \\
\hline $\mathrm{Ni}_{0.7} \mathrm{Fe}_{0.3} \mathrm{PS}_{3} @ \mathrm{Ti}_{3} \mathrm{C}_{2} \mathrm{~T}_{x}$ & OER & $282 \mathrm{mV}$ at $10 \mathrm{~mA} / \mathrm{cm}^{2}$ & $1.0 \mathrm{~mol} / \mathrm{L} \mathrm{KOH}$ & [102] \\
\hline $\mathrm{Co} / \mathrm{N}-\mathrm{CNTs} @ \mathrm{Ti}_{3} \mathrm{C}_{2} \mathrm{~T}_{x}$ & OER & $411 \mathrm{mV}$ at $10 \mathrm{~mA} / \mathrm{cm}^{2}$ & $0.1 \mathrm{~mol} / \mathrm{L} \mathrm{KOH}$ & [111] \\
\hline $\mathrm{CoP} @ 3 \mathrm{D} \mathrm{Ti}_{3} \mathrm{C}_{2} \mathrm{~T}_{x}$ & OER & $280 \mathrm{mV}$ at $10 \mathrm{~mA} / \mathrm{cm}^{2}$ & $1.0 \mathrm{~mol} / \mathrm{L} \mathrm{KOH}$ & [105] \\
\hline $\mathrm{g}-\mathrm{C}_{3} \mathrm{~N}_{4} / \mathrm{Ti}_{3} \mathrm{C}_{2} \mathrm{~T}_{x}$ & ORR & $0.79 \mathrm{~V}$ at half-wave potential & $0.1 \mathrm{~mol} / \mathrm{L} \mathrm{KOH}$ & [47] \\
\hline $\mathrm{FeNC} / \mathrm{Ti}_{3} \mathrm{C}_{2} \mathrm{~T}_{x}$ & ORR & $0.81 \mathrm{~V}$ at half-wave potential & $0.1 \mathrm{~mol} / \mathrm{L} \mathrm{KOH}$ & [112] \\
\hline $\mathrm{Ti}_{3} \mathrm{C}_{2} \mathrm{~T}_{x} / \mathrm{NW}-\mathrm{Ag}_{0.9} \mathrm{Ti}_{0.1}$ & ORR & $0.78 \mathrm{~V}$ at half-wave potential & $0.1 \mathrm{~mol} / \mathrm{L} \mathrm{KOH}$ & [113] \\
\hline $\mathrm{FePc} / \mathrm{Ti}_{3} \mathrm{C}_{2} \mathrm{~T}_{x}$ & ORR & $0.86 \mathrm{~V}$ at half-wave potential & $0.1 \mathrm{~mol} / \mathrm{L} \mathrm{KOH}$ & {$[48]$} \\
\hline $\mathrm{Mn}_{3} \mathrm{O}_{4} / \mathrm{Ti}_{3} \mathrm{C}_{2} \mathrm{~T}_{x}$ & ORR & $0.89 \mathrm{~V}$ at onset potential & $0.1 \mathrm{~mol} / \mathrm{L} \mathrm{KOH}$ & [114] \\
\hline $\mathrm{FeCo}(3: 1)-\mathrm{N}-\mathrm{d}-\mathrm{Ti}_{3} \mathrm{C}_{2}$ & ORR & $0.80 \mathrm{~V}$ at half-wave potential & $0.1 \mathrm{~mol} / \mathrm{L} \mathrm{KOH}$ & [115] \\
\hline Ultrathin $\mathrm{Ti}_{3} \mathrm{C}_{2} \mathrm{~T}_{x}$ & ORR & $0.85 \mathrm{~V}$ at onset potential & $0.1 \mathrm{~mol} / \mathrm{L} \mathrm{KOH}$ & [116] \\
\hline $\mathrm{Co} / \mathrm{N}-\mathrm{CNTs} @ \mathrm{Ti}_{3} \mathrm{C}_{2} \mathrm{~T}_{x}$ & ORR & $0.81 \mathrm{~V}$ at half-wave potential & $0.1 \mathrm{~mol} / \mathrm{L} \mathrm{KOH}$ & [111] \\
\hline $\mathrm{TiO}_{2} / \mathrm{Ti}_{3} \mathrm{C}_{2} \mathrm{~T}_{x}$ & NRR & $26.32 \mu \mathrm{g} /\left(\mathrm{h} \mathrm{mg}_{\text {cat }}\right) 8.42 \%$ faradaic efficiency at $-0.60 \mathrm{~V}$ & $0.1 \mathrm{~mol} / \mathrm{L} \mathrm{HCl}$ & [117] \\
\hline F-free $\mathrm{Ti}_{3} \mathrm{C}_{2} \mathrm{~T}_{x}$ & NRR & $26.32 \mu \mathrm{g} /\left(\mathrm{h} \mathrm{mg}_{\text {cat }}\right) 9.1 \%$ faradaic efficiency at $-0.3 \mathrm{~V}$ & $0.1 \mathrm{~mol} / \mathrm{L} \mathrm{HCl}$ & [118] \\
\hline $\mathrm{Ti}_{3} \mathrm{C}_{2} \mathrm{~T}_{x} / \mathrm{FeOOH}$ & NRR & $4.72 \mu \mathrm{g} /\left(\mathrm{h} \mathrm{cm}^{2}\right)$ at $-0.1 \mathrm{~V} 5.78 \%$ faradaic efficiency at $-0.2 \mathrm{~V}$ & $\begin{array}{l}0.5 \mathrm{~mol} / \mathrm{L} \mathrm{Li}_{2} \mathrm{SO}_{4}(\mathrm{pH}=2 \\
\text { adjusted by } 1 \mathrm{~mol} / \mathrm{L} \\
\mathrm{HCl})\end{array}$ & [49] \\
\hline $\mathrm{Ti}_{3} \mathrm{C}_{2} \mathrm{~T}_{x}$ & NRR & $20.4 \mu \mathrm{g} /(\mathrm{h} \mathrm{mg}$ cat $) 9.3 \%$ faradaic efficiency at $-0.4 \mathrm{~V}$ & $0.1 \mathrm{~mol} / \mathrm{L} \mathrm{HCl}$ & [119] \\
\hline
\end{tabular}


Table 1 (continued)

\begin{tabular}{lllll}
\hline Catalyst & Application & Performance & Electrolyte & References \\
\hline $\mathrm{MnO}_{2}-\mathrm{Ti}_{3} \mathrm{C}_{2} \mathrm{~T}_{x}$ & $\mathrm{NRR}$ & $34.12 \mu \mathrm{g} /(\mathrm{h} \mathrm{mg}$ cat $) 11.39 \%$ faradaic efficiency at $-0.55 \mathrm{~V}$ & $0.1 \mathrm{~mol} / \mathrm{L} \mathrm{HCl}$ & {$[120]$} \\
\hline
\end{tabular}
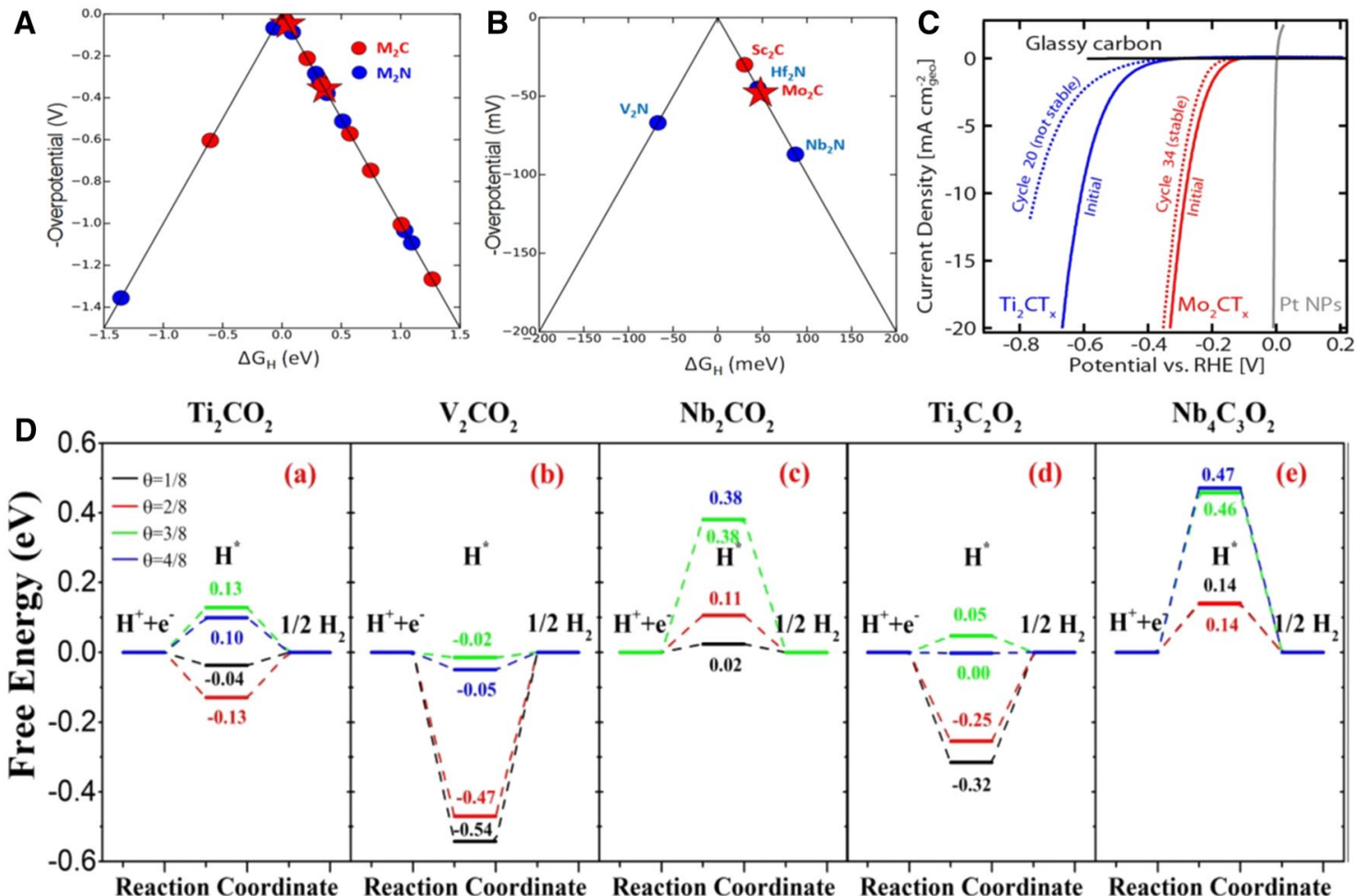

E

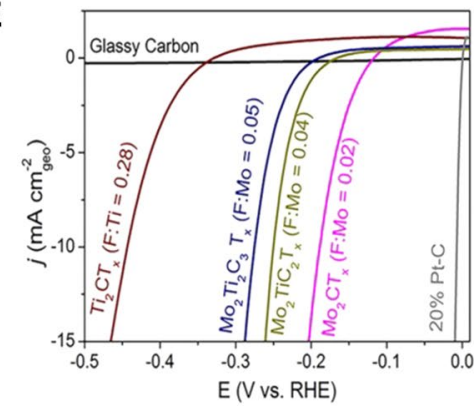

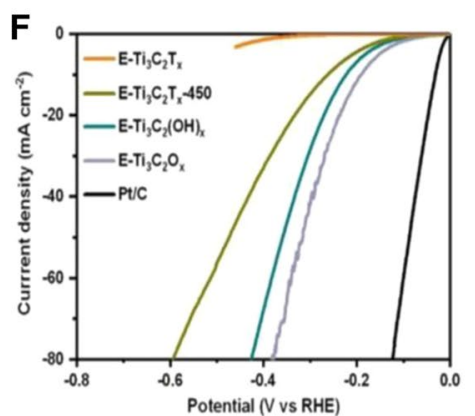

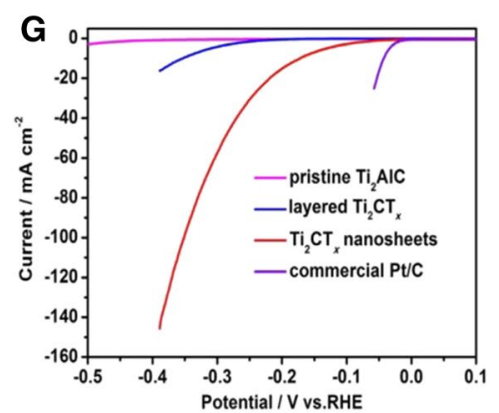

Fig. 3 A HER volcano curves with theoretical overpotentials for the studied MXenes. The stars represent two MXenes $\left(\mathrm{Ti}_{2} \mathrm{C}\right.$ and $\left.\mathrm{Mo}_{2} \mathrm{C}\right)$ in the experiment. B Zoomed-in portion of the top of the volcano in A. C Polarization curves of $\mathrm{Ti}_{2} \mathrm{CT}_{x}$ and $\mathrm{Mo}_{2} \mathrm{CT}_{x}$ nanosheets and $\mathrm{Pt}$ nanoparticles. Reproduced with permission [90]. Copyright 2016, American Chemical Society. D Free energy diagrams of HER processing on $\mathrm{Ti}_{2} \mathrm{CO}_{2}, \mathrm{~V}_{2} \mathrm{CO}_{2}, \mathrm{Nb}_{2} \mathrm{CO}_{2}, \mathrm{Ti}_{3} \mathrm{C}_{2} \mathrm{O}_{2}$, and $\mathrm{Nb}_{4} \mathrm{C}_{3} \mathrm{O}_{2}$. Reproduced with permission [123]. Copyright 2016, American Chemical Society. E Polarization curves of glassy carbon, $\mathrm{Ti}_{3} \mathrm{C}_{2} \mathrm{~T}_{x}$

which is clearly different from the mechanism of the widely studied $2 \mathrm{H}$ phase $\mathrm{MoS}_{2}$.

Gao et al. [123] studied the HER performance of various O-terminated 2D MXenes, such as $\mathrm{Ti}_{2} \mathrm{C}, \mathrm{V}_{2} \mathrm{C}, \mathrm{Nb}_{2} \mathrm{C}, \mathrm{Ti}_{3} \mathrm{C}_{2}$,
$(\mathrm{F}: \mathrm{Ti}=0.28), \mathrm{Mo}_{2} \mathrm{Ti}_{2} \mathrm{C}_{3} \mathrm{~T}_{x}(\mathrm{~F}: \mathrm{Mo}=0.05), \mathrm{Mo}_{2} \mathrm{TiC}_{2} \mathrm{~T}_{x}(\mathrm{~F}: \mathrm{Mo}=0.04)$, $\mathrm{Mo}_{2} \mathrm{CT}_{x}(\mathrm{~F}: \mathrm{Mo}=0.02)$, and $20 \% \mathrm{Pt} / \mathrm{C}$. Reproduced with permission [91]. Copyright 2018, American Chemical Society. F Polarization curves of $\mathrm{E}^{-\mathrm{Ti}_{3}} \mathrm{C}_{2} \mathrm{~T}_{x}, \mathrm{E}-\mathrm{Ti}_{3} \mathrm{C}_{2}(\mathrm{OH})_{x}, \mathrm{E}-\mathrm{Ti}_{3} \mathrm{C}_{2} \mathrm{O}_{x}, \mathrm{E}-\mathrm{Ti}_{3} \mathrm{C}_{2} \mathrm{~T}_{x}-450$, and $\mathrm{Pt} / \mathrm{C}$. Reproduced with permission [44]. Copyright 2011, Wiley-VCH. G Polarization curves of pristine $\mathrm{Ti}_{2} \mathrm{AlC}$, layered $\mathrm{Ti}_{2} \mathrm{CT}_{x}$ nanosheets, and $\mathrm{Pt} / \mathrm{C}$. Reproduced with permission [124]. Copyright 2018, Elsevier Ltd

and $\mathrm{Nb}_{4} \mathrm{C}_{3}$, by DFT calculations. As shown in Fig. 3d, different MXenes displayed different Gibbs free energies for the adsorption of atomic hydrogen $\left(\Delta G_{\mathrm{H}^{*} 0}\right)$ under different coverages. Among the MXenes tested, $\mathrm{Ti}_{3} \mathrm{C}_{2} \mathrm{O}_{2}$ notably 
showed the lowest $\Delta G_{\mathrm{H}^{*} 0}$ with a hydrogen coverage of $4 / 8$. The $\Delta G_{\mathrm{H}^{* 0}}$ of $\mathrm{Cr}_{2} \mathrm{CO}_{2}$ MXene with different hydrogen coverages has also been obtained by Cheng et al. [92].

Theoretical calculations indicate that modifying the surface functional groups of MXenes is an effective route to boost their HER performance, and many of these results have been verified by experiments. For example, Handoko et al. [91] first investigated the effect of five MXenes with different $\mathrm{F}$ coverages on their basal plane for HER and found that the presence of $\mathrm{F}$ terminations deteriorates the HER performance of these materials. As-obtained $\mathrm{Mo}_{2} \mathrm{CT}_{x}$ featuring low $\mathrm{F}$ coverage only required $189 \mathrm{mV}$ to achieve a current density of $10 \mathrm{~mA} / \mathrm{cm}^{2}$ (Fig. 3e). Besides, oxygen groups on the basal planes of $\mathrm{Mo}_{2} \mathrm{CT}_{x}$ proved to be catalytically active for HER. Jiang et al. [44] prepared oxygenfunctionalized ultrathin $\mathrm{Ti}_{3} \mathrm{C}_{2} \mathrm{~T}_{x}$ and achieved a HER performance $\left(190 \mathrm{mV}\right.$ at $\left.10 \mathrm{~mA} / \mathrm{cm}^{2}\right)$ higher than that of untreated $\mathrm{Ti}_{3} \mathrm{C}_{2} \mathrm{~T}_{x}$, as shown in Fig. 3f. Li et al. [124] synthesized rich F-terminated $\mathrm{Ti}_{2} \mathrm{CT}_{x}$ and obtained excellent HER performance with a small overpotential of $170 \mathrm{mV}$ at a current density of $10 \mathrm{~mA} / \mathrm{cm}^{2}$ (Fig. 3g). $\mathrm{V}_{4} \mathrm{C}_{3} \mathrm{~T}_{x}$ MXene has also been synthesized and directly used as a HER catalyst [93].

Yoon et al. [94] synthesized nitrided- $\mathrm{Ti}_{2} \mathrm{CT}_{x}\left(\mathrm{~N}-\mathrm{Ti}_{2} \mathrm{CT}_{x}\right)$ via the high-temperature nitridation of $2 \mathrm{D} \mathrm{Ti}_{2} \mathrm{CT}_{x}$ using $\mathrm{NaNH}_{2}$ (Fig. 4a). As shown in Fig. 4b, the obtained $\mathrm{N}-\mathrm{Ti}_{2} \mathrm{CT}_{x}$ showed high HER catalytic performance with an overpotential of $215 \mathrm{mV}$ at a current density of $10 \mathrm{~mA} /$ $\mathrm{cm}^{2}$, which is over three times smaller than that of pristine- $\mathrm{Ti}_{2} \mathrm{CT}_{x}(645 \mathrm{mV})$. The effects of nanostructures on the
HER catalytic activity of MXenes have been explored. For instance, Yang et al. [125] constructed 12 types of MXenes nanoribbon models and evaluated the role of MXenes nanoribbon edges on catalyzing HER. Nanoribbons of $\mathrm{Ti}_{3} \mathrm{C}_{2}$ and solid solution $(\mathrm{Ti}, \mathrm{Nb}) \mathrm{C}$ showed outstanding performance for HER and revealed low adsorption free energies (close to $0 \mathrm{eV}$ ) and small Tafel barriers below 0.42 and $0.17 \mathrm{eV}$, respectively (Fig. $4 \mathrm{c}-\mathrm{e}$ ). $\mathrm{Ti}_{3} \mathrm{C}_{2} \mathrm{~T}_{x}$ MXene nanofibers were successfully prepared by Yuan and co-workers [95], and the obtained nanofibers displayed enhanced HER activity with a small overpotential of $169 \mathrm{mV}$ at $10 \mathrm{~mA} / \mathrm{cm}^{2}$ (Fig. 4f) and a Tafel slope of $97 \mathrm{mV} / \mathrm{dec}$.

Hybridizing active components with MXene is yet another effective route to improve HER catalytic activity. Thus, the development of MXene-based nanohybrids has drawn wide attention. You et al. [126] predicted that Schottky barrier-free hole contacts could be formed at six MXenes (i.e., $\mathrm{V}_{4} \mathrm{C}_{3} \mathrm{O}_{2}, \mathrm{Mo}_{2} \mathrm{CO}_{2}, \mathrm{~V}_{2} \mathrm{NO}_{2}, \mathrm{Cr}_{2} \mathrm{NO}_{2} \mathrm{Cr}_{2} \mathrm{CO}_{2}$, and $\mathrm{V}_{2} \mathrm{CO}_{2}$ ) and $2 \mathrm{H}-\mathrm{MoS}_{2}$ contacting interfaces. The formation of unique interfaces was attributed to the high work functions of the MXenes (Fig. 5a), which were larger than the ionization energy of monolayer $2 \mathrm{H}-\mathrm{MoS}_{2}$, and the absence of the formation of interfacial gap states that usually strongly pin the Fermi level in the midgap of the semiconductor. The authors also found that efficient charge injection into $\mathrm{MoS}_{2}$ facilitated by the Schottky barrier-free contact could also increase the HER activity of the $2 \mathrm{H}-\mathrm{MoS}_{2}$ basal plane by improving its conductivity as well as its ability to adsorb hydrogen, being comparable to $1 \mathrm{~T}-\mathrm{MoS}_{2}$ (Fig. 5b, c).
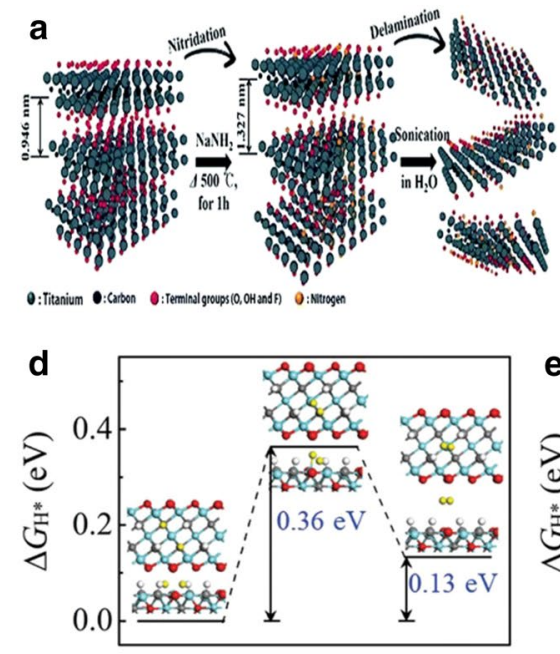

Reaction pathway
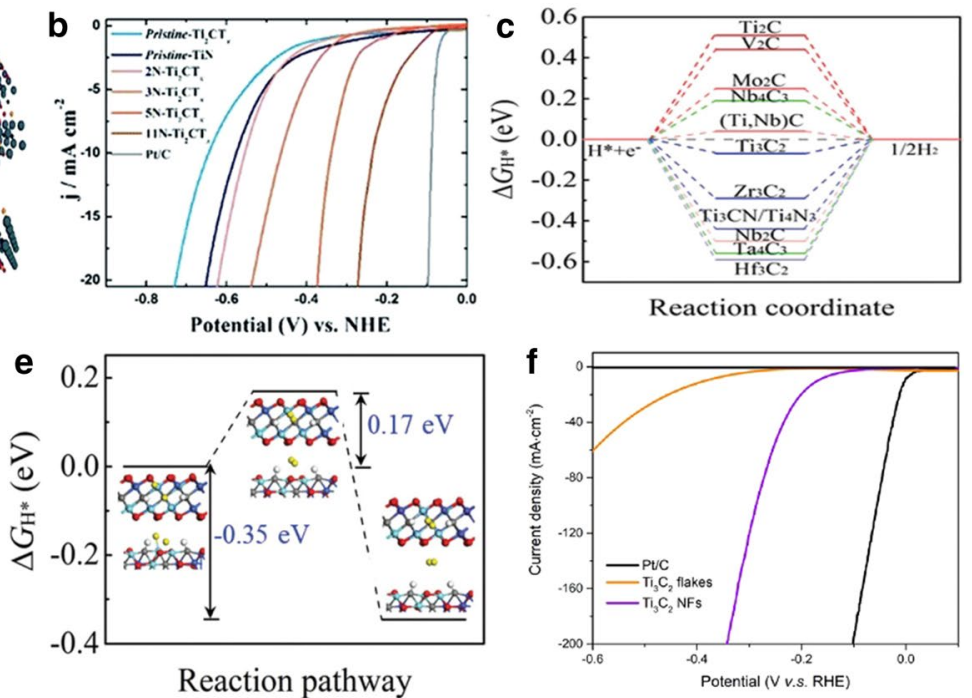

Reaction coordinate

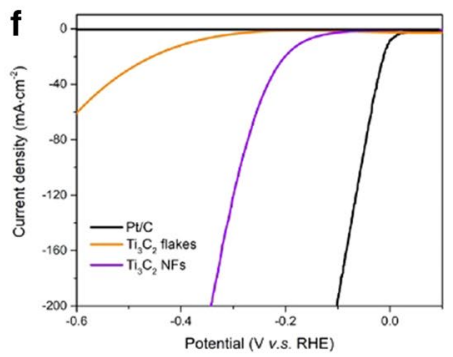

Fig. 4 a Preparations of the $\mathrm{N}-\mathrm{Ti}_{2} \mathrm{CT}_{x}$ nanosheets. b Polarization curves of $\mathrm{Ti}_{2} \mathrm{CT}_{x}$ with different nitridation degrees, pristine- $\mathrm{Ti}_{2} \mathrm{CT}_{x}$, TiN, and Pt/C. Reproduced with permission [94]. Copyright 2018, Royal Society of Chemistry. c Free energy diagrams for hydrogen evolution on the edges of various MXene nanoribbons. Free energy profiles of the Tafel reaction for $\mathrm{H}_{2}$ formation on $\mathbf{d}$ the edges of $\mathrm{Ti}_{3} \mathrm{C}_{2}$ and $\mathbf{e}(\mathrm{Ti}, \mathrm{Nb}) \mathrm{C}$ MXene nanoribbons, respectively. Reproduced with permission [125]. Copyright 2018, Royal Society of Chemistry. f Polarization curves of $\mathrm{Ti}_{3} \mathrm{C}_{2}$ flakes, $\mathrm{Ti}_{3} \mathrm{C}_{2}$ nanofibers, and $\mathrm{Pt} / \mathrm{C}$. Reproduced with permission [95]. Copyright 2018, American Chemical Society 

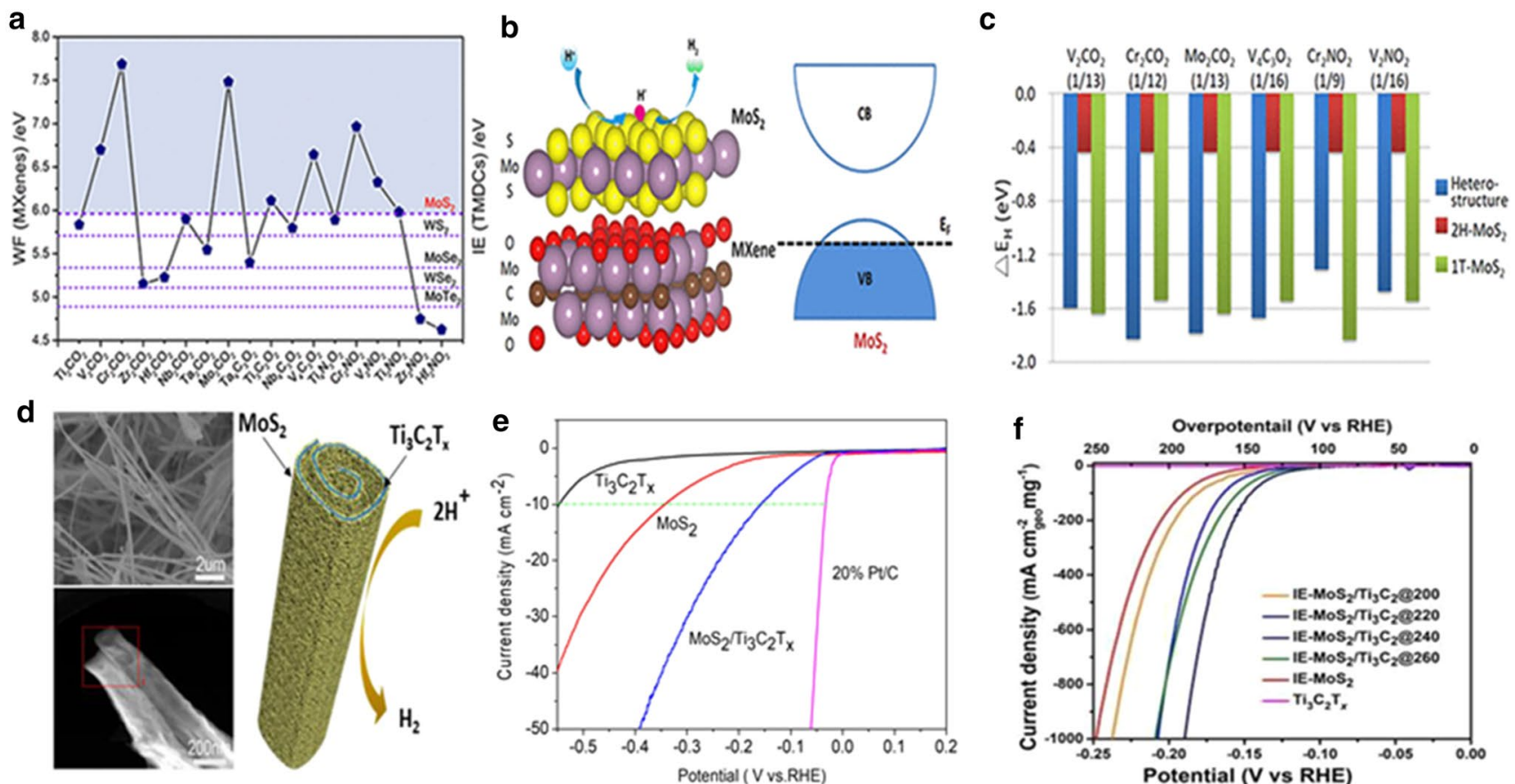

.20
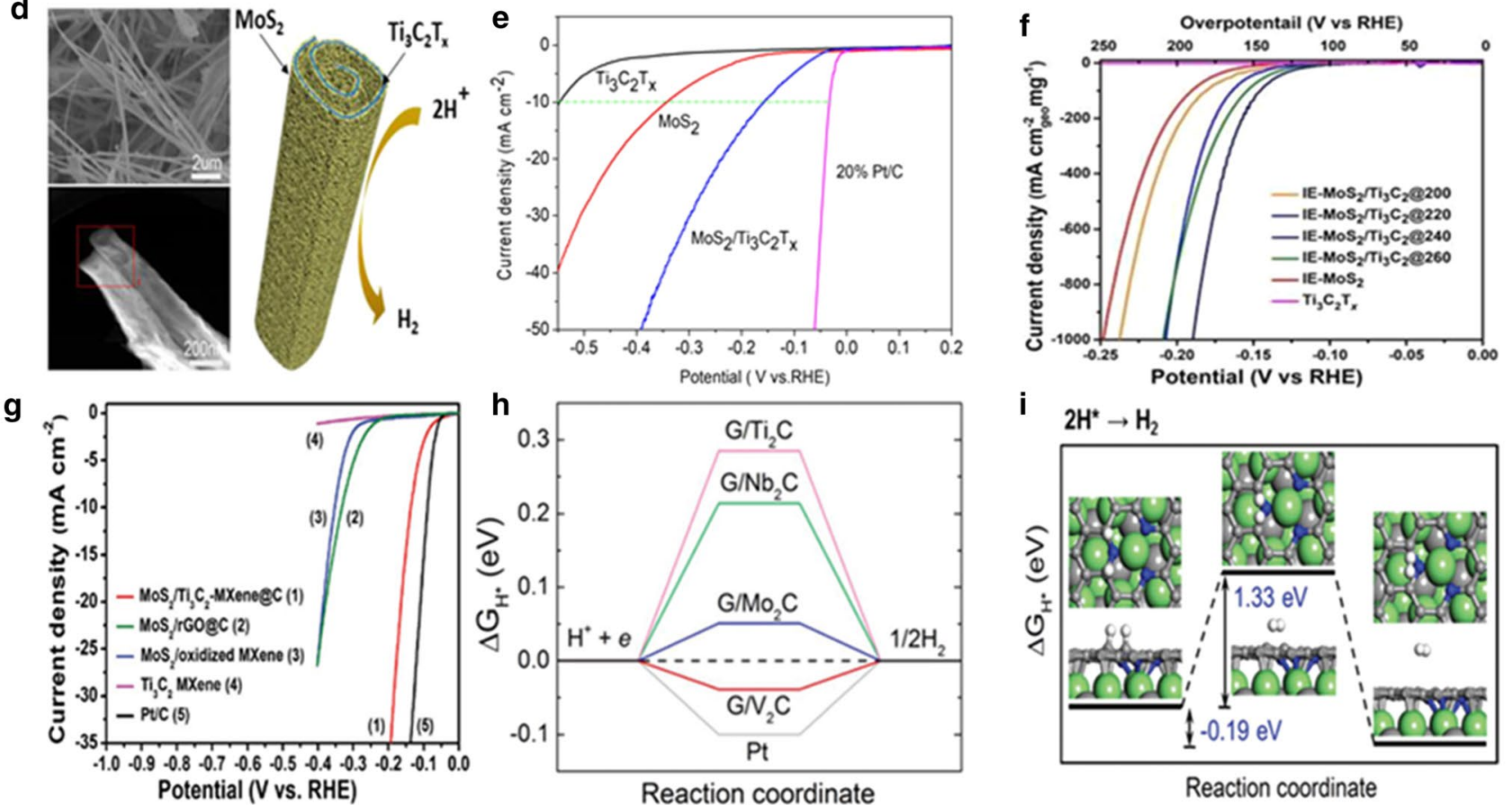

Fig. 5 a Work functions (denoted by dots) of different MXenes with $\mathrm{O}$ terminations compared with the ionization energies (denoted by dashed lines) of monolayer $\mathrm{MoS}_{2}, \mathrm{WS}_{2}, \mathrm{MoSe}_{2}, \mathrm{WSe}_{2}$, and $\mathrm{MoTe}_{2}$. b Schematic of the $\mathrm{MoS}_{2}$-catalyzed HER and metallic energy-band feature of $\mathrm{MoS}_{2}$ induced by $p$-type Schottky barrier-free contact. c Hydrogen adsorption energies of $2 \mathrm{H}-\mathrm{MoS}_{2}, 1 \mathrm{~T}-\mathrm{MoS}_{2}$, and $2 \mathrm{H}-\mathrm{MoS}_{2} /$ MXene heterostructures. The numbers in brackets represent the corresponding different $\mathrm{H}$ coverages. Reproduced with permission [126]. Copyright 2019, American Chemical Society. d Typical TEM and SEM images of a nanoroll-like $\mathrm{MoS}_{2} / \mathrm{Ti}_{3} \mathrm{C}_{2} \mathrm{~T}_{x}$ hybrid and schematic of the $\mathrm{MoS}_{2} / \mathrm{Ti}_{3} \mathrm{C}_{2} \mathrm{~T}_{x}$-catalyzed HER process. e Polarization curves of a $\mathrm{MoS}_{2} / \mathrm{Ti}_{3} \mathrm{C}_{2} \mathrm{~T}_{x}$ hybrid, pure $\mathrm{MoS}_{2}, \mathrm{Ti}_{3} \mathrm{C}_{2} \mathrm{~T}_{x}$ nanosheets, and $\mathrm{Pt} / \mathrm{C}$.

In another study, Ling et al. [127] used DFT calculations to predict that a low $\mathrm{S}$ vacancy concentration $(\sim 2.5 \%)$ in $\mathrm{MoS}_{2} /$ MXenes-OH heterostructures could result in the ideal free energy needed to enhance hydrogen evolution. The simulation results indicated that the HER catalytic performance of $\mathrm{MoS}_{2}$ could be remarkably improved by forming heterostructure with MXenes. These findings were also verified by recent experimental studies. For instance, our group developed a facile method to prepare hierarchical nanoroll-like
Reproduced with permission [42]. Copyright 2019, Elsevier Ltd. f Polarization curves of interlayer expanded- $\mathrm{MoS}_{2} / \mathrm{Ti}_{3} \mathrm{C}_{2}$ at various temperatures. Reproduced with permission [100]. Copyright 2018, Royal Society of Chemistry. g Polarization curves of $\mathrm{MoS}_{2} / \mathrm{Ti}_{3} \mathrm{C}_{2}$ MXene@C, MoS 2 /oxidized MXene, $\mathrm{MoS}_{2} / \mathrm{rGO} @ \mathrm{C}, \mathrm{Ti}_{3} \mathrm{C}_{2} \mathrm{MXene}$, and $\mathrm{Pt} / \mathrm{C}$ catalysts. Reproduced with permission [103]. Copyright 2011, Wiley-VCH. h Reaction free energy $\left(\Delta G_{\mathrm{H}^{*}}\right)$ of HER on the most active sites of different graphene/MXene heterostructures and on the Pt (111) surface. i Changes in $\Delta G_{\mathrm{H}^{*}}$ during HER on N-doped graphene over a $\mathrm{V}_{2} \mathrm{C}$ MXene monolayer. Reproduced with permission [128]. Copyright 2018, Royal Society of Chemistry

$\mathrm{MoS}_{2} / \mathrm{Ti}_{3} \mathrm{C}_{2} \mathrm{~T}_{x}$ hybrids by combining liquid nitrogen-freezing and annealing (Fig. 5d) [42]. The resulting unique hierarchical $\mathrm{MoS}_{2} / \mathrm{Ti}_{3} \mathrm{C}_{2} \mathrm{~T}_{x}$ nanohybrid showed outstanding HER catalytic activity with a low onset overpotential of $30 \mathrm{mV}$ (Fig. 5e) and an over-25-fold increase in exchange current density compared with $\mathrm{MoS}_{2}$. Attanayake et al. [100] prepared vertically aligned interlayer expanded $\mathrm{MoS}_{2}$ on a 2D $\mathrm{Ti}_{3} \mathrm{C}_{2}$ MXene by the microwave-assisted method. The resultant few-layered $\mathrm{MoS}_{2}$ showed a uniform interlayer spacing 
of $9.4 \AA$ and delivered a small onset potential of $95 \mathrm{mV}$ (Fig. 5f) and Tafel slope $(\sim 40 \mathrm{mV} / \mathrm{dec})$. Wu et al. [103] presented hierarchical $\mathrm{MoS}_{2} / \mathrm{Ti}_{3} \mathrm{C}_{2}$-MXene@C nanohybrids by coupling $\mathrm{MoS}_{2}$ nanosheets on carbon-stabilized $\mathrm{Ti}_{3} \mathrm{C}_{2}$ MXene. The obtained catalyst exhibited excellent performance with a low overpotential of $135 \mathrm{mV}$ at $10 \mathrm{~mA} / \mathrm{cm}^{2}$ and a low Tafel slope of $45 \mathrm{mV} / \mathrm{dec}$; these values are smaller than those of other counterpart catalysts (Fig. $5 \mathrm{~g}$ ). Indeed, our group presented $\mathrm{Co}-\mathrm{MoS}_{2} / \mathrm{Mo}_{2} \mathrm{CT}_{x}$ nanohybrids by engineering Co-doped $\mathrm{MoS}_{2}$ coupled with $\mathrm{Mo}_{2} \mathrm{CT}_{x}$ MXene [98]. The resulting hybrids exhibited a low overpotential of $112 \mathrm{mV}$ at $10 \mathrm{~mA} / \mathrm{cm}^{2}$ and good stability in $1 \mathrm{~mol} / \mathrm{L} \mathrm{KOH}$ aqueous solution.

Du et al. [102] reported the in situ growth of the Ni-based bimetal phosphorus trisulfide $\left(\mathrm{Ni}_{1-x} \mathrm{Fe}_{x} \mathrm{PS}_{3}\right)$ on the surface of $\mathrm{Ti}_{3} \mathrm{C}_{2} \mathrm{~T}_{x}$ MXene nanosheets by a simple self-assembly and subsequent solid-state reaction process. The optimized hybrids $\left(\mathrm{Ni}_{0.7} \mathrm{Fe}_{0.3} \mathrm{PS}_{3} @ \mathrm{MXene}\right)$ exhibited a low overpotential of $196 \mathrm{mV}$ for HER in $1 \mathrm{~mol} / \mathrm{L} \mathrm{KOH}$ solution. Zhou et al. [128] theoretically designed several heterostructures of $\mathrm{N}$-doped graphene/MXenes $\left(\mathrm{Ti}_{2} \mathrm{C}, \mathrm{Nb}_{2} \mathrm{C}, \mathrm{V}_{2} \mathrm{C}\right.$, and $\mathrm{Mo}_{2} \mathrm{C}$ ) as catalysts for HER. DFT calculations suggested that $\mathrm{N}$-doped graphene/heterostructures possess the lowest reaction free energies (close to $0 \mathrm{eV}$ ) and a low Tafel reaction barrier $(1.3 \mathrm{eV}$ ) for HER (Fig. $5 \mathrm{~g}, \mathrm{~h}$ ) owing to the strong electronic coupling between the MXene and N-doped graphene.

Recent studies indicate that the HER performance of MXenes could be improved by doping with metal atoms. $\mathrm{Li}$ et al. [129] studied the HER properties of modified $\mathrm{M}_{2} \mathrm{XO}_{2}$-type $\mathrm{MXenes}$ bearing transition metal atoms by high-throughput computational methods. Addition of transition metal atoms to several combinations, such as Os- $\mathrm{Ta}_{2} \mathrm{CO}_{2}, \mathrm{Ir}-\mathrm{Sc}_{2} \mathrm{CO}_{2}, \mathrm{Ag}-\mathrm{Nb}_{2} \mathrm{NO}_{2}, \mathrm{Re}-\mathrm{Nb}_{2} \mathrm{NO}_{2}$, and $\mathrm{W}-\mathrm{Nb}_{2} \mathrm{NO}_{2}$, could change the relevant reaction mechanism (from Volmer-Heyrovsky to Volmer-Tafel), induce electron redistributions on the surface of the MXene, and, ultimately, result in distinct enhancements in HER activity. Du et al. [43] reported an MXene $\left(\mathrm{Ti}_{3} \mathrm{C}_{2} \mathrm{~T}_{x}\right)$-based hybrid with simultaneous $\mathrm{Nb}$ doping and surface $\mathrm{Ni} / \mathrm{Co}$ alloy modification. DFT calculations indicated that $\mathrm{Nb}$ doping could shift the Fermi energy level toward the conduction band, leading to improved conductivity. Moreover, the surface $\mathrm{M}-\mathrm{H}$ affinity was modified by the $\mathrm{Ni} / \mathrm{Co}$ alloy, and the optimized catalyst showed the lowest Gibbs free energy for adsorbed $\mathrm{H}^{*}$ (Fig. 6a, b). The resultant $\mathrm{Ni}_{0.9} \mathrm{Co}_{0.1} @$ NTM (Nb-doped $\mathrm{Ti}_{3} \mathrm{C}_{2} \mathrm{~T}_{x}$ ) hybrids delivered excellent HER performance, only requiring a small overpotential of $43.4 \mathrm{mV}$ to deliver a current density of $10 \mathrm{~mA} / \mathrm{cm}^{2}$ in $1 \mathrm{~mol} / \mathrm{L} \mathrm{KOH}$ solution (Fig. 6c, d), and exhibited longterm stability. Using in situ co-reduction, Li et al. [96] prepared $\mathrm{Pt} / \mathrm{Ti}_{3} \mathrm{C}_{2} \mathrm{~T}_{x}$ via alloying $\mathrm{Pt}$ with Ti from the surface of $\mathrm{Ti}_{3} \mathrm{C}_{2} \mathrm{~T}_{x}$. In situ $\mathrm{X}$-ray absorption spectroscopy revealed that $\mathrm{Pt}$ transforms from a single atom into intermetallic compounds with increasing temperature (Fig. 6e). The asprepared $\mathrm{Pt} / \mathrm{Ti}_{3} \mathrm{C}_{2} \mathrm{~T}_{x}-550$ showed outstanding HER performance and only needed a low overpotential of $32.7 \mathrm{mV}$ at $10 \mathrm{~mA} / \mathrm{cm}^{2}$ (Fig. 6f); it also demonstrated a small Tafel slope of $32.3 \mathrm{mV} / \mathrm{dec}$. HER current normalization processing revealed that the respective mass activity and specific activity of $\mathrm{Pt} / \mathrm{Ti}_{3} \mathrm{C}_{2} \mathrm{~T}_{x}-550$ are 4.4 and 13 times higher than those of Pt/Vulcan at an overpotential of $70 \mathrm{mV}$ (Fig. $6 \mathrm{~g}$, h). As shown in Fig. 6i, DFT calculations demonstrated that (100)- and (111)-terminated $\mathrm{Pt}_{3} \mathrm{Ti}$ nanoparticles show $\mathrm{H}^{*}$ binding comparable with $\mathrm{Pt}$ (111). However, (110)-termination showed that $\mathrm{H}^{*}$ adsorption was excessively exergonic, leading to poisoning of the relative overpotential.

In another work, Zhang et al. [104] reported a novel electrochemical exfoliation method to prepare $\mathrm{Mo}_{2} \mathrm{TiC}_{2} \mathrm{~T}_{x}$ MXene nanosheets for HER. The obtained nanosheets possessed an abundance of exposed basal planes and Mo vacancies providing numerous active sites on which to immobilize single atoms and improve the HER catalytic property of the MXenes (Fig. 7a). Pt atoms anchored onto the $\mathrm{Mo}_{2} \mathrm{TiC}_{2} \mathrm{~T}_{x}$ nanosheets showed excellent catalytic performance. The obtained $\mathrm{Mo}_{2} \mathrm{TiC}_{2} \mathrm{~T}_{x}-\mathrm{Pt}_{\mathrm{SA}}$ catalysts only needed low overpotentials of 30 and $77 \mathrm{mV}$ to deliver current densities of 10 and $100 \mathrm{~mA} / \mathrm{cm}^{2}$, respectively. The as-prepared catalyst showed an outstanding mass activity of $8.3 \mathrm{~A} / \mathrm{mg}$, which is around 40 times greater than that of commercial Pt/C (0.21 A/mg; Fig. 7b, c). Strong covalent bonding between $\mathrm{Mo}_{2} \mathrm{TiC}_{2} \mathrm{~T}_{x}$ and positively charged $\mathrm{Pt}$ atoms endowed the $\mathrm{Mo}_{2} \mathrm{TiC}_{2} \mathrm{~T}_{x}-\mathrm{Pt}_{\mathrm{SA}}$ catalyst with outstanding long-term stability. DFT calculations suggested that single-atom $\mathrm{Pt}$ could lead to the redistribution of the electronic structure of $\mathrm{Mo}_{2} \mathrm{TiC}_{2} \mathrm{~T}_{x}$ and move up the d orbitals-electron domination close to the Fermi level (Fig. 7d, e), resulting in improved catalytic activity. As presented in Fig. 7f, the obtained $\mathrm{Mo}_{2} \mathrm{TiC}_{2} \mathrm{~T}_{x}-\mathrm{Pt}_{\mathrm{SA}}$ catalyst showed a low adsorption energy of $-0.08 \mathrm{eV}$, which is significantly lower than those of $\mathrm{Mo}_{2} \mathrm{TiC}_{2} \mathrm{O}_{2}(-0.19 \mathrm{eV})$ and $\mathrm{Pt} / \mathrm{C}(-0.10 \mathrm{eV})$. Other Pt-modified MXenes nanohybrids have been achieved by different methods, such as photoinduced reduction [97], $\mathrm{NaBH}_{4}$ reduction [99], and solution plasma modification [101], and the resulting hybrids generally showed remarkably improved performance for HER compared with pristine MXenes. Xiu et al. [105] synthesized CoP-3D MXene hybrids and studied their catalytic performance for HER. The obtained nanohybrids showed a low overpotential of $168 \mathrm{mV}$ at a current density of $10 \mathrm{~mA} / \mathrm{cm}^{2}$ in $1 \mathrm{~mol} / \mathrm{L} \mathrm{KOH}$ solution. This superior electrocatalytic activity could be attributed to the hierarchical 3D architecture of the catalysts, which greatly boosts their active surface area, promotes higher charge transfer kinetics, and increases their mass diffusion rate. 
a

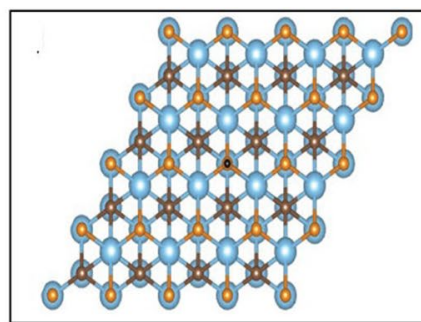

b 0.20
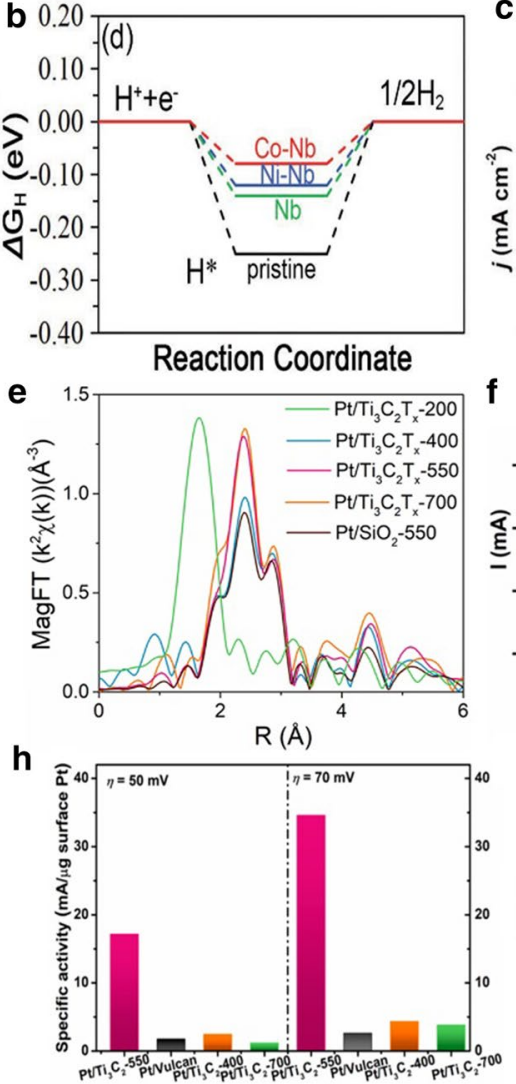
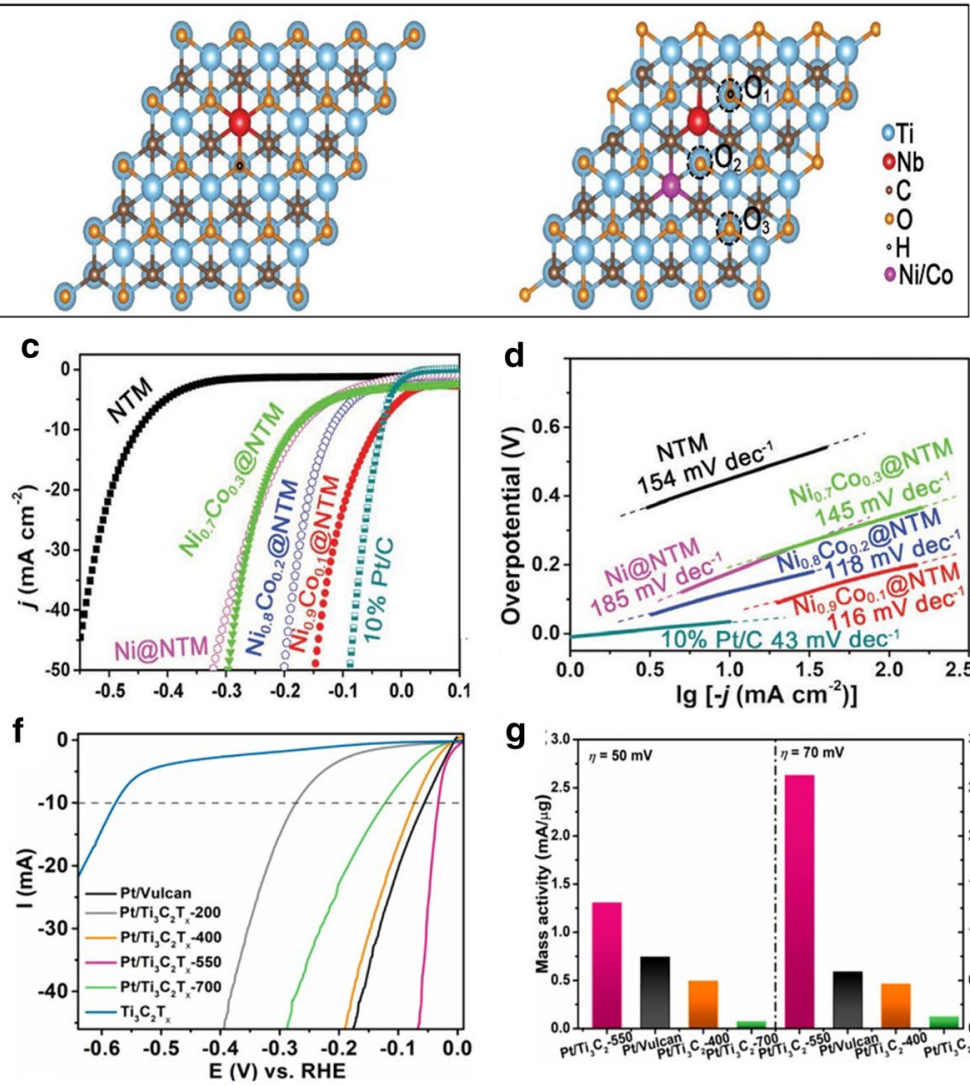

C
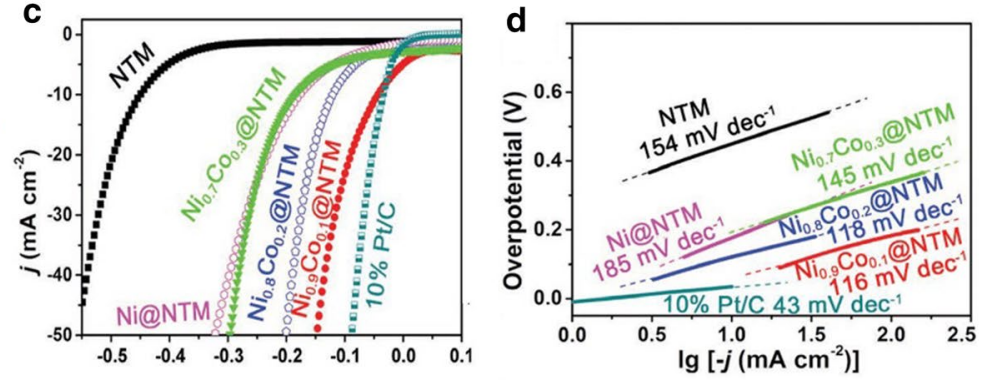

g

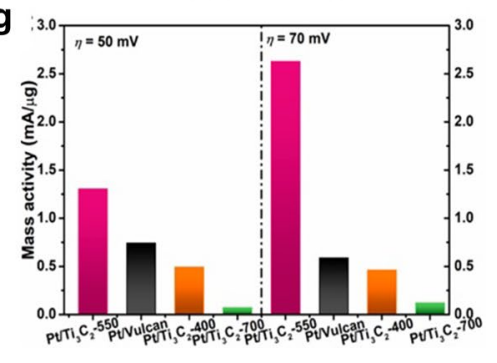

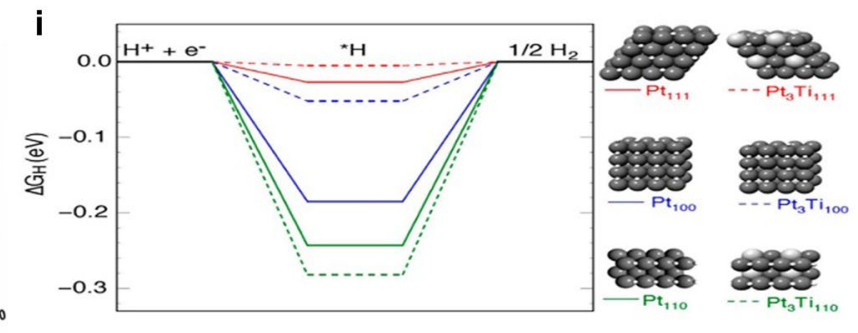

Fig. 6 a Atomistic configuration of pristine monolayer $\mathrm{Ti}_{3} \mathrm{C}_{2} \mathrm{O}_{2}$ with $\mathrm{H}^{*}$ adsorption, $\mathrm{Nb}$ doped on pristine monolayer $\mathrm{Ti}_{3} \mathrm{C}_{2} \mathrm{O}_{2}$ with $\mathrm{H}^{*}$ adsorption, $\mathrm{Co} / \mathrm{Ni}$ replacement of $\mathrm{Ti}$ atoms on $\mathrm{Nb}$-doped pristine monolayer $\mathrm{Ti}_{3} \mathrm{C}_{2} \mathrm{O}_{2}$, and the three different $\mathrm{H}^{*}$ adsorption $\mathrm{O}$ sites. b Gibbs free energies for $\mathrm{H}^{*}$ adsorbed on active sites shown in a M-doped $\mathrm{Ti}_{3} \mathrm{C}_{2} \mathrm{O}_{2}$. c Polarization curves of a series of $\mathrm{NiCo} @ \mathrm{Nb}$ doped $\mathrm{Ti}_{3} \mathrm{C}_{2} \mathrm{~T}_{x}$ MXene nanohybrids, $\mathrm{Ni} @ \mathrm{Nb}$-doped $\mathrm{Ti}_{3} \mathrm{C}_{2} \mathrm{~T}_{x}$ MXene nanohybrid, Nb-doped $\mathrm{Ti}_{3} \mathrm{C}_{2} \mathrm{~T}_{x}$ MXene, and $\mathrm{Pt} / \mathrm{C}$ in $1 \mathrm{~mol} / \mathrm{L} \mathrm{KOH}$. d Corresponding Tafel plots of a series of $\mathrm{NiCo} @ \mathrm{Nb}$-doped $\mathrm{Ti}_{3} \mathrm{C}_{2} \mathrm{~T}_{x}$ MXene nanohybrids, $\mathrm{Ni} @ \mathrm{Nb}$-doped $\mathrm{Ti}_{3} \mathrm{C}_{2} \mathrm{~T}_{x}$ MXene nanohybrid, $\mathrm{Nb}$-doped $\mathrm{Ti}_{3} \mathrm{C}_{2} \mathrm{~T}_{x}$ MXene, and $\mathrm{Pt} / \mathrm{C}$ in $1 \mathrm{~mol} / \mathrm{L} \mathrm{KOH}$. Reproduced

\section{Oxygen Evolution Reactions}

OER plays a crucial role in many important renewable energy conversion and storage methods, such as electrochemical water splitting and metal-air batteries. Nevertheless, the sluggish kinetics and high overpotential of OER make it imperative to search for high-performance catalysts. Noble-metal-based oxides (e.g., $\mathrm{RuO}_{2}$ and $\mathrm{IrO}_{2}$ ) are with permission [43]. Copyright 2019, Wiley-VCH. e Magnitude of the Fourier transform of the $k^{2}$ weighted $\mathrm{Pt}_{\mathrm{III}}$ edge in situ EXAFS of $\mathrm{Pt} / \mathrm{Ti}_{3} \mathrm{C}_{2} \mathrm{~T}_{x}$ reduced at different temperatures compared with that of $\mathrm{Pt} / \mathrm{SiO}_{2}$. f Polarization curves of $\mathrm{Pt} / \mathrm{Vulcan}, \mathrm{Pt} / \mathrm{Ti}_{3} \mathrm{C}_{2} \mathrm{~T}_{x}$ at different temperatures, and $\mathrm{Ti}_{3} \mathrm{C}_{2} \mathrm{~T}_{x}$. g Mass activity of $\mathrm{Pt} /$ Vulcan and $\mathrm{Pt} /$ $\mathrm{Ti}_{3} \mathrm{C}_{2} \mathrm{~T}_{x}$ catalysts with different treatments. h Specific activity of $\mathrm{Pt} /$ Vulcan and $\mathrm{Pt} / \mathrm{Ti}_{3} \mathrm{C}_{2} \mathrm{~T}_{x}$ catalysts. i DFT-calculated free energy diagrams of hydrogen evolution at the Pt (111), $\mathrm{Pt}_{3} \mathrm{Ti}$ (111), Pt (100), $\mathrm{Pt}_{3} \mathrm{Ti}$ (100), $\mathrm{Pt}$ (110), and $\mathrm{Pt}_{3} \mathrm{Ti}$ (110) surfaces. Reproduced with permission [96]. Copyright 2019, American Chemical Society

high-performance catalysts for OER, but their high cost and scarcity seriously hamper their broader applications [130]. Hence, great efforts have been devoted to develop earthabundant and high-activity catalysts that can replace precious metal-based materials.

MXene-based materials have received extensive attention for their potential applications in OER. For instance, $\mathrm{Yu}$ et al. [45] prepared hierarchical FeNi-LDH/ $\mathrm{Ti}_{3} \mathrm{C}_{2} \mathrm{~T}_{x}$ 
a

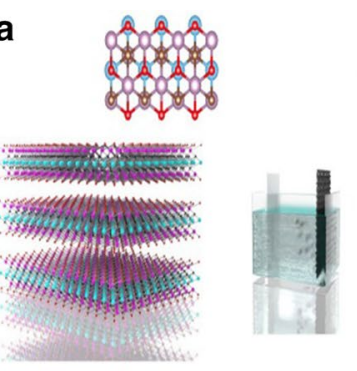

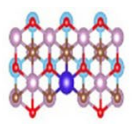

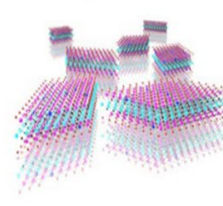

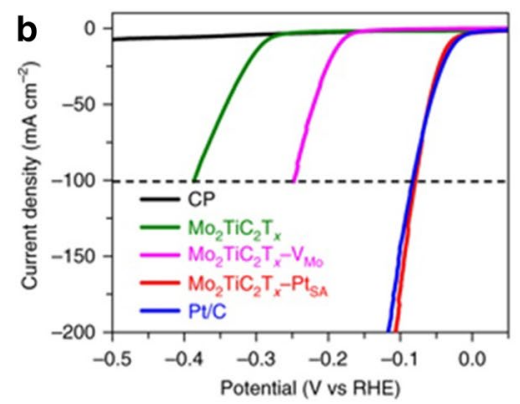

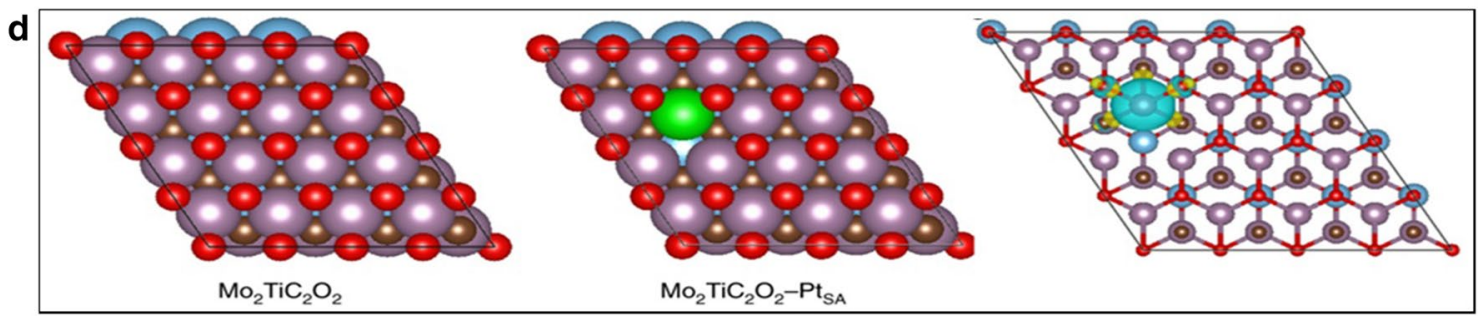

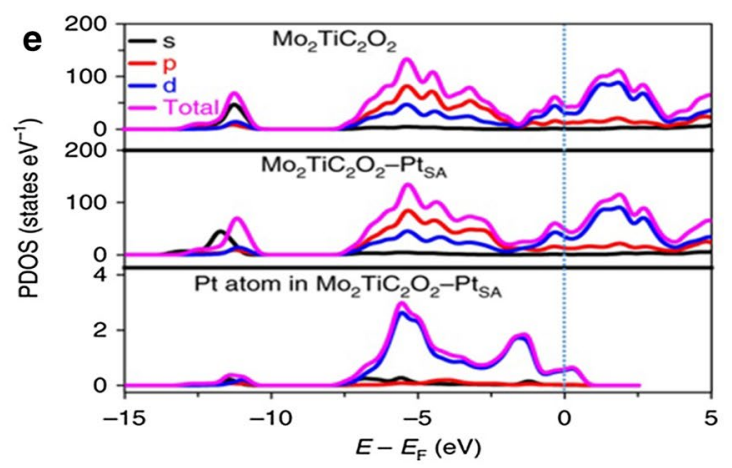

Fig. 7 a Schematic of the electrochemical exfoliation process of MXene with immobilized single $\mathrm{Pt}$ atoms. b Polarization curves of carbon paper, $\mathrm{Mo}_{2} \mathrm{TiC}_{2} \mathrm{~T}_{x}, \mathrm{Mo}_{2} \mathrm{TiC}_{2} \mathrm{~T}_{x}-\mathrm{V}_{\mathrm{Mo}}, \mathrm{Mo}_{2} \mathrm{TiC}_{2} \mathrm{~T}_{x}-\mathrm{Pt}_{\mathrm{SA}}$, and $\mathrm{Pt} / \mathrm{C}$. c Mass activity of state-of-the-art $\mathrm{Pt} / \mathrm{C}$ and $\mathrm{Mo}_{2} \mathrm{TiC}_{2} \mathrm{~T}_{x}-\mathrm{Pt}_{\mathrm{SA}}$. d Top view of the slab models used to describe $\mathrm{Mo}_{2} \mathrm{TiC}_{2} \mathrm{O}_{2}$ and $\mathrm{Mo}_{2} \mathrm{TiC}_{2} \mathrm{O}_{2}-\mathrm{Pt}_{\mathrm{SA}}$. Circles in blue, purple, green, brown, and red rep-

nanohybrids by coprecipitation of $\mathrm{Ni}^{2+}$ and $\mathrm{Fe}^{3+}$ in the presence of $\mathrm{Ti}_{3} \mathrm{C}_{2} \mathrm{~T}_{x}$ and urea (Fig. 8a). The as-synthesized hybrids showed superior OER activity and only needed a low overpotential of $298 \mathrm{mV}$ to deliver a current density of $10 \mathrm{~mA} / \mathrm{cm}^{2}$; they also demonstrated a low Tafel slope of $43 \mathrm{mV} / \mathrm{dec}$ (Fig. 8b-e). This achievement could be attributed to strong interfacial interactions and electronic coupling with prominent charge transfers between $\mathrm{Ti}_{3} \mathrm{C}_{2} \mathrm{~T}_{x}$ and FeNi-LDH. Such interaction and coupling not only enhance the conductivity and stability but also obviously facilitate the redox process of FeNi-LDH for OER. Ma et al. [108] prepared free-standing flexible films via the layer-by-layer self-assembly of graphitic carbon nitride $\left(\mathrm{g}-\mathrm{C}_{3} \mathrm{~N}_{4}\right)$ and titanium carbide $\left(\mathrm{Ti}_{3} \mathrm{C}_{2}\right)$, as shown in Fig. 8f. The obtained hierarchically porous films featured a highly hydrophilic surface and showed good OER activity; indeed, the catalysts only needed a small overpotential of $420 \mathrm{mV}$ to achieve a current density of $10 \mathrm{~mA} / \mathrm{cm}^{2}$ and revealed a small Tafel

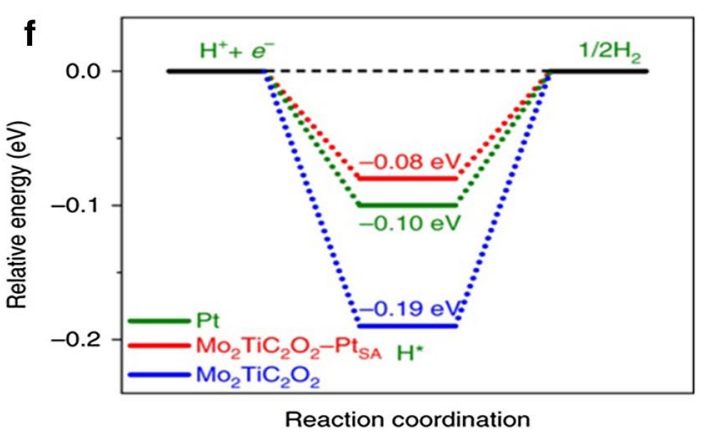

resent $\mathrm{Ti}, \mathrm{Mo}, \mathrm{Pt}, \mathrm{C}$, and $\mathrm{O}$ atoms, respectively. Charge density distribution differences between $\mathrm{Mo}_{2} \mathrm{TiC}_{2} \mathrm{O}_{2}$ and $\mathrm{Mo}_{2} \mathrm{TiC}_{2} \mathrm{O}_{2}-\mathrm{Pt}_{\mathrm{SA}}$ are also shown. e Calculated PDOS of $\mathrm{Mo}_{2} \mathrm{TiC}_{2} \mathrm{O}_{2}$ and $\mathrm{Mo}_{2} \mathrm{TiC}_{2} \mathrm{O}_{2}-\mathrm{Pt}_{\mathrm{SA}}$ with aligned Fermi levels. $f$ Free energy profiles of HER on $\mathrm{Mo}_{2} \mathrm{TiC}_{2} \mathrm{O}_{2}$, $\mathrm{Mo}_{2} \mathrm{TiC}_{2} \mathrm{O}_{2}-\mathrm{Pt}_{\mathrm{SA}}$ and $\mathrm{Pt} / \mathrm{C}$. Reproduced with permission [104]. Copyright 2018, Nature Publishing Group

slope of $74.6 \mathrm{mV} / \mathrm{dec}$ in $0.1 \mathrm{~mol} / \mathrm{L} \mathrm{KOH}$ solution (Fig. $8 \mathrm{i}$, j). Such excellent performance was attributed to the $\mathrm{Ti}-\mathrm{N}_{x}$ motifs of the catalyst, which act as electroactive sites. This hypothesis was verified by XPS and near-edge X-ray absorption fine structure spectroscopy (Fig. 8g, h). Tang and coworkers [109] constructed S-NiFe ${ }_{2} \mathrm{O}_{4} @ \mathrm{Ti}_{3} \mathrm{C}_{2} @ \mathrm{NF}$ hybrids and studied their OER performance. The obtained hybrids displayed a low overpotential of $270 \mathrm{~mA}$ at a current density of $20 \mathrm{~mA} / \mathrm{cm}^{2}$ and a small Tafel slope of $46.8 \mathrm{mV} / \mathrm{dec}$ in $1 \mathrm{~mol} / \mathrm{L} \mathrm{KOH}$ solution.

Interestingly, metal organic framework (MOF) and MOF derivatives have also been successfully hybridized with MXene nanosheets to achieve improved OER performance. For example, Zhao et al. [107] synthesized an MXene/MOF hybrid $\left(\mathrm{Ti}_{3} \mathrm{C}_{2} \mathrm{~T}_{x}-\mathrm{CoBDC}\right)$ via an interdiffusion reactionassisted method (Fig. 9a). The resultant hybrids needed a low overpotential of $410 \mathrm{mV}$ to deliver a current density of $10 \mathrm{~mA} / \mathrm{cm}^{2}$ and showed a low Tafel slope of $48.2 \mathrm{mV} /$ 

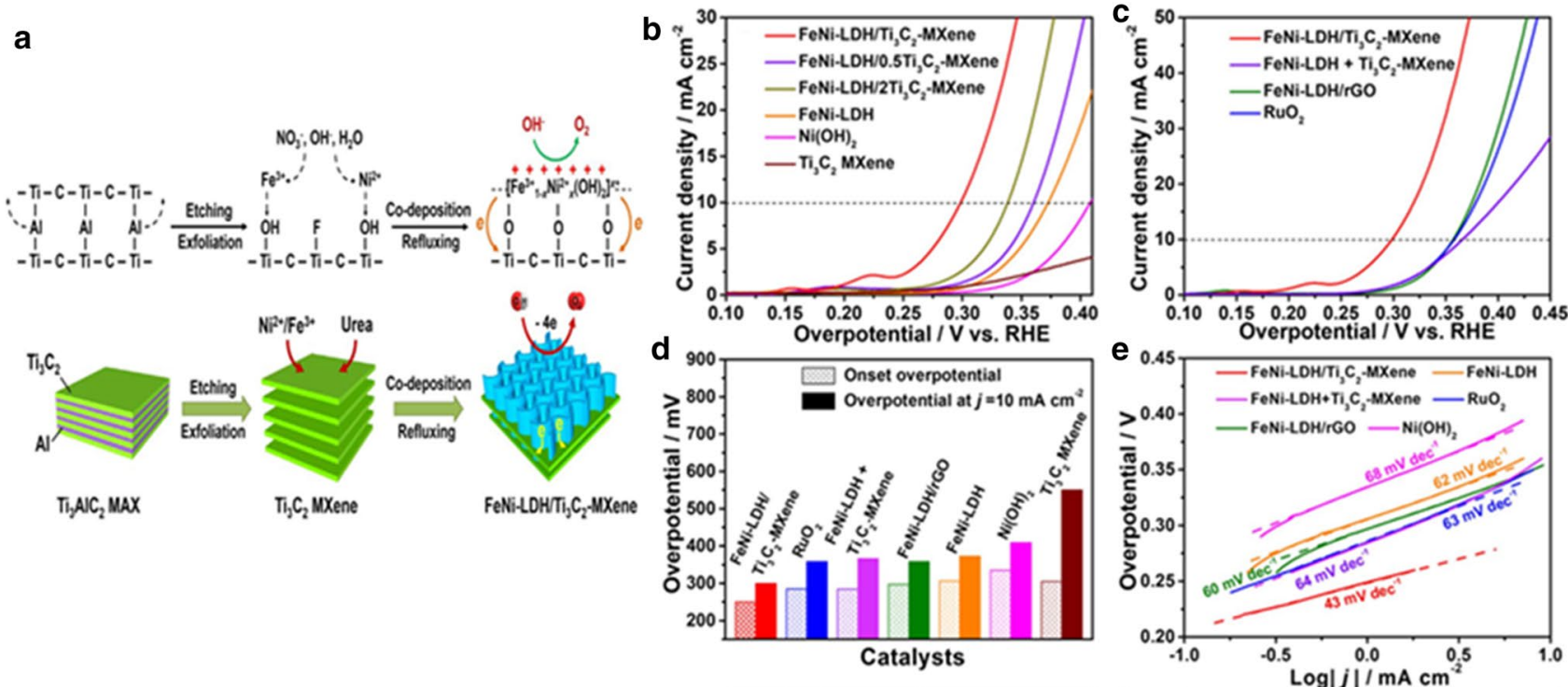

$\mathbf{f}$

\section{$\mathbf{g}$}
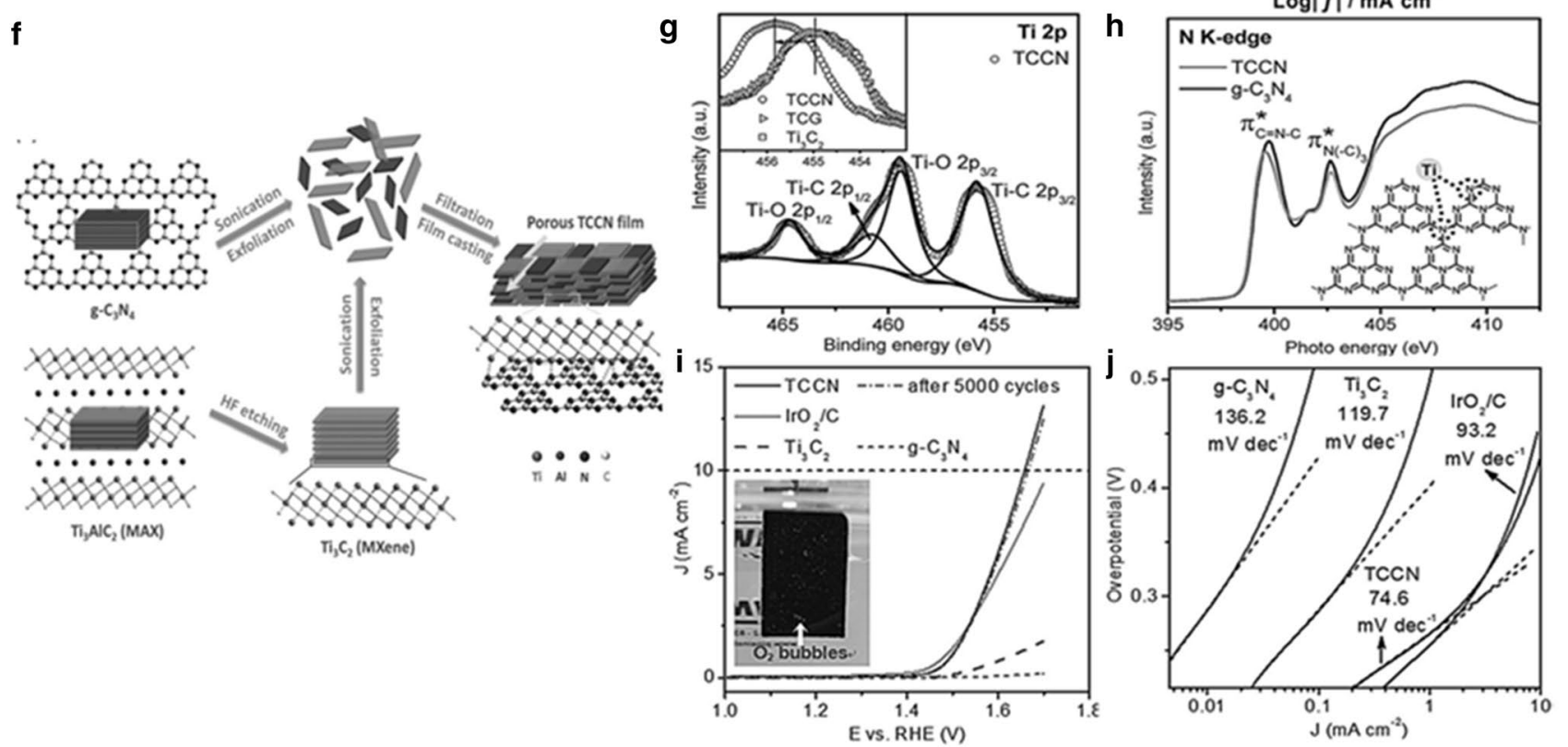

Fig. 8 a Schematic of the preparation of 2D hierarchical FeNi-LDH/ $\mathrm{Ti}_{3} \mathrm{C}_{2}$-MXene nanohybrids. b Polarization curves of FeNi-LDH/ $\mathrm{Ti}_{3} \mathrm{C}_{2}$-MXene with different FeNi-LDH contents, pure FeNi-LDH, $\mathrm{Ni}(\mathrm{OH})_{2}$, and pristine $\mathrm{Ti}_{3} \mathrm{C}_{2}$ MXene. c Polarization curves of FeNi$\mathrm{LDH} / \mathrm{Ti}_{3} \mathrm{C}_{2}-\mathrm{MXene}$ with 80 wt $\%$ FeNi-LDH, FeNi-LDH $+\mathrm{Ti}_{3} \mathrm{C}_{2^{-}}$ MXene, FeNi-LDH/rGO, and $\mathrm{RuO}_{2}$ catalysts. d Comparison of the catalysts in $\mathbf{b}$ in terms of onset overpotential and overpotential required to achieve a current density of $10 \mathrm{~mA} / \mathrm{cm}^{2}$. e Tafel plots of FeNi-LDH/ $\mathrm{Ti}_{3} \mathrm{C}_{2}$-MXene, FeNi-LDH $+\mathrm{Ti}_{3} \mathrm{C}_{2}$-MXene, FeNi-LDH/

dec in $0.1 \mathrm{~mol} / \mathrm{L} \mathrm{KOH}$ solution (Fig. 9b, c). This superior OER performance could be attributed to the well-defined interface between the CoBDC layer and $\mathrm{Ti}_{3} \mathrm{C}_{2} \mathrm{~T}_{x}$ nanosheets, which allows fast charge and ion transfer. The presence of metallic $\mathrm{Ti}_{3} \mathrm{C}_{2} \mathrm{~T}_{x}$ nanosheets not only prevents the porous CoBDC layers from aggregating but also improves charge and ion transfers. In another study, CoNi-ZIF-67@ $\mathrm{Ti}_{3} \mathrm{C}_{2} \mathrm{~T}_{x}$
rGO, FeNi-LDH, $\mathrm{Ni}(\mathrm{OH})_{2}$, and $\mathrm{RuO}_{2}$ catalysts. Reproduced with permission [45]. Copyright 2018, Elsevier Ltd. f Preparation of porous $\mathrm{Ti}_{3} \mathrm{C}_{2} / g-\mathrm{C}_{3} \mathrm{~N}_{4}$ hybrid films. $\mathrm{g}$ High-resolution XPS spectra of Ti $2 \mathrm{p}$ in the $\mathrm{Ti}_{3} \mathrm{C}_{2} / \mathrm{g}-\mathrm{C}_{3} \mathrm{~N}_{4}$ hybrid film in (f). $\mathbf{h} \mathrm{N}$ K-edge NEXAFS of TCCN and $\mathrm{g}_{-} \mathrm{C}_{3} \mathrm{~N}_{4}$; the inset displays the relevant $\mathrm{N}$ sites. i Polarization curves of the $\mathrm{Ti}_{3} \mathrm{C}_{2} / \mathrm{g}-\mathrm{C}_{3} \mathrm{~N}_{4}$ hybrid film, g- $\mathrm{C}_{3} \mathrm{~N}_{4}, \mathrm{Ti}_{3} \mathrm{C}_{2}$, and $\mathrm{IrO}_{2} / \mathrm{C}$. j Tafel plots of the $\mathrm{Ti}_{3} \mathrm{C}_{2} / \mathrm{g}-\mathrm{C}_{3} \mathrm{~N}_{4}$ hybrid film, g- $\mathrm{C}_{3} \mathrm{~N}_{4}, \mathrm{Ti}_{3} \mathrm{C}_{2}$, and $\mathrm{IrO}_{2} / \mathrm{C}$. Reproduced with permission [108]. Copyright 2016, Wiley$\mathrm{VCH}$

was prepared via a simple coprecipitation reaction [106]. Owing to the presence of $\mathrm{Ti}_{3} \mathrm{C}_{2} \mathrm{~T}_{x}$, the CoNi-ZIF-67 particles became smaller in size, and the average oxidation of $\mathrm{Co} / \mathrm{Ni}$ elements increased, thus endowing the catalyst with excellent OER performance. The CoNi-ZIF-67@ $\mathrm{Ti}_{3} \mathrm{C}_{2} \mathrm{~T}_{x}$ hybrids showed a low onset potential of $275 \mathrm{~mA}$ versus RHE and a Tafel slope of $65.1 \mathrm{mV} / \mathrm{dec}$. Zou et al. [110] prepared 
a

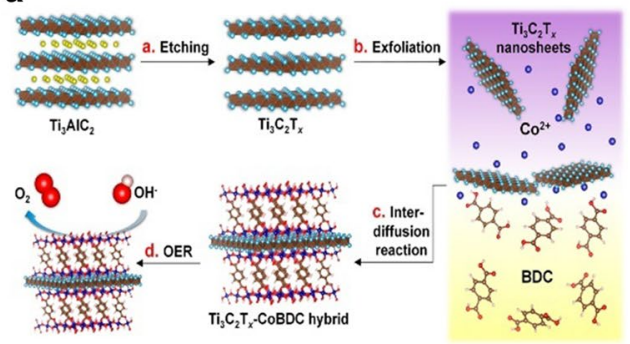

d

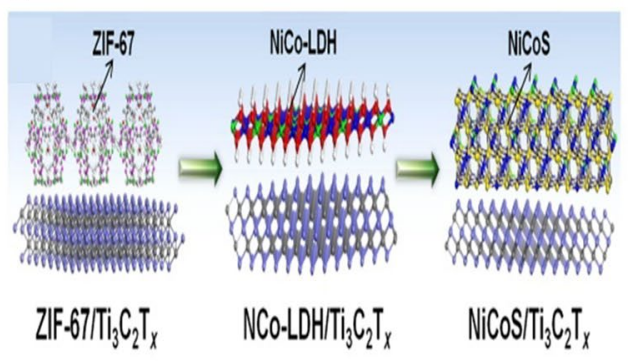

g

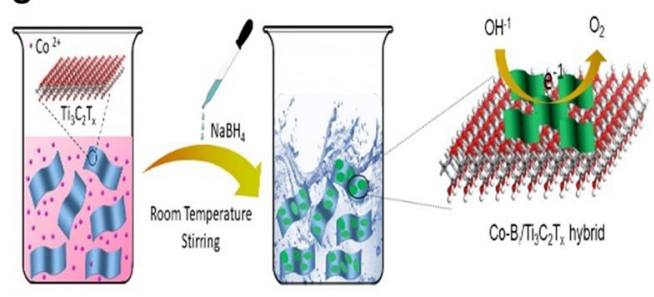

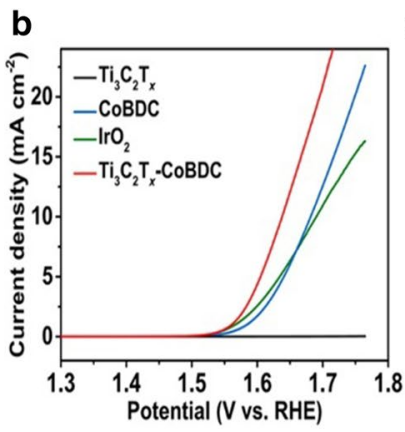

C

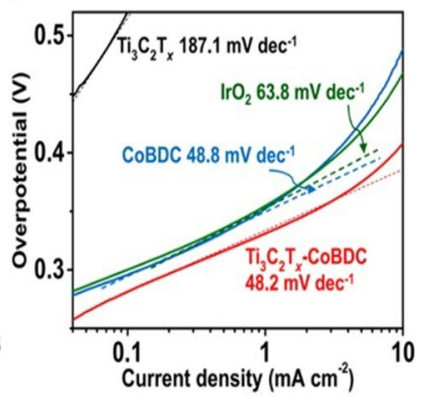

e

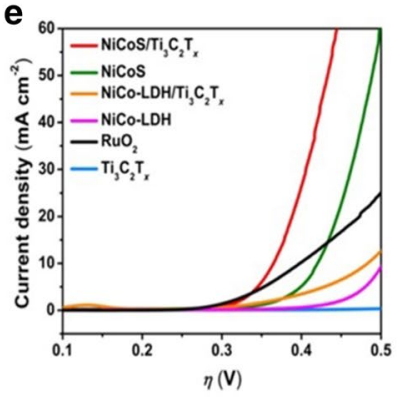

f
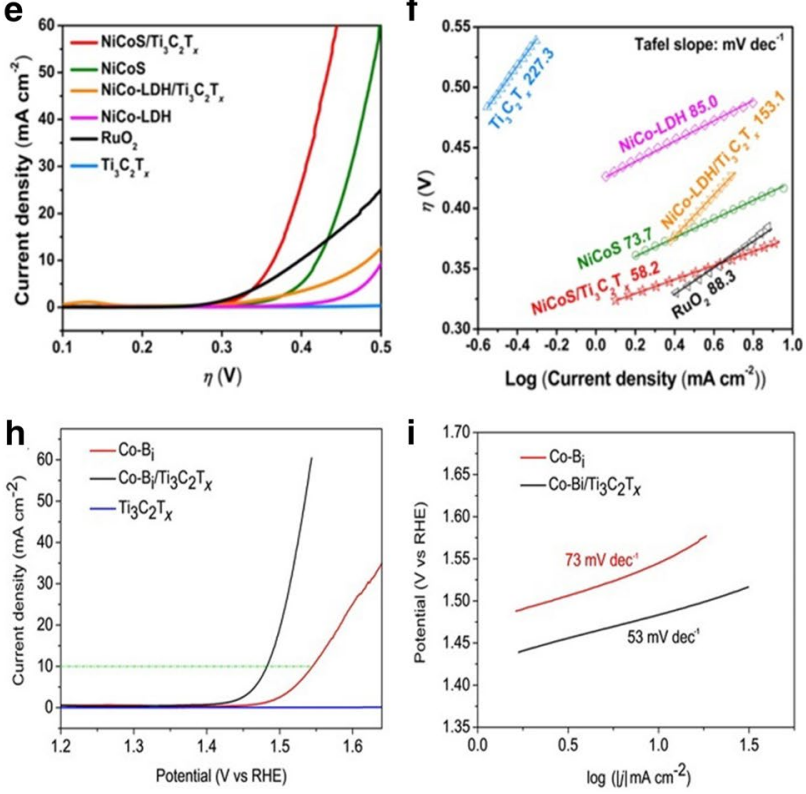

Fig. 9 a Preparation procedures of $\mathrm{Ti}_{3} \mathrm{C}_{2} \mathrm{~T}_{x}-\mathrm{CoBDC}$ hybrids for OER. b Polarization curves and $\mathbf{c}$ the corresponding Tafel plots of various electrodes modified by $\mathrm{Ti}_{3} \mathrm{C}_{2} \mathrm{~T}_{x}, \mathrm{CoBDC}, \mathrm{IrO}_{2}$, and a $\mathrm{Ti}_{3} \mathrm{C}_{2} \mathrm{~T}_{x}-\mathrm{CoBDC}$ hybrid in $0.1 \mathrm{~mol} / \mathrm{L} \mathrm{KOH}$ solution. Reproduced with permission [107]. Copyright 2017, American Chemical Society. d Synthesis of NiCoS/ $/ \mathrm{Ti}_{3} \mathrm{C}_{2} \mathrm{~T}_{x}$ hybrids. e Polarization curves and $\mathbf{f}$ the corresponding Tafel plots of $\mathrm{NiCoS} / \mathrm{Ti}_{3} \mathrm{C}_{2} \mathrm{~T}_{x}, \mathrm{NiCoS}, \mathrm{NiCo}-\mathrm{LDH} /$
$\mathrm{Ti}_{3} \mathrm{C}_{2} \mathrm{~T}_{x}, \mathrm{NiCo}-\mathrm{LDH}$, and $\mathrm{RuO}_{2}$. Reproduced with permission [110]. Copyright 2018, American Chemical Society. g Preparation of hierarchical $\mathrm{Co}-\mathrm{B}_{\mathrm{i}} / \mathrm{Ti}_{3} \mathrm{C}_{2} \mathrm{~T}_{x}$ hybrids at room temperature. $\mathbf{h}$ Polarization curves and $\mathbf{i}$ the corresponding Tafel plots of Co- $\mathrm{B}_{\mathrm{i}}$ nanosheets, a Co- $\mathrm{B}_{\mathrm{i}} / \mathrm{Ti}_{3} \mathrm{C}_{2} \mathrm{~T}_{x}$ hybrid, and $\mathrm{Ti}_{3} \mathrm{C}_{2} \mathrm{~T}_{x}$ nanosheets. Reproduced with permission [46]. Copyright 2018, Wiley-VCH a novel NiCoS/Ti ${ }_{3} \mathrm{C}_{2} \mathrm{~T}_{x}$ hybrid using an MOF-based method (Fig. 9d). The hybrids showed a small overpotential of $365 \mathrm{mV}$ at $10 \mathrm{~mA} / \mathrm{cm}^{2}$, a small Tafel slope of $58.2 \mathrm{mV} / \mathrm{dec}$ (Fig. 9e, f), and excellent stability.

Many new MXene-based hybrids also show promising applications in OER. For example, we synthesized a unique hierarchical cobalt borate $/ \mathrm{Ti}_{3} \mathrm{C}_{2} \mathrm{~T}_{x}$ MXene $\left(\mathrm{Co}-\mathrm{B}_{\mathrm{i}} / \mathrm{Ti}_{3} \mathrm{C}_{2} \mathrm{~T}_{x}\right)$ by a rapid chemical reaction at room temperature (Fig. $9 \mathrm{~g}$ ) [46]. The metallic $\mathrm{Ti}_{3} \mathrm{C}_{2} \mathrm{~T}_{x}$ nanosheets not only improved the electron transfer capacity of the material but also hindered the aggregation of $\mathrm{Co}-\mathrm{B}_{\mathrm{i}}$ nanosheets. The strong interaction between $\mathrm{Ti}_{3} \mathrm{C}_{2} \mathrm{~T}_{x}$ and $\mathrm{Co}-\mathrm{B}_{\mathrm{i}}$ nanosheets ensured strong charge transfer abilities and enhanced the electrostatic attraction of more anionic intermediates to achieve fast redox processes. Thus, the as-synthesized hybrids exhibited outstanding OER performance with a low overpotential of $250 \mathrm{mV}$ at $10 \mathrm{~mA} / \mathrm{cm}^{2}$ and a small Tafel slope of $53 \mathrm{mV} /$ dec (Fig. 9h, i).

\section{Oxygen Reduction Reaction}

ORR is the key half-reaction in renewable energy conversion devices; it is characterized by inherent environmental friendliness and low cost and has been applied to fuel cells and rechargeable metal-air batteries. However, ORR often suffers from sluggish kinetics, which seriously hinders the overall power performance of these devices. Today, Pdbased catalysts are regarded as the optimal ORR catalyst [131]. However, developing low-cost and high-efficiency catalysts for ORR remains a crucial endeavor. 
Liu and Li [132] simulated a series of $\mathrm{Pt} / v-\mathrm{Ti}_{n+1} \mathrm{C}_{n} \mathrm{~T}_{x}$ ( $n=1-3, \mathrm{~T}=\mathrm{O}$ and/or $\mathrm{F}$ ) heterostructures by DFT calculations. As displayed in Fig. 10a, F-terminated MXenes were predicted to display better performance in ORR than their O-terminated counterparts; however, F-terminated MXenes may demonstrate lower stability on account of their weaker chemical bonding. A variety of MXene-based materials have been explored to enhance ORR performance. For instance, Li et al. [48] prepared $\mathrm{FePc} / \mathrm{Ti}_{3} \mathrm{C}_{2} \mathrm{~T}_{x}$ hybrids by a facile self-assembly method in dimethylformamide solution. Owing to the presence of $\mathrm{Ti}_{3} \mathrm{C}_{2} \mathrm{~T}_{x}$, obvious Fe $3 d$ electron delocalization and spin-state transition of $\mathrm{Fe}$ (II) ions were confirmed by a series of characterization analysis, such as ESR and Mössbauer spectroscopy, as presented in Fig. 10b-d. More importantly, changes in electron configuration led to lower local electron densities and higher spin states in the $\mathrm{Fe}$ (II) centers, which promoted oxygen adsorption and reduction in active $\mathrm{FeN}_{4}$ sites. As shown in
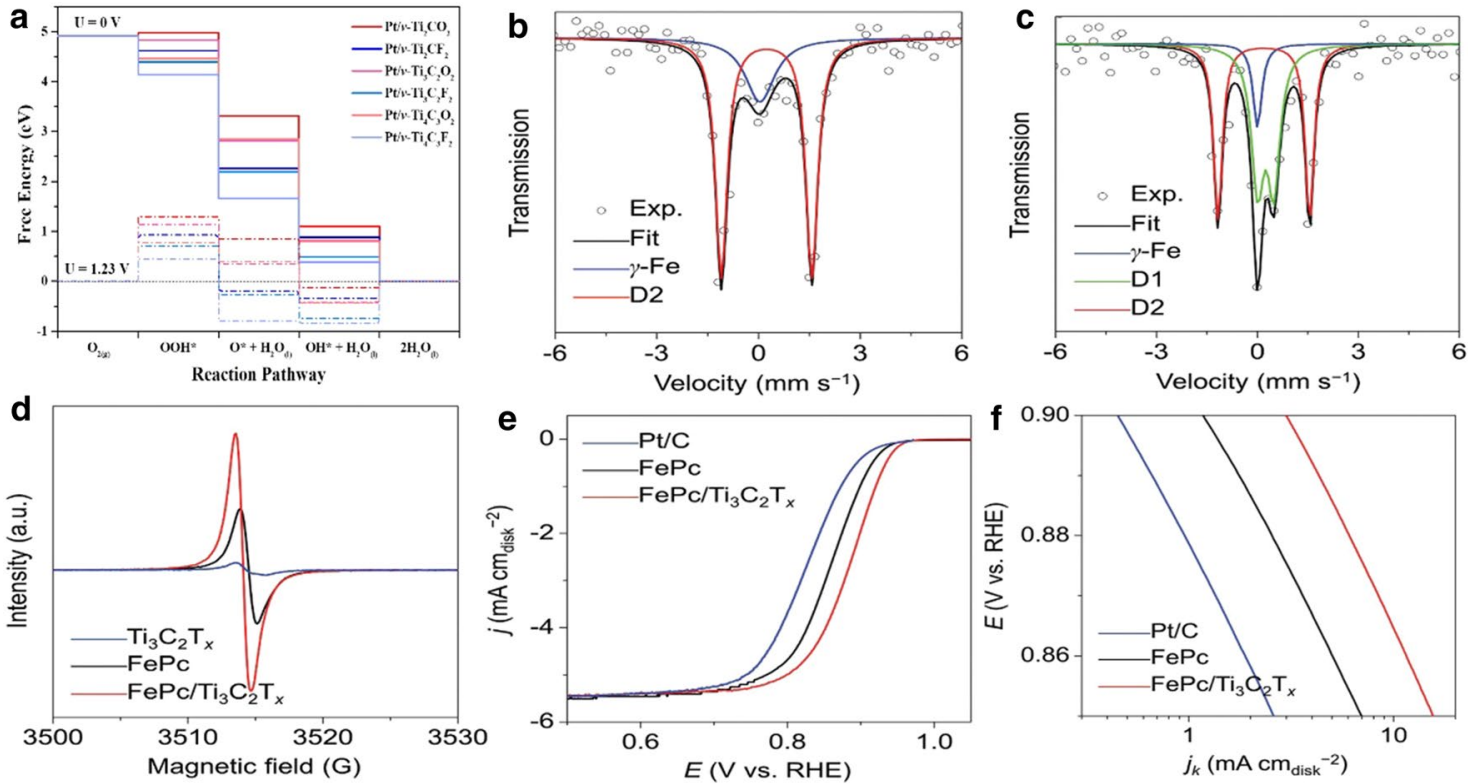

g
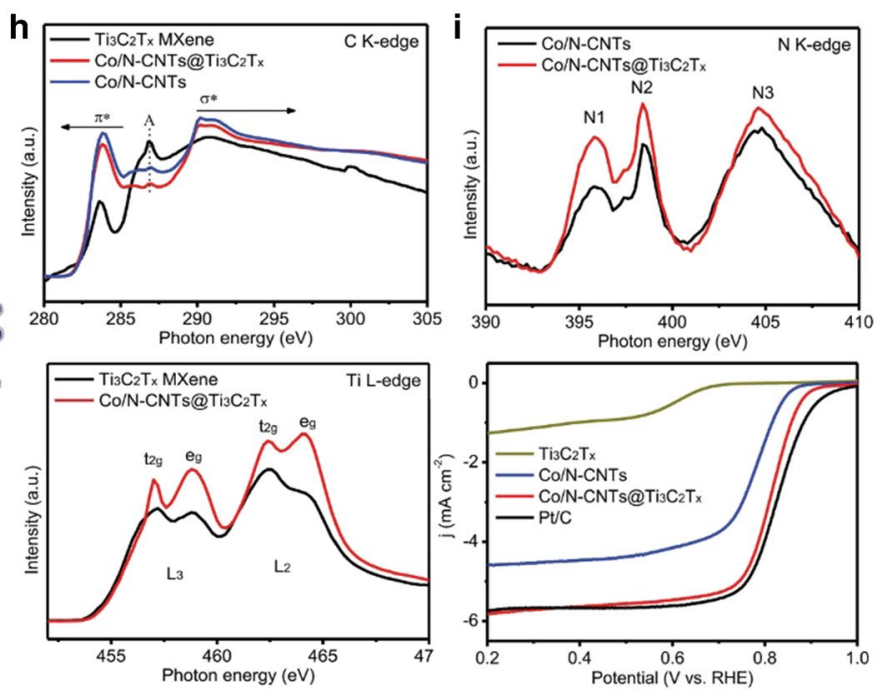

Fig. 10 a Free energy diagram of ORR intermediates on $\mathrm{Pt} / \mathrm{v}$ $\mathrm{Ti}_{n+1} \mathrm{C}_{n} \mathrm{~T}_{2}(n=1-3, \mathrm{~T}=\mathrm{O}$ or F) surfaces. Reproduced with permission [132]. Copyright 2019, American Chemical Society. b Fe Mössbauer transmission spectra and $\mathbf{c}$ deconvolution of pristine $\mathrm{FePc}$ and $\mathrm{FePc} / \mathrm{Ti}_{3} \mathrm{C}_{2} \mathrm{~T}_{x}$. d X-band ESR spectra of pristine $\mathrm{Ti}_{3} \mathrm{C}_{2} \mathrm{~T}_{x}, \mathrm{FePc}$, and $\mathrm{FePc} / \mathrm{Ti}_{3} \mathrm{C}_{2} \mathrm{~T}_{x}$. e Polarization curves and $\mathbf{f}$ the corresponding Tafel plots of pristine $\mathrm{FePc}, \mathrm{FePc} / \mathrm{Ti}_{3} \mathrm{C}_{2} \mathrm{~T}_{x}$, and $\mathrm{Pt} / \mathrm{C}$. Reproduced with permission [48]. Copyright 2018, Wiley-VCH. g Preparation of $\mathrm{Co} / \mathrm{N}-$
CNTs@ $\mathrm{Ti}_{3} \mathrm{C}_{2} \mathrm{~T}_{x}$ composites. h C K-edge XANES spectra of $\mathrm{Ti}_{3} \mathrm{C}_{2} \mathrm{~T}_{x}$ MXene, Co/N-CNTs@ $\mathrm{Ti}_{3} \mathrm{C}_{2} \mathrm{~T}_{x}$, and Co/N-CNTs. i N K-edge XANES spectra of $\mathrm{Co} / \mathrm{N}-\mathrm{CNTs}$ and $\mathrm{Co} / \mathrm{N}-\mathrm{CNTs} @ \mathrm{Ti}_{3} \mathrm{C}_{2} \mathrm{~T}_{x}$. j Ti L-edge XANES spectra of $\mathrm{Ti}_{3} \mathrm{C}_{2} \mathrm{~T}_{x}$ MXene and Co/N-CNTs@ $\mathrm{Ti}_{3} \mathrm{C}_{2} \mathrm{~T}_{x}$. $\mathbf{k}$ Polarization curves of $\mathrm{Ti}_{3} \mathrm{C}_{2} \mathrm{~T}_{x}, \mathrm{Co} / \mathrm{N}-\mathrm{CNTs}, \mathrm{Co} / \mathrm{N}-\mathrm{CNTs} @ \mathrm{Ti}_{3} \mathrm{C}_{2} \mathrm{~T}_{x}$, and Pt/C. Reproduced with permission [111]. Copyright 2018, Wiley$\mathrm{VCH}$ 
Fig. 10e, f, the optimized hybrids showed lower half-wave potentials $(-0.886$ vs. RHE) compared with pure FePc $(-0.886$ vs. RHE) and commercial Pt/C $(-0.84 \mathrm{~V}$ vs. RHE). The catalysts also, respectively, showed two- and fivefold higher specific ORR activity than pure FePc and commercial $\mathrm{Pt} / \mathrm{C}$ in $0.1 \mathrm{~mol} / \mathrm{L} \mathrm{KOH}$ solution.

Zhang et al. [111] presented a new type of Co/N-CNTs@ $\mathrm{Ti}_{3} \mathrm{C}_{2} \mathrm{~T}_{x}$ hybrid synthesized by an in situ growth strategy (Fig. $10 \mathrm{~g}$ ). The resulting catalyst showed superior ORR catalytic performance with a low onset potential of $0.936 \mathrm{~V}$ versus RHE and a half-wave potential of $0.815 \mathrm{~V}$ versus RHE in $0.1 \mathrm{~mol} / \mathrm{L} \mathrm{KOH}$ aqueous solution (Fig. 10k); such performance was attributed to strong interfacial coupling and electron transfers in the composite, which were well verified by XANES (Fig. 10h-j). A series of nanohybrids, such as $\mathrm{Mn}_{3} \mathrm{O}_{4} / \mathrm{Ti}_{3} \mathrm{C}_{2} \mathrm{~T}_{x}$ nanocomposites [114], $\mathrm{C}_{3} \mathrm{~N}_{4} / \mathrm{Ti}_{3} \mathrm{C}_{2}$ heterostructures [47], FeNC/MXene nanohybrids [112], urchin-like MXene- $\mathrm{Ag}_{0.9} \mathrm{Ti}_{0.1}$ nanowire composites [113], and $\mathrm{FeCo}(3: 1)-\mathrm{N}-d-\mathrm{Ti}_{3} \mathrm{C}_{2}$ MXene hybrids [115], have also been proven to display outstanding ORR performance.

\section{Nitrogen Reduction Reaction}

$\mathrm{NH}_{3}$ is considered a promising alternative energy carrier on account of its high energy density. At present, large-scale $\mathrm{NH}_{3}$ production is primarily conducted via the Haber-Bosch method at high-pressure and high-temperature conditions using $\mathrm{H}_{2}$ and nitrogen $\mathrm{N}_{2}$ as the virgin gas. However, this process consumes large amounts of energy and generates massive amounts of $\mathrm{CO}_{2}$. Thus, developing sustainable and economical $\mathrm{N}_{2}$-fixation methods is urgently needed. Electrocatalytic NRR has attracted much attention due to its innate advantages, including reaction under ambient conditions and water as the hydrogen source [133]. However, NRR processes remain at the infant stages of development, and designs of efficient and low-cost electrocatalysts continue to challenge researchers.

MXene-based materials have recently been studied as catalysts for NRR. For example, Azofra et al. [50] predicted the $\mathrm{N}_{2}$-capture behaviors of $\mathrm{M}_{3} \mathrm{C}_{2}$ MXenes using DFT calculations and found that $\mathrm{V}_{3} \mathrm{C}_{2}$ and $\mathrm{Nb}_{3} \mathrm{C}_{2}$ are excellent candidates as NRR catalysts due to their low reaction energies of 0.32 and $0.39 \mathrm{eV}$ (vs. a standard hydrogen electrode), respectively (Fig. 11a). $\mathrm{V}_{3} \mathrm{C}_{2}$ showed a low activation barrier of $0.64 \mathrm{eV}$, which is smaller than that of $\mathrm{Nb}_{3} \mathrm{C}_{2}(0.85 \mathrm{eV})$, for the first proton-electron transfer (rate-determining step). Gao et al. [134] predicted the catalytic activity of a series of single atoms (i.e., $\mathrm{Sc}, \mathrm{Ti}, \mathrm{V}, \mathrm{Cr}, \mathrm{Mn}, \mathrm{Fe}, \mathrm{Co}, \mathrm{Ni}, \mathrm{Cu}, \mathrm{Zn}$, $\mathrm{Mo}, \mathrm{Ru}, \mathrm{Rh}, \mathrm{Pd}, \mathrm{Ag}, \mathrm{Cd}$, and $\mathrm{Au}$ ) anchored onto $\mathrm{Ti}_{3} \mathrm{C}_{2} \mathrm{O}_{2}$ by calculating their Gibbs free energies. The authors suggested that end-on $\mathrm{N}_{2}$ adsorption is energetically advantageous and that negative free energies represent outstanding $\mathrm{N}_{2}$ activation properties. Hydrogenations of $\mathrm{N}_{2}$ into $* \mathrm{NNH}$ and of $* \mathrm{NH}_{2}$ into $\mathrm{NH}_{3}$ were considered possible potentiallimiting steps. In another study, Cheng et al. [135] carried out DFT calculations to investigate the catalytic activity of single transition metal atom ( $\mathrm{Mo}, \mathrm{Mn}, \mathrm{Fe}, \mathrm{Co}, \mathrm{Ni}$, or $\mathrm{Cu}$ )decorated $\mathrm{M}_{2} \mathrm{NO}_{2}$-type MXenes $(\mathrm{M}=\mathrm{Ti}, \mathrm{V}$, and $\mathrm{Cr})$ for NRR. $\mathrm{Mo} / \mathrm{Ti}_{2} \mathrm{NO}_{2}$ was screened as a very promising candidate catalyst with a low overpotential of $0.16 \mathrm{eV}$. This result could be ascribed to the strong bonding strength between Mo and $\mathrm{Ti}_{2} \mathrm{NO}_{2}$. Moreover, $\mathrm{Mo} / \mathrm{Ti}_{2} \mathrm{NO}_{2}$ showed a low Gibbs free energy $(0.12 \mathrm{eV})$ for $\mathrm{NH}_{3}$ desorption, which promotes $\mathrm{NH}_{3}$ release, and exhibited excellent metallic characteristics, which could effectively promote electron transfer between Mo and $\mathrm{Ti}_{2} \mathrm{NO}_{2}$. Zheng and co-workers [136] studied the NRR performance of single-atom B-decorated MXenes using DFT calculations. Here, B-doped $\mathrm{Mo}_{2} \mathrm{CO}_{2}$ and $\mathrm{W}_{2} \mathrm{CO}_{2}$ MXenes showed excellent catalytic activity and selectivity with limiting potentials of -0.20 and $-0.24 \mathrm{~V}$, respectively (Fig. 11b-d). Hydrogenation of $* \mathrm{~N}_{2}$ into $* \mathrm{~N}_{2} \mathrm{H}$ could be facilitated by the high tendency of B-to-adsorbate electron donation. However, conversion of $* \mathrm{NH}_{2}$ into $* \mathrm{NH}_{3}$ was seriously hindered by strong $\mathrm{B}-\mathrm{N}$ bonding.

Some experiments have been performed to investigate the NRR activity of MXene-based materials. For example, Luo et al. [49] first verified that the central $\mathrm{Ti}$ atom in the MXene $\mathrm{Ti}_{3} \mathrm{C}_{2} \mathrm{~T}_{x}$ is the most active site for $\mathrm{N}_{2}$ adsorption $(1.34 \mathrm{eV})$ by comparison with $\mathrm{C}(-0.16 \mathrm{eV}), \mathrm{O}(-1.21 \mathrm{eV})$, and lateral $\mathrm{Ti}(-0.95 \mathrm{eV})$ atoms. In addition, the basal plane of MXene is inert relative to edge planes owing to the former's lower exposure of Ti sites, as shown in Fig. 12a, b. When smaller $\mathrm{Ti}_{3} \mathrm{C}_{2} \mathrm{~T}_{x}$ MXenes were dispersed on vertically aligned metal $\mathrm{FeOOH}$ nanosheets, a faradaic efficiency of $5.78 \%$ under $-0.2 \mathrm{~V}$ versus RHE was obtained; this value is 1.25 times higher than the maximum value obtained from an MXene/stainless steel mesh (4.62\%) under $-0.1 \mathrm{~V}$ versus RHE, as presented in Fig. 12c, d. Li and co-workers [118] directly applied small-sized $(\sim 50-100 \mathrm{~nm})$ F-free $\mathrm{Ti}_{3} \mathrm{C}_{2} \mathrm{~T}_{x}$ nanosheets for NRR. The obtained catalyst showed an $\mathrm{NH}_{3}$ yield of $36.9 \mu \mathrm{g} /\left(\mathrm{h} \mathrm{mg}_{\text {cat }}\right)$ and faradaic efficiency of $9.1 \%$ at $-0.3 \mathrm{~V}$ versus $\mathrm{RHE}$ in $0.1 \mathrm{~mol} / \mathrm{L} \mathrm{HCl}$ (Fig. 12e). These values are, once again, much larger than those of F-based MXenes due to the unique size effect and fluorine-free characteristics to the novel catalysts. In another study, Zhao et al. [119] reported that $\mathrm{Ti}_{3} \mathrm{C}_{2} \mathrm{~T}_{x}$ MXene nanosheets could serve as catalysts for NRR. The catalysts achieved an $\mathrm{NH}_{3}$ yield of $20.4 \mu \mathrm{g} /\left(\mathrm{h} \mathrm{mg} \mathrm{gat}_{\text {cat }}\right)$ and a faradaic efficiency of $9.3 \%$ at $-0.4 \mathrm{~V}$ versus RHE. DFT results demonstrated that the distal NRR mechanism was more favorable, and the related $* \mathrm{NH}_{2} / \mathrm{NH}_{3}$ reaction was the rate-determining step. Zhang et al. [117] prepared $\mathrm{TiO}_{2} / \mathrm{Ti}_{3} \mathrm{C}_{2} \mathrm{~T}_{x}$ hybrids by using a simple hydrothermal method and studied their catalytic activity for NRR. The obtained hybrids were tested in $0.1 \mathrm{~mol} / \mathrm{L} \mathrm{HCl}$ and showed good catalytic performance with an $\mathrm{NH}_{3}$ yield of $26.32 \mu \mathrm{g} /$ $\left(\mathrm{h} \mathrm{mg}_{\text {cat }}\right)$ and faradaic efficiency of $8.42 \%$ at $-0.60 \mathrm{~V}$ versus 
a
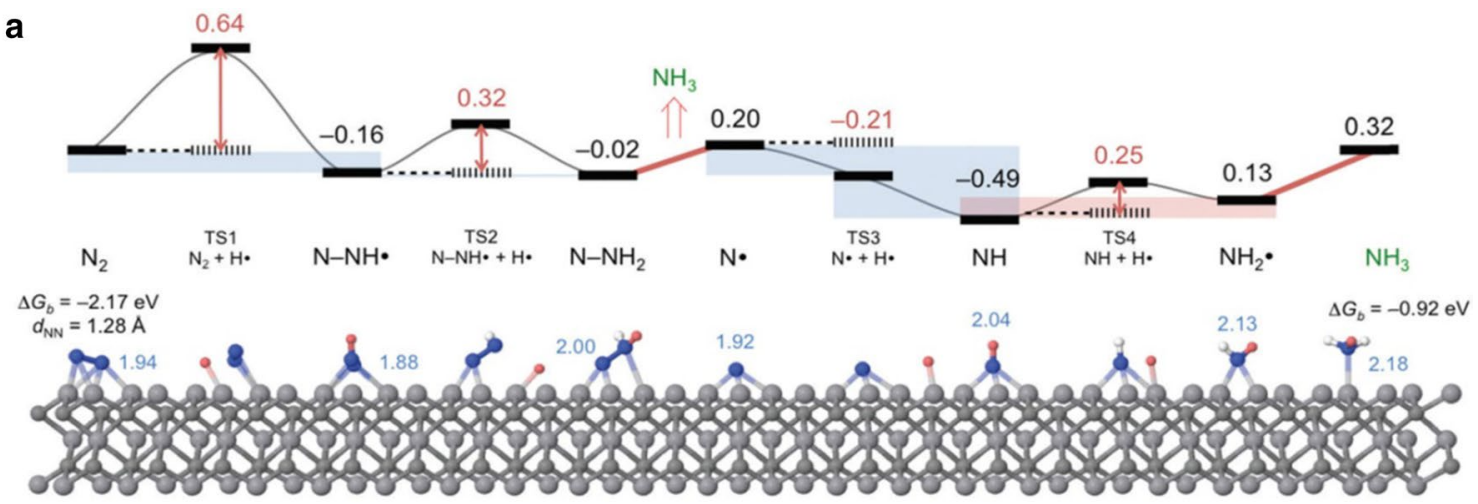

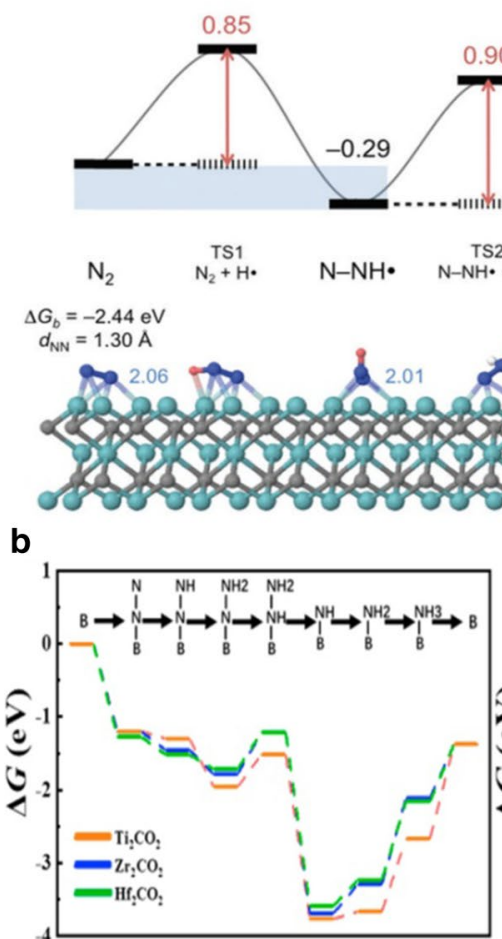

Reaction coordinates

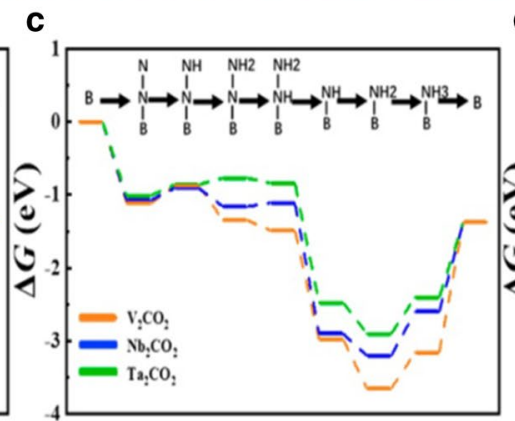

Reaction coordinates

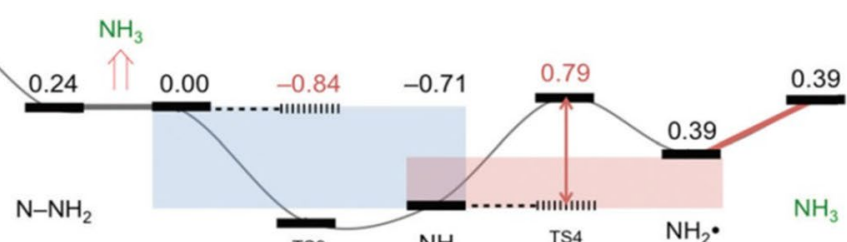

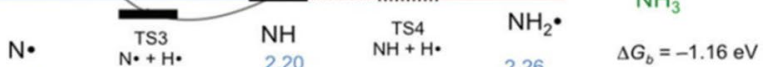

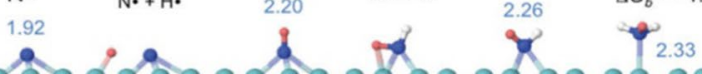
(1000)

d

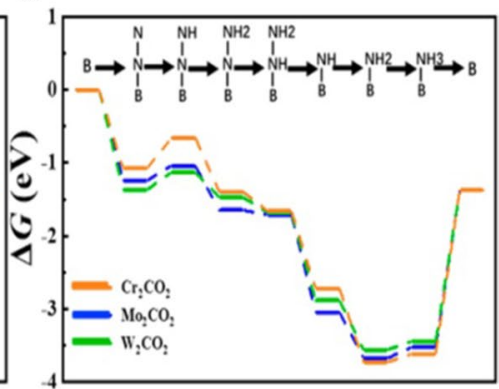

Reaction coordinates

Fig. 11 a Minimum energy path for $\mathrm{N}_{2}$ conversion into $\mathrm{NH}_{3}$ catalyzed by $\mathrm{V}_{3} \mathrm{C}_{2}$ (top) and $\mathrm{Nb}_{3} \mathrm{C}_{2}$ (bottom) MXenes. Reproduced with permission [50]. Copyright 2016, Royal Society of Chemistry. Free energy profiles for the NRR catalyzed by group b IV (Ti, Zr, Hf), c

RHE (Fig. 12f, g); these results are believed to originate from the synergistic effect between $\mathrm{TiO}_{2}$ nanoparticles and $\mathrm{Ti}_{3} \mathrm{C}_{2} \mathrm{~T}_{x}$ nanosheets. Kong and co-workers [120] reported that an $\mathrm{MnO}_{2}$-decorated $\mathrm{Ti}_{3} \mathrm{C}_{2} \mathrm{~T}_{x}$ MXene nanohybrid could serve as an electrocatalyst for NRR with excellent durability and outstanding selectivity. This nanohybrid showed a large $\mathrm{NH}_{3}$ yield of $34.12 \mu \mathrm{g} /\left(\mathrm{h} \mathrm{mg}_{\text {cat }}\right)$ and high faradaic efficiency of $11.39 \%$ under $0.55 \mathrm{~V}$ versus RHE in $0.1 \mathrm{~mol} / \mathrm{L}$ $\mathrm{HCl}$ (Fig. 12h). As shown in Fig. 12i, DFT calculations indicated that unsaturated surface $\mathrm{Mn}$ atoms could serve as active sites for adsorption and activation of $\mathrm{N}_{2}$. The first
V ( V, Nb, Ta), and d VI (Cr, Mo, W) MXenes with B centers. Reproduced with permission [136]. Copyright 2019, American Chemical Society

hydrogenation process in this strategy was identified as the rate-determining step.

\section{$\mathrm{CO}_{2}$ Reduction Reaction}

Large-scale anthropogenic $\mathrm{CO}_{2}$ emissions cause serious environmental issues, including global warming and extinction of species, among others. Converting $\mathrm{CO}_{2}$ by $\mathrm{CO}_{2} \mathrm{RR}$ into value-added chemicals and fuels has attracted extensive research attention due to the environment-friendly characteristics of this technology $[137,138]$. 

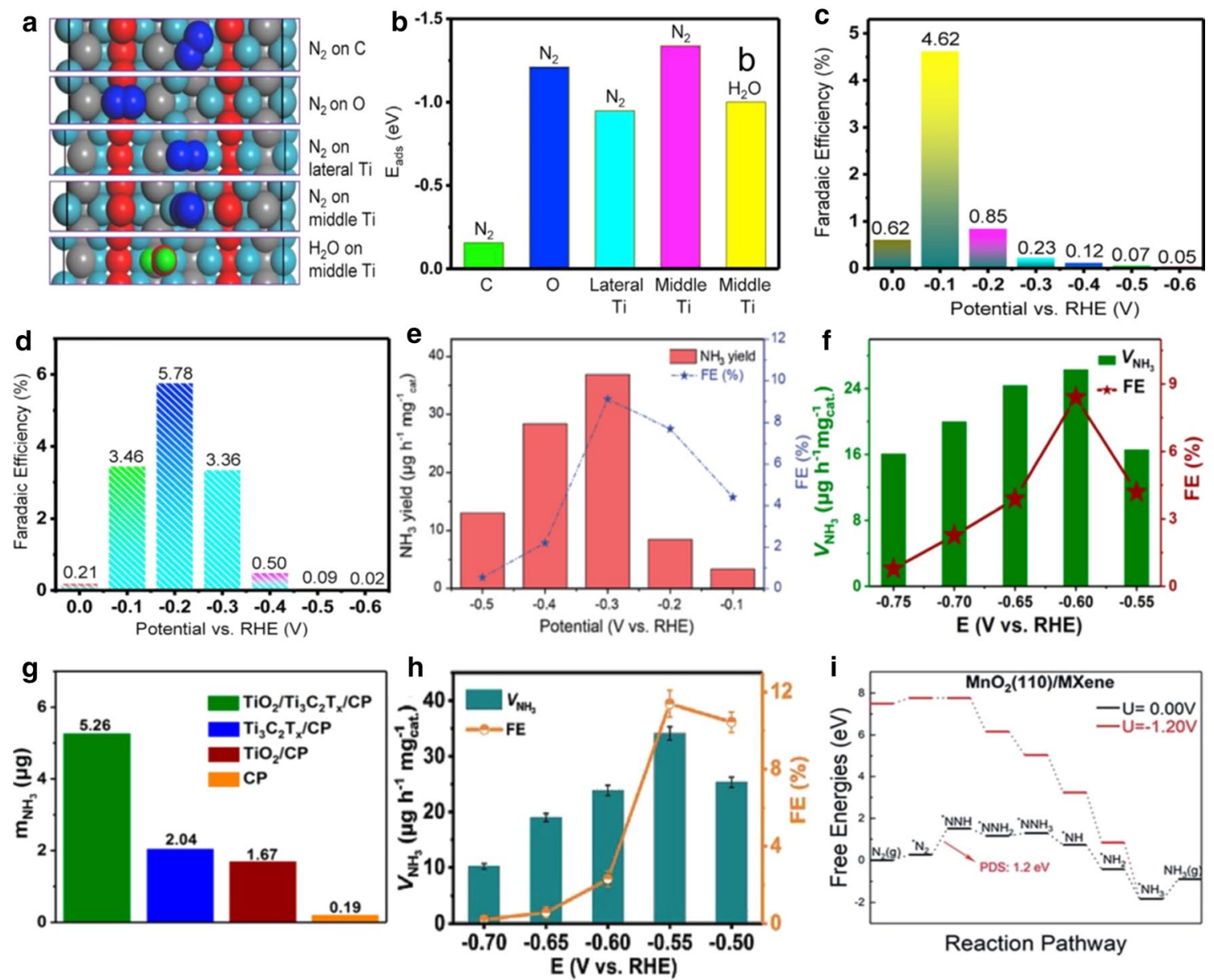

Fig. 12 a Optimized structures of $\mathrm{Ti}_{3} \mathrm{C}_{2} \mathrm{~T}_{x}$ MXenes and the corresponding adsorption energies for $\mathrm{N}_{2}$ on various atomic sites and $\mathrm{H}_{2} \mathrm{O}$ on the middle Ti atomic site. $\mathbf{b}-\mathbf{d}$ Faradic efficiencies of a $\mathrm{Ti}_{3} \mathrm{C}_{2} \mathrm{~T}_{x}$ MXene/stainless steel mesh and $\mathrm{Ti}_{3} \mathrm{C}_{2} \mathrm{~T}_{x} \mathrm{MXene} / \mathrm{FeOOH}$ at different potentials, respectively. Reproduced with permission [49]. Copyright 2018, Elsevier Ltd. e $\mathrm{NH}_{3}$ yields and faradaic efficiencies of $\mathrm{F}$-free $\mathrm{Ti}_{3} \mathrm{C}_{2} \mathrm{~T}_{x}$ nanosheets and $\mathrm{Ti}_{3} \mathrm{C}_{2} \mathrm{~T}_{x} /$ carbon paper at various potentials. Reproduced with permission [118]. Copyright 2019, Royal Society of Chemistry. $\mathbf{f} \mathrm{NH}_{3}$ yields and faradaic efficiencies of $\mathrm{TiO}_{2} / \mathrm{Ti}_{3} \mathrm{C}_{2} \mathrm{~T}_{x}$

The electrocatalytic $\mathrm{CO}_{2} \mathrm{RR}$ activity of MXenes has been explored by using theoretical DFT calculations. For example, Chen et al. [139] studied different $-\mathrm{OH}$ terminated MXenes for $\mathrm{CO}_{2} \mathrm{RR}$ by theoretical calculation and found that $\mathrm{Sc}_{2} \mathrm{C}(\mathrm{OH})_{2}$ is a highly promising candidate for catalyzing the $\mathrm{CO}_{2} \mathrm{RR}$ of $\mathrm{CO}_{2}$ into $\mathrm{CH}_{4}$ with a limiting potential of $-0.53 \mathrm{~V}$. This excellent performance could be attributed to the high reactivity of $\mathrm{H}$ atoms in the $-\mathrm{OH}$ termination groups of the MXene, which is conducive to the formation of stable structures with intermediates and lowering of the necessary overpotential. MXene catalysts with low charge migration during the potential-limiting step have also been suggested to demonstrate good $\mathrm{CO}_{2} \mathrm{RR}$ performance. $\mathrm{Li}$ et al. [140] predicted that IV-VI series MXenes show excellent performance for $\mathrm{CO}_{2}$ capture. $\mathrm{Cr}_{3} \mathrm{C}_{2}$ and $\mathrm{Mo}_{3} \mathrm{C}_{2}$ at various potentials. $\mathrm{g}$ Amounts of $\mathrm{NH}_{3}$ obtained from carbon paper (CP), $\mathrm{TiO}_{2} / \mathrm{CP}, \mathrm{Ti}_{3} \mathrm{C}_{2} \mathrm{~T}_{x} / \mathrm{CP}$, and $\mathrm{TiO}_{2} / \mathrm{Ti}_{3} \mathrm{C}_{2} \mathrm{~T}_{x} / \mathrm{CP}$ at $-0.6 \mathrm{~V}$ after $2 \mathrm{~h}$ of electrolysis. Reproduced with permission [117]. Copyright 2019,

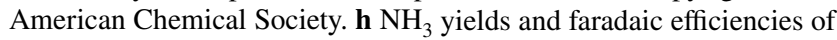
$\mathrm{MnO}_{2}-\mathrm{Ti}_{3} \mathrm{C}_{2} \mathrm{~T}_{x}$ at various potentials. $\mathbf{i}$ Gibbs free energy profiles for NRR over $\mathrm{MnO}_{2}$ (110)-MXene surfaces through the traditional distal pathway. Reproduced with permission [120]. Copyright 2019, Royal Society of Chemistry

MXenes have been considered highly promising candidates for the selective conversion of $\mathrm{CO}_{2}$ into $\mathrm{CH}_{4}$. The authors also found that the formation process of OCHO- and $\mathrm{HOCO}$. radicals occurs as a spontaneous reaction in the early hydrogenation steps, which was the rate-determining step of $\mathrm{CO}_{2}$ into $\mathrm{CH}_{4}$ conversion process. According to the calculated minimum energy path results, the $\mathrm{CO}_{2} \rightarrow \mathrm{CH}_{4}$ conversion process over bare $\mathrm{Cr}_{3} \mathrm{C}_{2}$ and $\mathrm{Mo}_{3} \mathrm{C}_{2}$ required overpotentials of 1.05 and $1.31 \mathrm{eV}$, respectively (Fig. 13a, b). However, functional group (e.g., $-\mathrm{O}$ or $-\mathrm{OH}$ )-terminated MXenes $\left(\mathrm{Mo}_{3} \mathrm{C}_{2}\right)$ required very low energy inputs (Fig. 13c, d). In another study, Handoko and co-workers [51] reported that $\mathrm{W}_{2} \mathrm{CO}_{2}$ and $\mathrm{Ti}_{2} \mathrm{CO}_{2}$ are highly promising $\mathrm{M}_{2} \mathrm{XO}_{2}$ MXene candidates for $\mathrm{CO}_{2} \mathrm{RR}$ owing to their low overpotential and good selectivity. This excellent performance could be 
Fig. 13 a Side view of the minimum energy path for $\mathrm{CO}_{2}$ conversion into $* \mathrm{CH}_{4}$ and ** $\mathrm{H}_{2} \mathrm{O}$ catalyzed by $\mathrm{Mo}_{3} \mathrm{C}_{2}$. b Minimum energy path for $\mathrm{CO}_{2}$ conversion into $* \mathrm{CH}_{4}$ and $* * \mathrm{H}_{2} \mathrm{O}$ catalyzed by $\mathrm{Cr}_{3} \mathrm{C}_{2}$. Minimum energy path for $\mathrm{CO}_{2}$ conversion into $\mathrm{CH}_{4}$ and $\mathrm{H}_{2} \mathrm{O}$ over $\mathbf{c} \mathrm{Mo}_{3} \mathrm{C}_{2}(\mathrm{OH})_{2}$ and d $\mathrm{Mo}_{3} \mathrm{C}_{2} \mathrm{O}_{2}$. Reproduced with permission [140]. Copyright 2019, American Chemical Society a

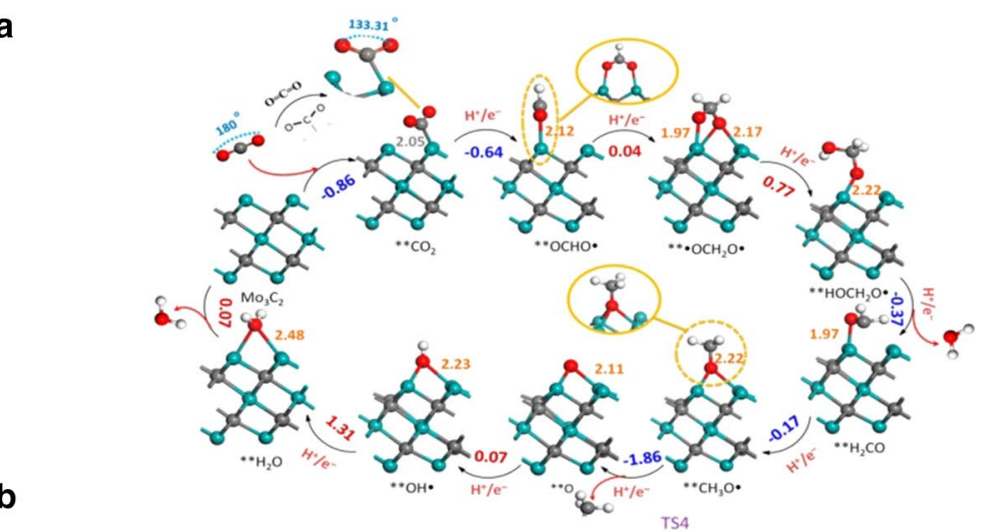

b
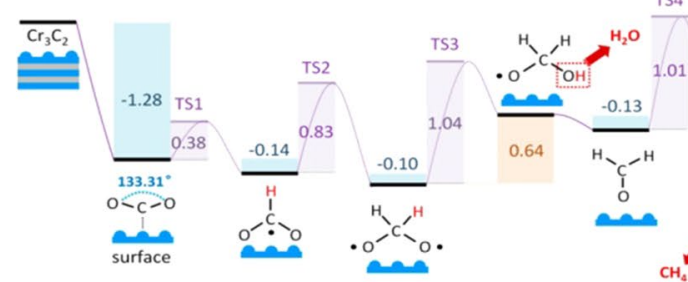

1.01
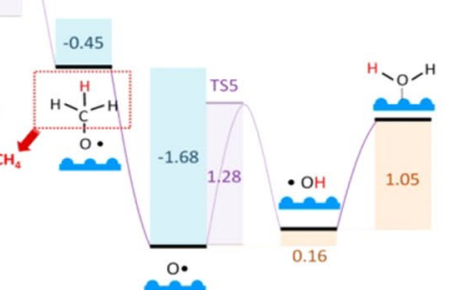

C
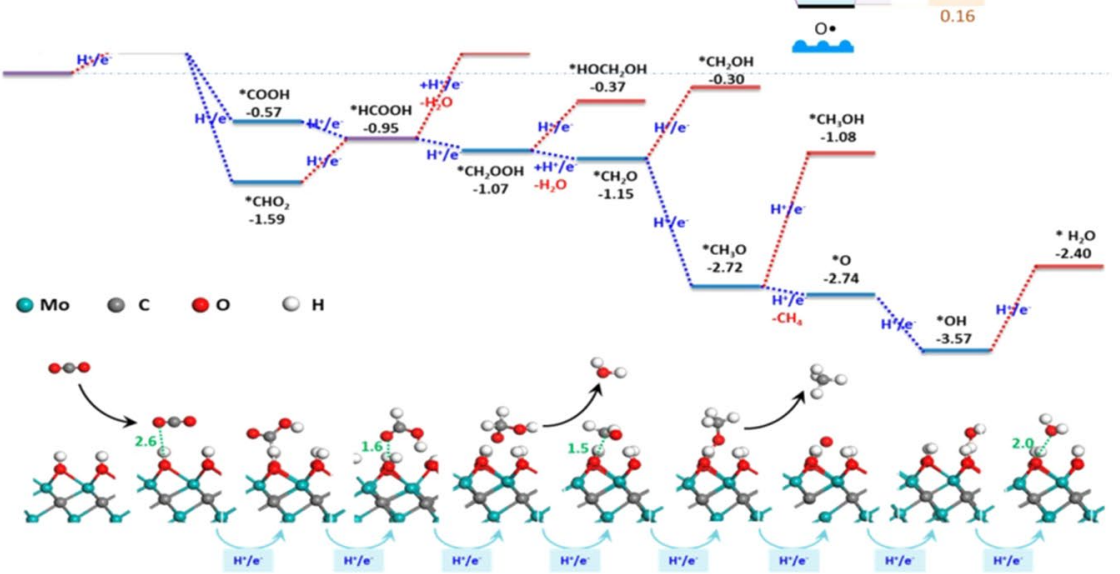

d

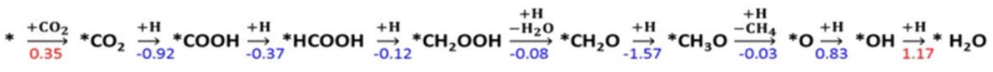

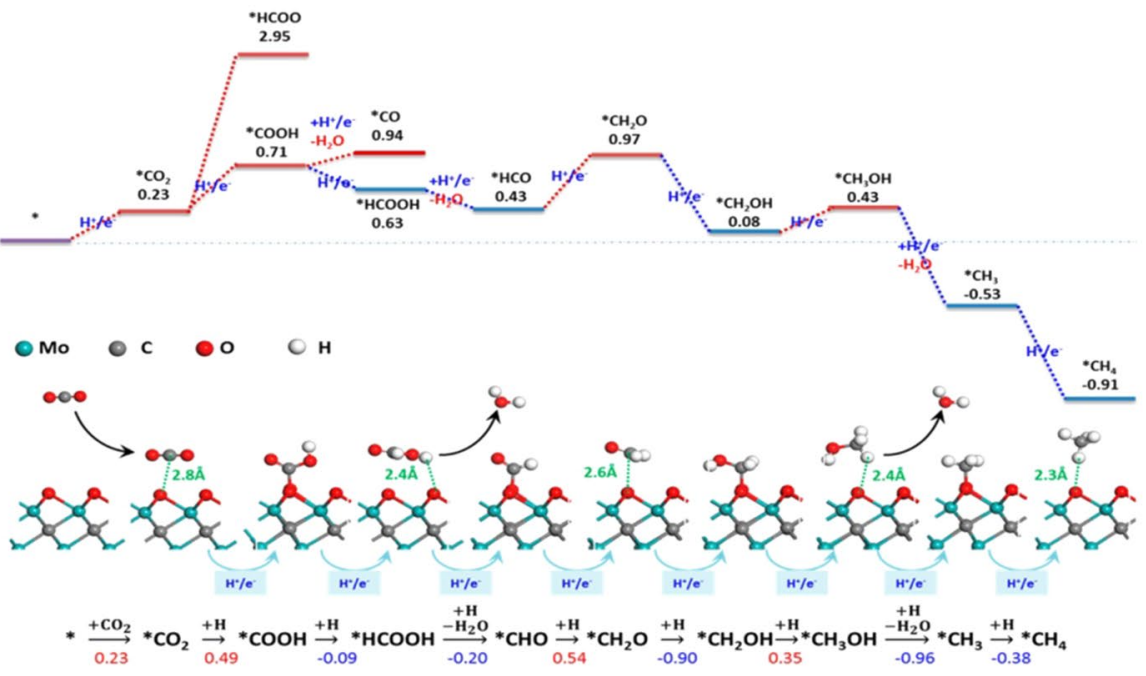


attributed to the accessibility of the $* \mathrm{HCOOH}$ pathway, which is energetically more favorable compared with *CO pathway. In addition, $\mathrm{O}$ termination groups on MXenes help stabilize the reaction intermediates. Thus far, however, no experimental study on MXene-based catalysts for $\mathrm{CO}_{2} \mathrm{RR}$ has yet been reported.

\section{Summary and Outlook}

As an emerging class of 2D materials, MXenes show tremendous potential in electrochemical energy conversion. In this review, we systematically summarized recent advances in MXenes-based materials in electrocatalysis, including HER, OER, ORR, NRR, and $\mathrm{CO}_{2}$ RR. Many high-performance MXenes-based catalysts featuring distinct inherent properties, such as excellent metallic conductivity, rich surface chemistry, and unique morphology, have been prepared. We outlined two common strategies for improving the electrocatalytic property of MXene-based catalysts. First, surface functional groups (e.g., $-\mathrm{O},-\mathrm{OH}$, and $-\mathrm{F}$ ) and exposed terminal metal sites (e.g., Ti, Mo, $\mathrm{Nb}$, and $\mathrm{V}$ ) can serve as catalytic activity sites, as verified by theoretical calculations and experiments. Thus, regulating the surface chemistry of these molecules is a promising strategy to enhance the electrocatalytic property of MXenes. Second, constructing nanohybrids with other active components (e.g., nanoparticles, monoatomics, and other 2D materials) is another effective strategy to improve the electrocatalytic performance of MXene-based materials. The surface functional groups of MXenes endow them with the ability to easily form strong interactions with different components. Many metallic MXenes show enhanced charge-carrier transfer properties, and their 2D structure can prevent the active materials from aggregating.

Despite the initial successes obtained from MXene-based electrocatalysts, however, many challenges remain to be solved. For example, more novel MXenes must have been predicted and synthesized by theoretical calculations and experimental methods. The electrocatalytic performance of these materials should also be systematically investigated. The electrocatalytic performance of MXenes-based materials for some applications (e.g., $\mathrm{CO}_{2} \mathrm{RR}$ ) remains mostly theoretical. Thus, experimental studies should be performed to verify the results of theoretical calculations. Moreover, great efforts have been exerted to develop MXene-based catalysts for electrocatalysis, but elucidating the relevant catalytic mechanism has proven to be difficult. Therefore, more advanced characterizations (e.g., in situ microscopy and spectroscopy) and theoretical calculations must be conducted to promote the rational design of MXene-based catalysts.
Open Access This article is licensed under a Creative Commons Attribution 4.0 International License, which permits use, sharing, adaptation, distribution and reproduction in any medium or format, as long as you give appropriate credit to the original author(s) and the source, provide a link to the Creative Commons licence, and indicate if changes were made. The images or other third party material in this article are included in the article's Creative Commons licence, unless indicated otherwise in a credit line to the material. If material is not included in the article's Creative Commons licence and your intended use is not permitted by statutory regulation or exceeds the permitted use, you will need to obtain permission directly from the copyright holder. To view a copy of this licence, visit http://creativecommons.org/licenses/by/4.0/.

\section{References}

1. Novoselov KS, Geim AK, Morozov SV et al (2004) Electric field effect in atomically thin carbon films. Science 306(5696):666-669

2. Bonaccorso F, Colombo L, Yu G et al (2015) 2D materials: graphene, related two-dimensional crystals, and hybrid systems for energy conversion and storage. Science 347(6217):1246501

3. Geng DC, Yang HY (2018) Recent advances in growth of novel 2D materials: beyond graphene and transition metal dichalcogenides. Adv Mater 30(45):e1800865

4. Feng RJ, Lei WY, Liu G et al (2018) Visible- and NIR-light responsive black-phosphorus-based nanostructures in solar fuel production and environmental remediation. Adv Mater 30(49):e1804770

5. Mendoza-Sánchez B, Gogotsi Y (2016) Synthesis of twodimensional materials for capacitive energy storage. Adv Mater 28(29):6104-6135

6. Wang D, Wang ZG, Wang L et al (2015) Ultrathin membranes of single-layered $\mathrm{MoS}_{2}$ nanosheets for high-permeance hydrogen separation. Nanoscale 7(42):17649-17652

7. Abraham J, Vasu KS, Williams CD et al (2017) Tunable sieving of ions using graphene oxide membranes. Nat Nanotechnol 12(6):546-550

8. Reina G, González-Domínguez JM, Criado A et al (2017) Promises, facts and challenges for graphene in biomedical applications. Chem Soc Rev 46(15):4400-4416

9. Fan XB, Xu PT, Zhou DK et al (2015) Fast and efficient preparation of exfoliated $2 \mathrm{H} \mathrm{MoS}_{2}$ nanosheets by sonication-assisted lithium intercalation and infrared laser-induced $1 \mathrm{~T}$ to $2 \mathrm{H}$ phase reversion. Nano Lett 15(9):5956-5960

10. Fan XB, Xu PT, Li YC et al (2016) Controlled exfoliation of $\mathrm{MoS}_{2}$ crystals into trilayer nanosheets. J Am Chem Soc 138(15):5143-5149

11. Hai X, Chang K, Pang H et al (2016) Engineering the edges of $\mathrm{MoS}_{2}\left(\mathrm{WS}_{2}\right)$ crystals for direct exfoliation into monolayers in polar micromolecular solvents. J Am Chem Soc 138(45):14962-14969

12. Liu H, Du YC, Deng YX et al (2015) Semiconducting black phosphorus: synthesis, transport properties and electronic applications. Chem Soc Rev 44(9):2732-2743

13. Ambrosi A, Sofer Z, Pumera M (2017) Electrochemical exfoliation of layered black phosphorus into phosphorene. Angew Chem 56(35):10443-10445

14. Yasaei P, Kumar B, Foroozan T et al (2015) High-quality black phosphorus atomic layers by liquid-phase exfoliation. Adv Mater 27(11):1887-1892

15. Li Z, Zhuang JC, Chen L et al (2016) Observation of van hove singularities in twisted silicene multilayers. ACS Cent Sci 2(8):517-521 
16. Lang JL, Ding B, Zhang S et al (2017) Scalable synthesis of 2D Si nanosheets. Adv Mater 29(31):1701777

17. Ares P, Palacios JJ, Abellán G et al (2018) Recent progress on antimonene: a new bidimensional material. Adv Mater 30(2): 1703771

18. Gibaja C, Rodriguez-San-Miguel D, Ares P et al (2016) Fewlayer antimonene by liquid-phase exfoliation. Angew Chem 55(46): 14345-14349

19. Zhu WS, Gao X, Li Q et al (2016) Controlled gas exfoliation of boron nitride into few-layered nanosheets. Angew Chem 55(36): 10766-10770

20. Weng QH, Wang XB, Wang X et al (2016) Functionalized hexagonal boron nitride nanomaterials: emerging properties and applications. Chem Soc Rev 45(14):3989-4012

21. Luo W, Wang YB, Hitz E et al (2017) Solution processed boron nitride nanosheets: synthesis, assemblies and emerging applications. Adv Funct Mater 27(31):1701450

22. Yu JF, Wang Q, O'Hare D et al (2017) Preparation of two dimensional layered double hydroxide nanosheets and their applications. Chem Soc Rev 46(19):5950-5974

23. Anasori B, Lukatskaya MR, Gogotsi Y (2017) 2D metal carbides and nitrides (MXenes) for energy storage. Nat Rev Mater 2(2): 16098

24. Sang XH, Xie Y, Lin MW et al (2016) Atomic defects in monolayer titanium carbide $\left(\mathrm{Ti}_{3} \mathrm{C}_{2} \mathrm{~T}_{x}\right)$ MXene. ACS Nano 10(10):9193-9200

25. Li Z, Wu Y (2019) 2D early transition metal carbides (MXenes) for catalysis. Small 15(29):e1804736

26. Mashtalir O, Lukatskaya MR, Zhao MQ et al (2015) Amineassisted delamination of $\mathrm{Nb}_{2} \mathrm{C}$ MXene for Li-ion energy storage devices. Adv Mater 27(23):3501-3506

27. Lian P, Dong Y, Wu Z-S et al (2017) Alkalized $\mathrm{Ti}_{3} \mathrm{C}_{2}$ MXene nanoribbons with expanded interlayer spacing for high-capacity sodium and potassium ion batteries. Nano Energy 40:1-8

28. Tang Q, Zhou Z, Shen PW (2012) Are MXenes promising anode materials for Li ion batteries? Computational studies on electronic properties and Li storage capability of $\mathrm{Ti}_{3} \mathrm{C}_{2}$ and $\mathrm{Ti}_{3} \mathrm{C}_{2} \mathrm{X}_{2}(\mathrm{X}=\mathrm{F}, \mathrm{OH})$ monolayer. $\mathrm{J}$ Am Chem Soc 134(40):16909-16916

29. Ashton M, Hennig RG, Sinnott SB (2016) Computational characterization of lightweight multilayer MXene Li-ion battery anodes. Appl Phys Lett 108(2):023901

30. Liu G, Zou J, Tang Q et al (2017) Surface modified $\mathrm{Ti}_{3} \mathrm{C}_{2}$ MXene nanosheets for tumor targeting photothermal/photodynamic/chemo synergistic therapy. ACS Appl Mater Interfaces 9(46):40077-40086

31. Lin H, Wang XG, Yu LD et al (2017) Two-dimensional ultrathin MXene ceramic nanosheets for photothermal conversion. Nano Lett 17(1):384-391

32. Dai C, Lin H, Xu G et al (2017) Biocompatible 2D titanium carbide (MXenes) composite nanosheets for $\mathrm{pH}$-responsive MRIguided tumor hyperthermia. Chem Mater 29(20):8637-8652

33. Peng C, Yang XF, Li YH et al (2016) Hybrids of two-dimensional $\mathrm{Ti}_{3} \mathrm{C}_{2}$ and $\mathrm{TiO}_{2}$ exposing 001 facets toward enhanced photocatalytic activity. ACS Appl Mater Interfaces 8(9):6051-6060

34. Gao YP, Wang LB, Zhou AG et al (2015) Hydrothermal synthesis of $\mathrm{TiO}_{2} / \mathrm{Ti}_{3} \mathrm{C}_{2}$ nanocomposites with enhanced photocatalytic activity. Mater Lett 150:62-64

35. Ran JR, Gao GP, Li FT et al (2017) $\mathrm{Ti}_{3} \mathrm{C}_{2}$ MXene co-catalyst on metal sulfide photo-absorbers for enhanced visible-light photocatalytic hydrogen production. Nat Commun 8:13907

36. Lin ZF, Barbara D, Taberna P-L et al (2016) Capacitance of $\mathrm{Ti}_{3} \mathrm{C}_{2} \mathrm{~T}_{x}$ MXene in ionic liquid electrolyte. J Power Sources 326:575-579

37. Dall'Agnese Y, Rozier P, Taberna P-L et al (2016) Capacitance of two-dimensional titanium carbide (MXene) and MXene/carbon nanotube composites in organic electrolytes. J Power Sources 306:510-515

38. Ghidiu M, Lukatskaya MR, Zhao MQ et al (2014) Conductive two-dimensional titanium carbide 'clay' with high volumetric capacitance. Nature 516(7529):78-81

39. Ding L, Wei YY, Li LB et al (2018) MXene molecular sieving membranes for highly efficient gas separation. Nat Commun 9(1): 155

40. Berdiyorov GR, Madjet ME, Mahmoud KA (2016) Ionic sieving through $\mathrm{Ti}_{3} \mathrm{C}_{2}(\mathrm{OH})_{2}$ MXene: first-principles calculations. Appl Phys Lett 108(11):113110

41. Ding L, Wei YY, Wang YJ et al (2017) A two-dimensional lamellar membrane: MXene nanosheet stacks. Angew Chem 56(7):1825-1829

42. Liu JP, Liu YZ, Xu DY et al (2019) Hierarchical "nanoroll" like $\mathrm{MoS}_{2} / \mathrm{Ti}_{3} \mathrm{C}_{2} \mathrm{~T}_{x}$ hybrid with high electrocatalytic hydrogen evolution activity. Appl Catal B Environ 241:89-94

43. Du CF, Sun XL, Yu H et al (2019) Synergy of Nb doping and surface alloy enhanced on water-alkali electrocatalytic hydrogen generation performance in Ti-based MXene. Adv Sci 6(11): 1900116

44. Jiang YN, Sun T, Xie X et al (2019) Oxygen-functionalized ultrathin $\mathrm{Ti}_{3} \mathrm{C}_{2} \mathrm{~T}_{x}$ MXene for enhanced electrocatalytic hydrogen evolution. Chemsuschem 12(7):1368-1373

45. Yu MZ, Zhou S, Wang ZY et al (2018) Boosting electrocatalytic oxygen evolution by synergistically coupling layered double hydroxide with MXene. Nano Energy 44:181-190

46. Liu JP, Chen T, Juan P et al (2018) Hierarchical cobalt borate/MXenes hybrid with extraordinary electrocatalytic performance in oxygen evolution reaction. Chemsuschem 11(21):3758-3765

47. Yu XL, Yin WC, Wang $\mathrm{T}$ et al (2019) Decorating $\mathrm{g}-\mathrm{C}_{3} \mathrm{~N}_{4}$ nanosheets with $\mathrm{Ti}_{3} \mathrm{C}_{2}$ MXene nanoparticles for efficient oxygen reduction reaction. Langmuir 35(8):2909-2916

48. Li ZL, Zhuang ZC, Lv F et al (2018) The marriage of the $\mathrm{FeN}_{4}$ moiety and MXene boosts oxygen reduction catalysis: $\mathrm{Fe} 3 \mathrm{~d}$ electron delocalization matters. Adv Mater 30(43):e1803220

49. Luo Y, Chen G-F, Ding L et al (2019) Efficient electrocatalytic $\mathrm{N}_{2}$ fixation with MXene under ambient conditions. Joule 3(1):279-289

50. Azofra LM, Li N, MacFarlane DR et al (2016) Promising prospects for $2 \mathrm{D} \mathrm{d} \mathrm{d}^{2}-\mathrm{d}^{4} \mathrm{M}_{3} \mathrm{C}_{2}$ transition metal carbides (MXenes) in $\mathrm{N}_{2}$ capture and conversion into ammonia. Energy Environ Sci 9(8):2545-2549

51. Handoko AD, Khoo KH, Tan TL et al (2018) Establishing new scaling relations on two-dimensional MXenes for $\mathrm{CO}_{2}$ electroreduction. J Mater Chem A 6(44):21885-21890

52. Zhao D, Chen Z, Yang WJ et al (2019) MXene $\left(\mathrm{Ti}_{3} \mathrm{C}_{2}\right)$ vacancy-confined single-atom catalyst for efficient functionalization of $\mathrm{CO}_{2}$. J Am Chem Soc 141(9):4086-4093

53. Pang JB, Mendes RG, Bachmatiuk A et al (2019) Applications of 2D MXenes in energy conversion and storage systems. Chem Soc Rev 48(1):72-133

54. Li XQ, Wang CY, Cao Y et al (2018) Functional MXene materials: progress of their applications. Chem Asian $\mathrm{J}$ 13(19):2742-2757

55. Zhang X, Zhang ZH, Zhou Z (2018) MXene-based materials for electrochemical energy storage. J Energy Chem 27(1):73-85

56. Handoko AD, Steinmann SN, Seh ZW (2019) Theory-guided materials design: two-dimensional MXenes in electro- and photocatalysis. Nanoscale Horiz 4(4):809-827

57. Naguib M, Kurtoglu M, Presser V et al (2011) Two-dimensional nanocrystals produced by exfoliation of $\mathrm{Ti}_{3} \mathrm{AlC}_{2}$. Adv Mater 23(37):4248-4253 
58. Liang X, Garsuch A, Nazar LF (2015) Sulfur cathodes based on conductive MXene nanosheets for high-performance lithiumsulfur batteries. Angew Chem 54(13):3907-3911

59. Du F, Tang H, Pan LM et al (2017) Environmental friendly scalable production of colloidal 2D titanium carbonitride MXene with minimized nanosheets restacking for excellent cycle life lithium-ion batteries. Electrochim Acta 235:690-699

60. Naguib M, Mashtalir O, Carle J et al (2012) Two-dimensional transition metal carbides. ACS Nano 6(2):1322-1331

61. Halim J, Kota S, Lukatskaya MR et al (2016) Synthesis and characterization of 2D molybdenum carbide (MXene). Adv Funct Mater 26(18):3118-3127

62. Anasori B, Dahlqvist M, Halim J et al (2015) Experimental and theoretical characterization of ordered MAX phases $\mathrm{Mo}_{2} \mathrm{TiAlC}_{2}$ and $\mathrm{Mo}_{2} \mathrm{Ti}_{2} \mathrm{AlC}_{3}$. J Appl Phys 118(9):094304

63. Zhou J, Zha XH, Chen FY et al (2016) A two-dimensional zirconium carbide by selective etching of $\mathrm{Al}_{3} \mathrm{C}_{3}$ from nanolaminated $\mathrm{Zr}_{3} \mathrm{Al}_{3} \mathrm{C}_{5}$. Angew Chem 128(16):5092-5097

64. Zhou J, Zha XH, Zhou XB et al (2017) Synthesis and electrochemical properties of two-dimensional hafnium carbide. ACS Nano 11(4):3841-3850

65. Yang J, Naguib M, Ghidiu M et al (2016) Two-dimensional Nb-based $\mathrm{M}_{4} \mathrm{C}_{3}$ solid solutions (MXenes). J Am Ceram Soc 99(2):660-666

66. Wu M, Wang BX, Hu QK et al (2018) The synthesis process and thermal stability of $\mathrm{V}_{2} \mathrm{C}$ MXene. Materials 11(11):2112

67. Wang X, Garnero C, Rochard G et al (2017) A new etching environment $\left(\mathrm{FeF}_{3} / \mathrm{HCl}\right)$ for the synthesis of two-dimensional titanium carbide MXenes: a route towards selective reactivity vs. water. J Mater Chem A 5(41):22012-22023

68. Wang LB, Zhang H, Wang B et al (2016) Synthesis and electrochemical performance of $\mathrm{Ti}_{3} \mathrm{C}_{2} \mathrm{~T}_{x}$ with hydrothermal process. Electron Mater Lett 12(5):702-710

69. Feng AH, Yu Y, Wang Y et al (2017) Two-dimensional MXene $\mathrm{Ti}_{3} \mathrm{C}_{2}$ produced by exfoliation of $\mathrm{Ti}_{3} \mathrm{AlC}_{2}$. Mater Des 114:161-166

70. Urbankowski P, Anasori B, Makaryan T et al (2016) Synthesis of two-dimensional titanium nitride $\mathrm{Ti}_{4} \mathrm{~N}_{3}$ (MXene). Nanoscale 8(22):11385-11391

71. Lipatov A, Alhabeb M, Lukatskaya MR et al (2016) Effect of synthesis on quality, electronic properties and environmental stability of individual monolayer $\mathrm{Ti}_{3} \mathrm{C}_{2}$ MXene flakes. Adv Electron Mater 2(12): 1600255

72. Xuan JN, Wang ZQ, Chen YY et al (2016) Organic-base-driven intercalation and delamination for the production of functionalized titanium carbide nanosheets with superior photothermal therapeutic performance. Angew Chem 55(47):14569-14574

73. Li GN, Tan L, Zhang YM et al (2017) Highly efficiently delaminated single-layered MXene nanosheets with large lateral size. Langmuir 33(36):9000-9006

74. Pang SY, Wong YT, Yuan SG et al (2019) Universal strategy for HF-free facile and rapid synthesis of two-dimensional MXenes as multifunctional energy materials. J Am Chem Soc 141(24):9610-9616

75. Li M, Lu J, Luo K et al (2019) Element replacement approach by reaction with Lewis acidic molten salts to synthesize nanolaminated MAX phases and MXenes. J Am Chem Soc 141(11):4730-4737

76. Chen XF, Zhu YZ, Zhang M et al (2019) $N$-butyllithium-treated $\mathrm{Ti}_{3} \mathrm{C}_{2} \mathrm{~T}_{x}$ MXene with excellent pseudocapacitor performance. ACS Nano 13(8):9449-9456

77. Hu T, Li ZJ, Hu MM et al (2017) Chemical origin of terminationfunctionalized MXenes: $\mathrm{Ti}_{3} \mathrm{C}_{2} \mathrm{~T}_{2}$ as a case study. J Phys Chem C 121(35):19254-19261
78. Fu ZH, Zhang QF, Legut D et al (2016) Stabilization and strengthening effects of functional groups in two-dimensional titanium carbide. Phys Rev B 94(10):104103

79. Meng QQ, Ma JL, Zhang YH et al (2018) The S-functionalized $\mathrm{Ti}_{3} \mathrm{C}_{2}$ Mxene as a high capacity electrode material for Na-ion batteries: a DFT study. Nanoscale 10(7):3385-3392

80. Wang XF, Shen X, Gao YR et al (2015) Atomic-scale recognition of surface structure and intercalation mechanism of $\mathrm{Ti}_{3} \mathrm{C}_{2} \mathrm{X}$. J Am Chem Soc 137(7):2715-2721

81. Karlsson LH, Birch J, Halim J et al (2015) Atomically resolved structural and chemical investigation of single MXene sheets. Nano Lett 15(8):4955-4960

82. Hope MA, Forse AC, Griffith KJ et al (2016) NMR reveals the surface functionalisation of $\mathrm{Ti}_{3} \mathrm{C}_{2}$ MXene. Phys Chem Chem Phys 18(7):5099-5102

83. Harris KJ, Bugnet M, Naguib M et al (2015) Direct measurement of surface termination groups and their connectivity in the 2D MXene $\mathrm{V}_{2} \mathrm{CT}_{x}$ using NMR spectroscopy. J Phys Chem C 119(24):13713-13720

84. Fredrickson KD, Anasori B, Seh ZW et al (2016) Effects of applied potential and water intercalation on the surface chemistry of $\mathrm{Ti}_{2} \mathrm{C}$ and $\mathrm{Mo}_{2} \mathrm{C}$ MXenes. J Phys Chem C 120(50):28432-28440

85. Wang G, Liao Y (2017) Theoretical prediction of robust and intrinsic half-metallicity in $\mathrm{Ni}_{2} \mathrm{~N}$ MXene with different types of surface terminations. Appl Surf Sci 426:804-811

86. Enyashin AN, Ivanovskii AL (2012) Atomic structure, comparative stability and electronic properties of hydroxylated $\mathrm{Ti}_{2} \mathrm{C}$ and $\mathrm{Ti}_{3} \mathrm{C}_{2}$ nanotubes. Comput Theor Chem 989:27-32

87. Zhao SJ, Kang W, Xue JM (2015) MXene nanoribbons. J Mater Chem C 3(4):879-888

88. Halim J, Lukatskaya MR, Cook KM et al (2014) Transparent conductive two-dimensional titanium carbide epitaxial thin films. Chem Mater 26(7):2374-2381

89. Lai S, Jeon J, Jang SK et al (2015) Surface group modification and carrier transport properties of layered transition metal carbides $\left(\mathrm{Ti}_{2} \mathrm{CT}_{x}, \mathrm{~T}\right.$ : $-\mathrm{OH},-\mathrm{F}$ and $\left.-\mathrm{O}\right)$. Nanoscale 7(46):19390-19396

90. Seh ZW, Fredrickson KD, Anasori B et al (2016) Two-dimensional molybdenum carbide (MXene) as an efficient electrocatalyst for hydrogen evolution. ACS Energy Lett 1(3):589-594

91. Handoko AD, Fredrickson KD, Anasori B et al (2018) Tuning the basal plane functionalization of two-dimensional metal carbides (MXenes) to control hydrogen evolution activity. ACS Appl Energy Mater 1(1):173-180

92. Li S, Tuo P, Xie JF et al (2018) Ultrathin MXene nanosheets with rich fluorine termination groups realizing efficient electrocatalytic hydrogen evolution. Nano Energy 47:512-518

93. Tran MH, Schäfer T, Shahraei A et al (2018) Adding a new member to the MXene family: synthesis, structure, and electrocatalytic activity for the hydrogen evolution reaction of $\mathrm{V}_{4} \mathrm{C}_{3} \mathrm{~T}_{x}$. ACS Appl Energy Mater 1(8):3908-3914

94. Yoon Y, Tiwari AP, Lee M et al (2018) Enhanced electrocatalytic activity by chemical nitridation of two-dimensional titanium carbide MXene for hydrogen evolution. J Mater Chem A 6(42):20869-20877

95. Yuan W, Cheng LF, An YR et al (2018) MXene nanofibers as highly active catalysts for hydrogen evolution reaction. ACS Sustain Chem Eng 6(7):8976-8982

96. Li Z, Qi ZY, Wang SW et al (2019) In situ formed $\mathrm{Pt}_{3} \mathrm{Ti}$ nanoparticles on a two-dimensional transition metal carbide (MXene) used as efficient catalysts for hydrogen evolution reactions. Nano Lett 19(8):5102-5108

97. Yuan YY, Li HS, Wang LG et al (2019) Achieving highly efficient catalysts for hydrogen evolution reaction by electronic 
state modification of platinum on versatile $\mathrm{Ti}_{3} \mathrm{C}_{2} \mathrm{~T}_{x}$ (MXene). ACS Sustain Chem Eng 7(4):4266-4273

98. Liang JM, Ding CY, Liu JP et al (2019) Heterostructure engineering of Co-doped $\mathrm{MoS}_{2}$ coupled with $\mathrm{Mo}_{2} \mathrm{CT}_{x}$ MXene for enhanced hydrogen evolution in alkaline media. Nanoscale 11(22):10992-11000

99. Filip J, Zavahir S, Lorencova L et al (2019) Tailoring electrocatalytic properties of $\mathrm{Pt}$ nanoparticles grown on $\mathrm{Ti}_{3} \mathrm{C}_{2} \mathrm{~T}_{x}$ MXene surface. J Electrochem Soc 166(2):H54-H62

100. Attanayake NH, Abeyweera SC, Thenuwara AC et al (2018) Vertically aligned $\mathrm{MoS}_{2}$ on $\mathrm{Ti}_{3} \mathrm{C}_{2}$ (MXene) as an improved HER catalyst. J Mater Chem A 6(35):16882-16889

101. Cui BB, Hu B, Liu JM et al (2018) Solution-plasma-assisted bimetallic oxide alloy nanoparticles of $\mathrm{Pt}$ and $\mathrm{Pd}$ embedded within two-dimensional $\mathrm{Ti}_{3} \mathrm{C}_{2} \mathrm{~T}_{x}$ nanosheets as highly active electrocatalysts for overall water splitting. ACS Appl Mater Interfaces 10(28):23858-23873

102. Du C-F, Dinh KN, Liang QH et al (2018) Self-assemble and in situ formation of $\mathrm{Ni}_{1-x} \mathrm{Fe}_{x} \mathrm{PS}_{3}$ nanomosaic-decorated MXene hybrids for overall water splitting. Adv Energy Mater 8(26): 1801127

103. Wu XH, Wang ZY, Yu MZ et al (2017) Stabilizing the MXenes by carbon nanoplating for developing hierarchical nanohybrids with efficient lithium storage and hydrogen evolution capability. Adv Mater 29(24):1607017

104. Zhang JQ, Zhao YF, Guo X et al (2018) Single platinum atoms immobilized on an MXene as an efficient catalyst for the hydrogen evolution reaction. Nat Catal 1(12):985-992

105. Xiu LY, Wang ZY, Yu MZ et al (2018) Aggregation-resistant 3D MXene-based architecture as efficient bifunctional electrocatalyst for overall water splitting. ACS Nano 12(8):8017-8028

106. Wen YY, Wei ZT, Ma C et al (2019) MXene boosted CoNiZIF-67 as highly efficient electrocatalysts for oxygen evolution. Nanomaterials 9(5):775

107. Zhao L, Dong BL, Li SZ et al (2017) Interdiffusion reactionassisted hybridization of two-dimensional metal-organic frameworks and $\mathrm{Ti}_{3} \mathrm{C}_{2} \mathrm{~T}_{x}$ nanosheets for electrocatalytic oxygen evolution. ACS Nano 11(6):5800-5807

108. Ma TY, Cao JL, Jaroniec M et al (2016) Interacting carbon nitride and titanium carbide nanosheets for high-performance oxygen evolution. Angew Chem 55(3):1138-1142

109. Tang Y, Yang CH, Yang YW et al (2019) Three dimensional hierarchical network structure of $\mathrm{S}-\mathrm{NiFe}_{2} \mathrm{O}_{4}$ modified few-layer titanium carbides (MXene) flakes on nickel foam as a high efficient electrocatalyst for oxygen evolution. Electrochim Acta 296:762-770

110. Zou HY, He BW, Kuang PY et al (2018) Metal-organic framework-derived nickel-cobalt sulfide on ultrathin Mxene nanosheets for electrocatalytic oxygen evolution. ACS Appl Mater Interfaces 10(26):22311-22319

111. Zhang YK, Jiang HL, Lin YX et al (2018) In situ growth of cobalt nanoparticles encapsulated nitrogen-doped carbon nanotubes among $\mathrm{Ti}_{3} \mathrm{C}_{2} \mathrm{~T}_{x}$ (MXene) matrix for oxygen reduction and evolution. Adv Mater Interfaces 5(16): 1800392

112. Wen YY, Ma C, Wei ZT et al (2019) FeNC/MXene hybrid nanosheet as an efficient electrocatalyst for oxygen reduction reaction. RSC Adv 9(24):13424-13430

113. Zhang ZW, Li HN, Zou GD et al (2016) Self-reduction synthesis of new MXene/Ag composites with unexpected electrocatalytic activity. ACS Sustain Chem Eng 4(12):6763-6771

114. Xue Q, Pei ZX, Huang $\mathrm{Y}$ et al (2017) $\mathrm{Mn}_{3} \mathrm{O}_{4}$ nanoparticles on layer-structured $\mathrm{Ti}_{3} \mathrm{C}_{2}$ MXene towards the oxygen reduction reaction and zinc-air batteries. J Mater Chem A 5(39):20818-20823

115. Chen LG, Lin YX, Fu JY et al (2018) Hybridization of binary non-precious-metal nanoparticles with $\mathrm{d}^{-\mathrm{Ti}_{3} \mathrm{C}_{2}} \mathrm{MXene}$ for catalyzing the oxygen reduction reaction. ChemElectroChem 5(21):3307-3314

116. Lin H, Chen LS, Lu XY et al (2019) Two-dimensional titanium carbide MXenes as efficient non-noble metal electrocatalysts for oxygen reduction reaction. Sci China Mater 62(5):662-670

117. Zhang J, Yang L, Wang HB et al (2019) In situ hydrothermal growth of $\mathrm{TiO}_{2}$ nanoparticles on a conductive $\mathrm{Ti}_{3} \mathrm{C}_{2} \mathrm{~T}_{x}$ MXene nanosheet: a synergistically active Ti-based nanohybrid electrocatalyst for enhanced $\mathrm{N}_{2}$ reduction to $\mathrm{NH}_{3}$ at ambient conditions. Inorg Chem 58(9):5414-5418

118. Li TF, Yan XD, Huang LJ et al (2019) Fluorine-free $\mathrm{Ti}_{3} \mathrm{C}_{2} \mathrm{~T}_{x}$ $(\mathrm{T}=\mathrm{O}, \mathrm{OH})$ nanosheets $(\sim 50-100 \mathrm{~nm})$ for nitrogen fixation under ambient conditions. J Mater Chem A 7(24):14462-14465

119. Zhao JX, Zhang L, Xie X-Y et al (2018) $\mathrm{Ti}_{3} \mathrm{C}_{2} \mathrm{~T}_{x}(\mathrm{~T}=\mathrm{F}$, $\mathrm{OH}) \mathrm{MXene}$ nanosheets: conductive $2 \mathrm{D}$ catalysts for ambient electrohydrogenation of $\mathrm{N}_{2}$ to $\mathrm{NH}_{3}$. J Mater Chem A 6(47):24031-24035

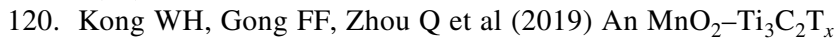
MXene nanohybrid: an efficient and durable electrocatalyst toward artificial $\mathrm{N}_{2}$ fixation to $\mathrm{NH}_{3}$ under ambient conditions. J Mater Chem A 7(32):18823-18827

121. Zou XX, Zhang Y (2015) Noble metal-free hydrogen evolution catalysts for water splitting. Chem Soc Rev 44(15):5148-5180

122. Di J, Yan C, Handoko AD et al (2018) Ultrathin two-dimensional materials for photo- and electrocatalytic hydrogen evolution. Mater Today 21(7):749-770

123. Gao GP, O’Mullane AP, Du A (2017) A new family of promising catalysts for the hydrogen evolution reaction. ACS Catal 7(1):494-500

124. Cheng YW, Wang LJ, Li Y et al (2019) Etching and exfoliation properties of $\mathrm{Cr}_{2} \mathrm{AlC}$ into $\mathrm{Cr}_{2} \mathrm{CO}_{2}$ and the electrocatalytic performances of $2 \mathrm{D} \mathrm{Cr}_{2} \mathrm{CO}_{2}$ MXene. J Phys Chem C 123(25):15629-15636

125. Yang XW, Gao N, Zhou S et al (2018) MXene nanoribbons as electrocatalysts for the hydrogen evolution reaction with fast kinetics. Phys Chem Chem Phys 20(29):19390-19397

126. You JX, Si C, Zhou J et al (2019) Contacting $\mathrm{MoS}_{2}$ to MXene: vanishing $p$-type Schottky barrier and enhanced hydrogen evolution catalysis. J Phys Chem C 123(6):3719-3726

127. Ling FL, Kang W, Jing HR et al (2019) Enhancing hydrogen evolution on the basal plane of transition metal dichacolgenide van der Waals heterostructures. NPJ Comput Mater 5(1):20

128. Zhou S, Yang XW, Pei W et al (2018) Heterostructures of MXenes and $\mathrm{N}$-doped graphene as highly active bifunctional electrocatalysts. Nanoscale 10(23):10876-10883

129. Li PK, Zhu JG, Handoko AD et al (2018) High-throughput theoretical optimization of the hydrogen evolution reaction on MXenes by transition metal modification. J Mater Chem A 6(10):4271-4278

130. Shi QR, Zhu CZ, Du D et al (2019) Robust noble metal-based electrocatalysts for oxygen evolution reaction. Chem Soc Rev 48(12):3181-3192

131. Zheng Y, Jiao Y, Jaroniec M et al (2012) Nanostructured metalfree electrochemical catalysts for highly efficient oxygen reduction. Small 8(23):3550-3566 
132. Liu CY, Li EY (2019) Termination effects of Pt/v-Ti ${ }_{n+1} C_{n} T_{2}$ MXene surfaces for oxygen reduction reaction catalysis. ACS Appl Mater Interfaces 11(1):1638-1644

133. Tang C, Qiao SZ (2019) How to explore ambient electrocatalytic nitrogen reduction reliably and insightfully. Chem Soc Rev 48(12):3166-3180

134. Gao YJ, Zhuo H, Cao YY et al (2019) A theoretical study of electrocatalytic ammonia synthesis on single metal atom/ MXene. Chin J Catal 40(2):152-159

135. Cheng YW, Dai JH, Song Y et al (2019) Single molybdenum atom anchored on $2 \mathrm{D} \mathrm{Ti}_{2} \mathrm{NO}_{2}$ MXene as a promising electrocatalyst for $\mathrm{N}_{2}$ fixation. Nanoscale 11(39):18132-18141

136. Zheng S, Li S, Mei Z et al (2019) Electrochemical nitrogen reduction reaction performance of single-boron catalysts tuned by MXene substrates. J Phys Chem Lett 10(22):6984-6989

137. Zhang L, Zhao ZJ, Gong JL (2017) Nanostructured materials for heterogeneous electrocatalytic $\mathrm{CO}_{2}$ reduction and their related reaction mechanisms. Angew Chem 56(38):11326-11353

138. Handoko AD, Wei FX et al (2018) Understanding heterogeneous electrocatalytic carbon dioxide reduction through operando techniques. Nat Catal 1(12):922-934

139. Chen HT, Handoko AD, Xiao JW et al (2019) Catalytic effect on $\mathrm{CO}_{2}$ electroreduction by hydroxyl-terminated two-dimensional MXenes. ACS Appl Mater Interfaces 11(40):36571-36579
140. Li N, Chen XZ, Ong WJ et al (2017) Understanding of electrochemical mechanisms for $\mathrm{CO}_{2}$ capture and conversion into hydrocarbon fuels in transition-metal carbides (MXenes). ACS Nano 11(11):10825-10833

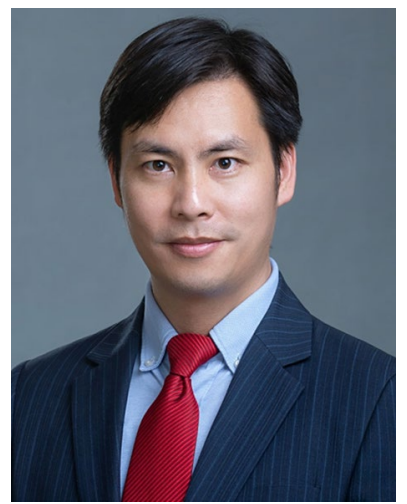

Xiaobin Fan is currently a professor at Tianjin University, China. His research interests include the preparation and applications of new nanomaterials and green chemistry. 